\title{
PROBLEMA DE PROPAGAÇÃO DE TRINCAS EM CONDIÇÕES DE FRETTING
}

\author{
RAPHAEL ARAÚJO CARDOSO
}

DISSERTAÇÃO DE MESTRADO EM CIÊNCIAS MECÂNICAS DEPARTAMENTO DE ENGENHARIA MECÂNICA

\section{FACULDADE DE TECNOLOGIA UNIVERSIDADE DE BRASÍLIA}




\section{DISSERTAÇÃO DE MESTRADO EM CIÊNCIAS MECÂNICAS}

\section{PROBLEMA DE PROPAGAÇÃO DE TRINCAS EM CONDIÇÕES DE FRETTING}

RAPHAEL ARAÚJO CARDOSO

ORIENTADOR: JOSÉ ALEXANDER ARAÚJO

PUBLICAÇÃO ENM.DM-233/2014

Brasília, 20 de agosto de 2015 


\title{
DISSERTAÇÃO DE MESTRADO EM CIÊNCIAS MECÂNICAS
}

\section{PROBLEMA DE PROPAGAÇÃO DE TRINCAS EM CONDIÇÕES DE FRETTING}

\author{
RAPHAEL ARAÚJO CARDOSO
}

\begin{abstract}
DISSERTAÇÃO DE MESTRADO SUBMETIDA AO DEPARTAMENTO DE ENGENHARIA MECÂNICA DA FACULDADE DE TECNOLOGIA DA UNIVERSIDADE DE BRASÍLIA COMO PARTE DOS REQUISITOS PARA A OBTENÇÃO DO GRAU DE MESTRE.
\end{abstract}

\section{Banca Examinadora}

Prof. José Alexander Araújo, D.Phil (ENM-FT-UnB)

(Orientador)

Prof. Francisco Evangelista Junior, PhD (ENC-FT-UnB)
(Examinador Externo)

Prof. Edgar Nobuo Mamiya, DSc (ENM-FT-UnB)

(Examinador Interno) 


\section{FICHA CATALOGRÁFICA}

CARDOSO, RAPHAEL ARAÚJO

PROBLEMA DE PROPAGAÇÃO DE TRINCAS EM CONDIÇÕES DE FRETTING.

[Distrito Federal] 2015.

81p., 210 x 297 mm (ENM/FT/UnB, Mestre, Ciências Mecânicas, 2015)

Dissertação de Mestrado - Universidade de Brasília. Faculdade de Tecnologia.

Departamento de Engenharia Mecânica.
1. Fadiga por Fretting
2. Fadiga Multiaxial
3. Parada de Trincas Curtas
4. Propagação de Trincas
I. ENM/FT/UnB
II. Título (ENM.DM-233/2015)

\section{REFERÊNCIA BIBLIOGRÁFICA}

CARDOSO, R. A., (2015) Problema de propagação de trincas em condições de fretting. Dissertação de mestrado, Publicação ENM.DM-233/2015, Departamento de Engenharia Mecânica, Universidade de Brasília, DF, 81p.

\section{CESSÃO DE DIREITOS}

AUTOR: Raphael Araújo Cardoso.

TÍTULO: Problema de propagação de trincas em condições de fretting.

GRAU: Mestre

ANO: 2015

É concedida à Universidade de Brasília permissão para reproduzir cópias desta dissertação de mestrado e para emprestar ou vender tais cópias somente para propósitos acadêmicos e científicos. $\mathrm{O}$ autor reserva outros direitos de publicação e nenhuma parte dessa dissertação de mestrado pode ser reproduzida sem autorização por escrito do autor.

Raphael Araújo Cardoso

Correio Eletrônico: rapha_2213@hotmail.com 


\section{Agradecimentos}

Agradeço primeiramente a Deus, sem o qual nada seria possível.

Agradeço a minha mãe em especial e a toda minha família que sempre me apoiaram e me deram o suporte necessário.

Ao professor José Alexander Araújo, pela dedicação, pelas críticas construtivas, pela contribuição na minha formação acadêmica e profissional e pelo incentivo ao longo desses últimos anos.

Agradeço a minha grande companheira Nayara Santos da Fonseca que sempre me apoiou e esteve ao meu lado.

Aos colegas de laboratório com quem trabalhei e sempre contribuíram de forma construtiva para minha formação.

Raphael Araújo Cardoso 
The aim of this work is to evaluate the crack behaviour under fretting conditions. A more generic methodology was proposed to predict the short crack arrest phenomenon and different models to estimate the direction of crack initiation and further propagation were also assessed. Classical theories as the distribution dislocation technique and robust commercial FEM routines were used to calculate the most important mechanical parameters involved in these theories. Available experimental data were collected to verify the accuracy of the present methodologies. The methodology proposed here to evaluate short crack arrest was able to provide better estimates than other available in the literature when a more generic curve for the stress intensity factor threshold $\left(\Delta K_{t h}\right)$, based on the Bezant's material parameter, $\gamma$, was used. Concerning the estimate of crack initiation direction, two methodologies based on the Theory of Critical Distances were assessed and one of them (the Critical Direction Method) could satisfactory provide the direction of crack initiation, whereas the other model, based on a non-local critical plane approach, led to high discrepancies. Two methodologies were also tested to predict crack propagation path and one of them, based on the calculation of the stress intensity factor of an infinitesimal kinked crack emerging from the original one, was able to provide good results, whereas the other methodology, based on the shear stress range near to the crack tip, led to inaccurate results.

\section{RESUMO}

O objetivo desse trabalho é avaliar o fenômeno de propagação de trincas em condições de fretting. Uma metodologia mais genérica para estimar o fenômeno de parada de trincas curtas foi proposta e diferentes modelos para estimar a direção de iniciação e a posterior propagação de trincas também foram avaliados. Teorias clássicas como o método da distribuição das discordâncias e rotinas robustas em elementos finitos foram utilizadas para calcular os parâmetros mais importantes desse trabalho. Dados experimentais disponíveis na literatura foram utilizados para verificar a acurácia das metodologias em estudo. A metodologia proposta para avaliar o fenômeno de parada de trincas curtas foi capaz fornecer melhores resultados que outras presentes na literatura quando uma curva mais genérica para o fator de intensidade de tensão limiar $\left(\Delta K_{t h}\right)$, baseada no parâmetro material de Bazant, $\gamma$, foi utilizada. A respeito da estimativa da direção de iniciação de trincas, duas metodologias baseadas na Teoria das Distâncias Críticas foram avaliadas e um delas (o Método da Direção Crítica) foi capaz de fornecer satisfatoriamente a direção de iniciação das trincas, enquanto que a outra metodologia baseada em uma abordagem não-local de plano crítico levou a grandes erros nas estimativas. Duas outras diferentes metodologias também foram testadas para prever o caminho de propagação de trincas sendo que uma delas, baseada no cálculo do fator de intensidade de tensão de uma trinca infinitesimal emergindo de uma trinca preexistente, foi capaz de fornecer bons resultados, enquanto que a outra metodologia, baseada na faixa de tensão cisalhante nas proximidades da ponta da trinca, conduziu a resultados discrepantes em relação as observações experimentais. 
1 INTRODUÇÃO

1.1 CONTEXTUALIZAÇÃO

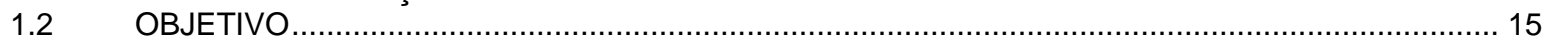

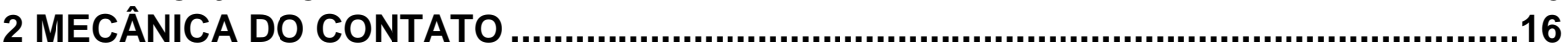

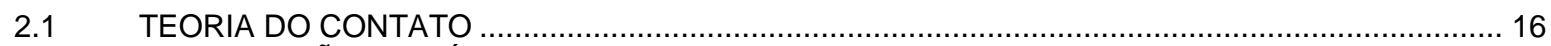

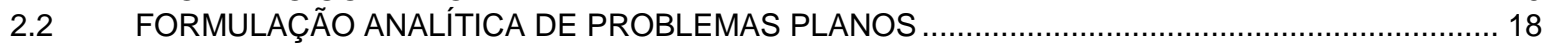

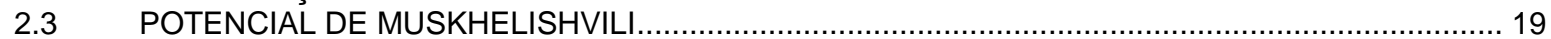

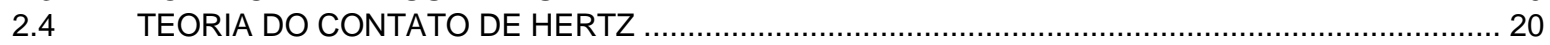

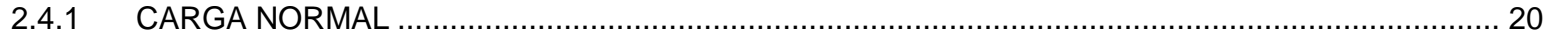

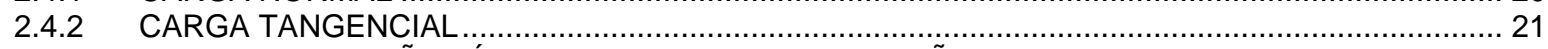

2.4.3 CAMPO DE TENSÃO CÍCLICO NO INTERIOR DA REGIÃO DO CONTATO ..............................2 25

3 FADIGA UNIAXIAL E MULTIAXIAL ...........................................................................26

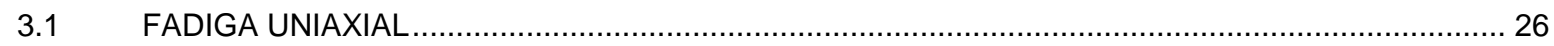

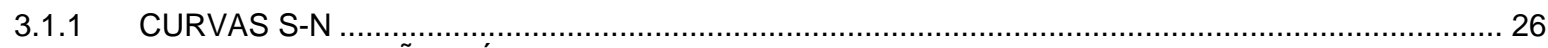

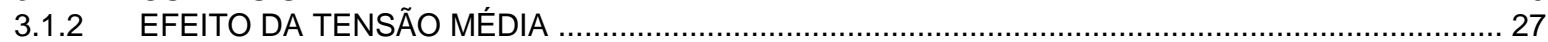

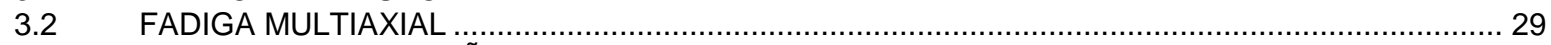

3.2.1 AMPLITUDE DE TENSÃO CISALHANTE EM CARREGAMENTOS MULTIAXIAS ........................30

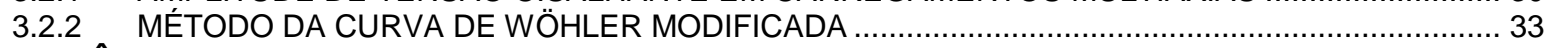

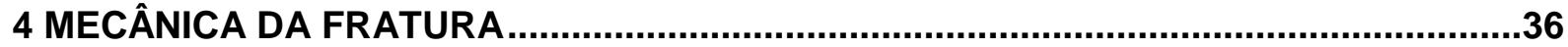

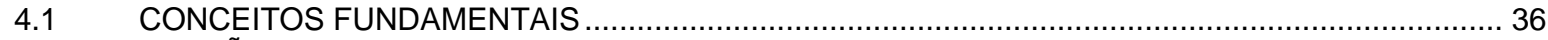

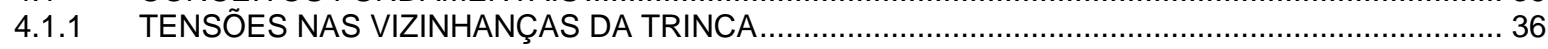

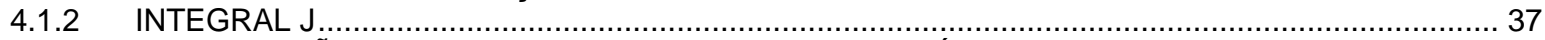

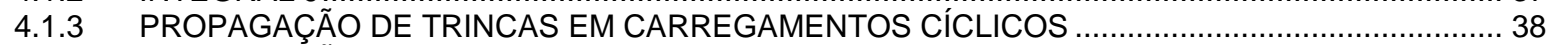

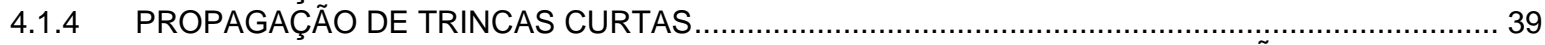

4.2 METODOLOGIA PARA O CALCULO DO FATOR DE INTENSIDADE DE TENSÃO EM

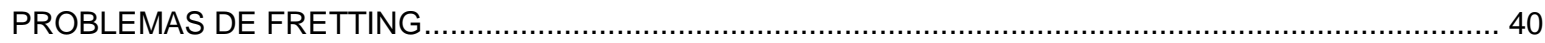

5 METODOLOGIAS . .45

5.1 METODOLOGIAS PARA PREVER PARADA DO PROPAGAÇÃO DE TRINCAS CURTAS EM

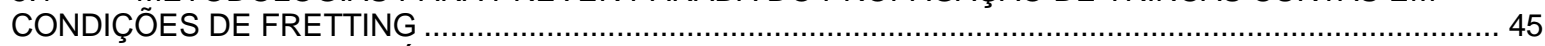

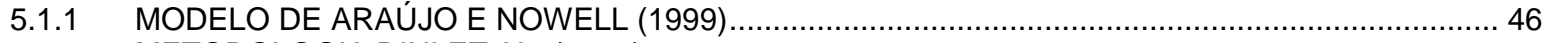

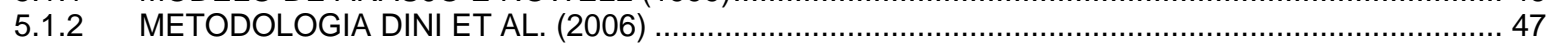

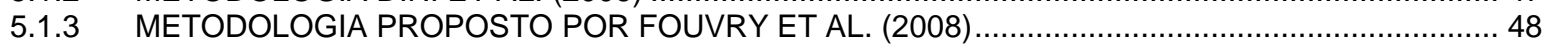

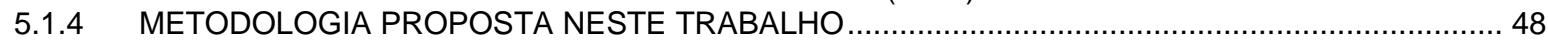

5.2 CRITÉRIOS PARA ESTIMAR A DIREÇÃO DE INICIAÇÃO DE TRINCAS EM CONDIÇÕES DE

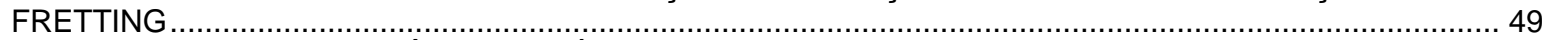

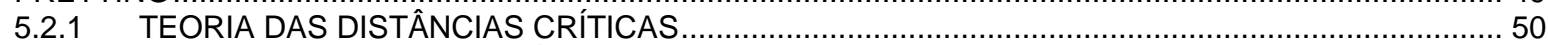

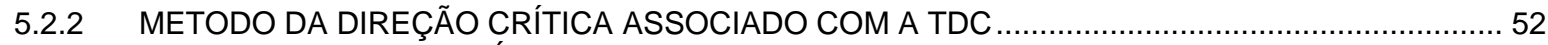

5.2.3 MODELO DE PLANO CRÍTICO APLICADO EM TERMOS DA TDC

5.3 CRITÉRIOS PARA ESTIMAR O CAMINHO DE PROPAGAÇÃO DE TRINCAS ...........................55

6 DADOS EXPERIMENTAIS .........................................................................................55

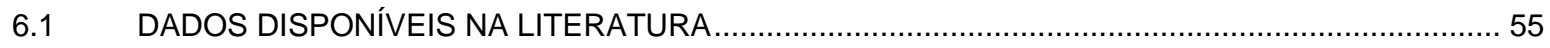

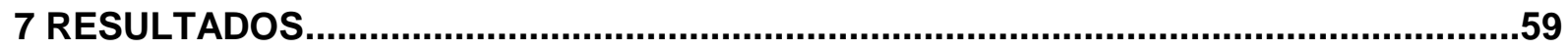

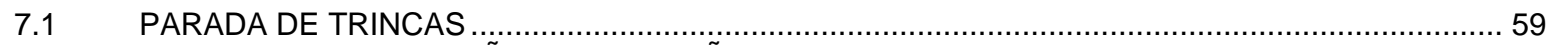

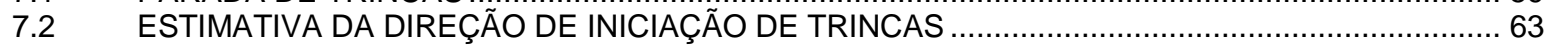

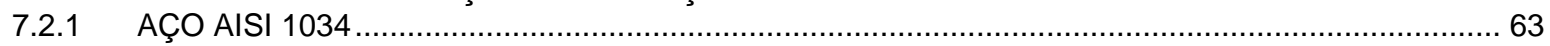

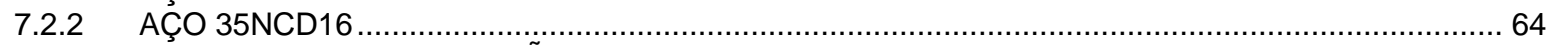

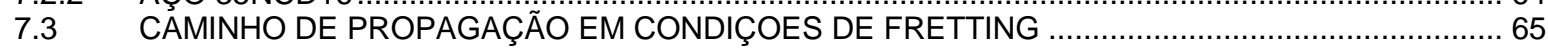

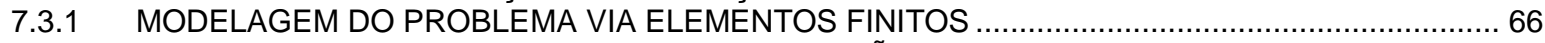

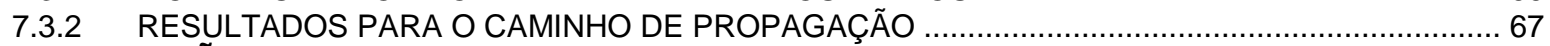

7 CONCLUSÃO

REFERENCIAS BIBLIOGRAFICAS ...................................................................

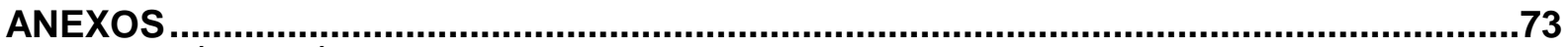

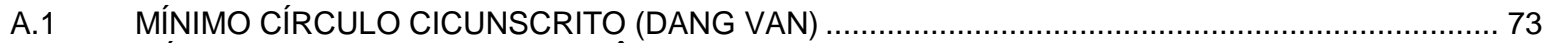

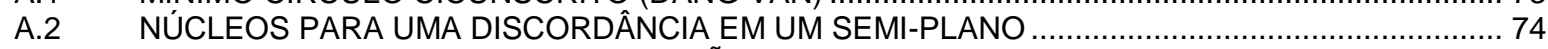

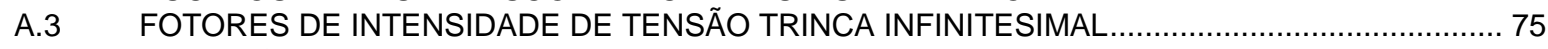

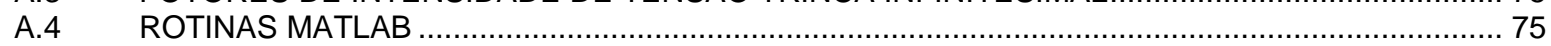


Figura 1- Regiões de contato em cabos condutores

Figura 2-Configurações ilustrando situações típicas onde ocorre fadiga por fretting na indústria aeronáutica: (a) Conexão tipo rabo de andorinha e (b) Junta parafusada

Figura 3- Caracterização de contatos: (a) Incompleto e não-conforme; (b) Completo; (c) Incompleto com singularidade; (d) Incompleto e conforme. ................................................. 16

Figura 4-Contato normal entre corpos elasticamente similares .......................................... 17

Figura 5-Zona de adesão e escorregamento ................................................................. 18

Figura 6-Contato entre corpos elasticamente similares................................................... 18

Figura 7 - Semi-plano submetido a uma distribuição de tensão arbitrária ............................... 19

Figura 8- Contato entre dois corpos elasticamente similares, submetidos a uma força normal

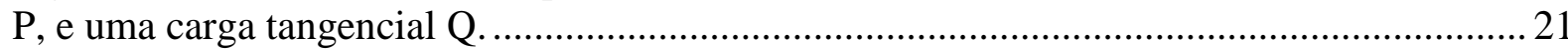

Figura 9- Regiões de escorregamento e de adesão para o contato entre cilindros em regime de

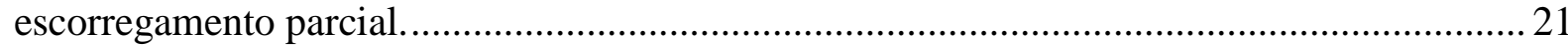

Figura 10- Perfil de distribuição de tensões normais e cisalhantes para uma configuração de

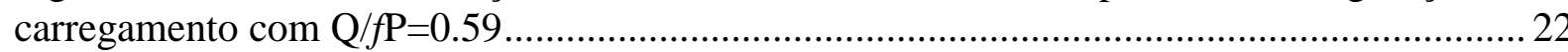

Figura 11- Variação da carga Q com o tempo .................................................................. 23

Figura 12- Variação das tensões cisalhantes na superfície do contato em diferentes instantes de tempo para um carregamento Q cíclico....................................................................... 24

Figura 13- Construção esquemática da curva S-N ............................................................ 26

Figura 14- Curva SxN para metais ferrosos e não ferrosos................................................ 27

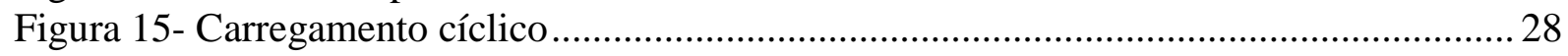

Figura 16- Efeito da tensão média............................................................................... 28

Figura 17- Relação entre limite de resistência à fadiga contra tensão média ...........................29

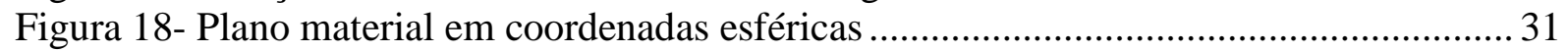

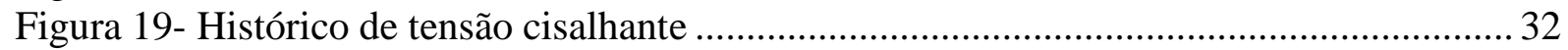

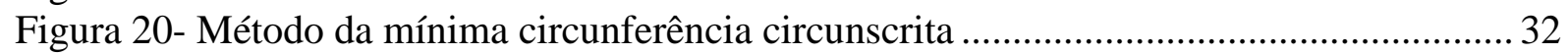

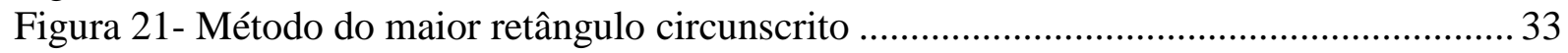

Figura 22- Distribuição das tensões no plano material $\Delta$, Susmel et al. (2004) ........................ 34

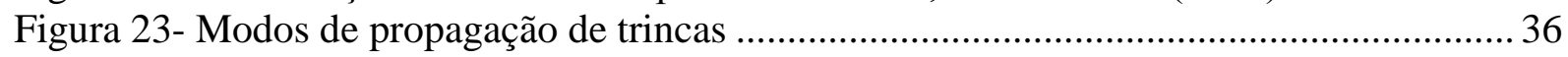

Figura 24- Trinca em um plano infinito sujeito a tensão normal .......................................... 37

Figura 25- Zona plástica e de dominância de K na ponta da trinca ....................................... 37

Figura 26- Integral J na proximidades da ponta da trinca .................................................. 38

Figura 27- Taxa de crescimento da trinca em função de $\Delta \mathrm{K}$.................................................. 39

Figura 28-Princípio de Bueckner: (a) Corpo sem a trinca sujeito a cargas de contato; (b) corpo trincado na ausência de cargas externas, mas com as tensões ao longo da trinca iguais e postas

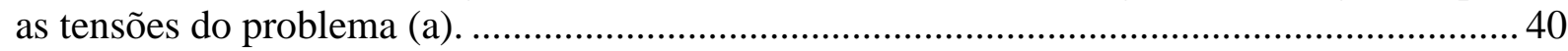
Figura 29- Princípio de Bueckner: (a) Corpo sem a trinca sujeito a cargas externas, (b) corpo trincado na ausência de cargas externas, mas com tensões ao longo da linha da trinca iguais em módulo, mas opostas as do problema (a) ..................................................................... 42 Figura 30- Efeito do tamanho da trinca (a) tensão limiar e (b) no fator intensidade de tensão para uma grande variedade de ligas de engenharia (Kitagawa-Takahashi, 1976). ................ 45

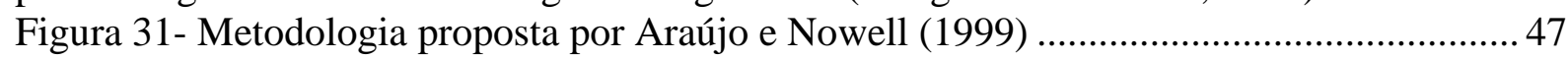

Figura 32- Metodologia proposta por Dini el Al., (2006) ................................................ 47

Figura 33- Metodologia utilizada por Fouvry pra estimar comprimento de trincas paradas ... 48

Figura 34- Limiar de propagação de trincas através da curva de Bazant ................................ 49

Figura 35- Estágios de propagação de trincas .......................................................................50

Figura 36- Diferentes formalizações da Teoria das Distâncias Críticas: (a) Método do Ponto;

(b) Método da Linha; (c) Método da Área. ........................................................................ 51 
Figura 37- (a) Campo de tensão nas proximidades da zona crítica em termos do método da linha em coordenadas cilíndricas; (b) Plano crítico em termos do método do ponto ...............52

Figura 38- Trinca infinitesimal emergindo da trinca original ............................................. 53

Figura 39- Critério da mínima faixa de tensão cisalhante aplicado na ponta da trinca.............54

Figura 40- Perfil da trinca em microscópio eletrônico para o aço AISI 1034 .........................57

Figura 41- Esquematização do perfil de propagação da trinca .............................................58

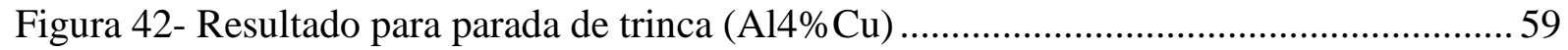

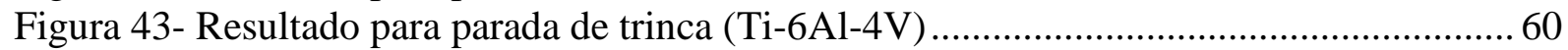

Figura 44- Metodologia para estimar comprimento de trincas que param de crescer ............ 60

Figura 45- Comparação entre o comprimento final de trincas que param de crescer com a

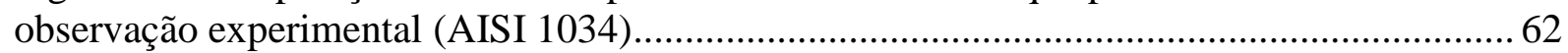

Figura 46- O método da direção crítica aplicada ao aço AISI 1034, ..................................... 63

Figura 47- O modelo de plano crítico aplicado no centro da zona de processo para o aço AISI

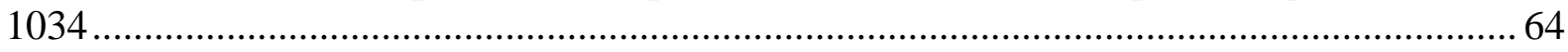

Figura 48- Resultados para a direção de iniciação de trincas para o aço 35NCD16 (a) método

da direção crítica; (b) modelo de plano crítico no centro da zona de processo......................... 65

Figura 49- Modelagem do problema de fretting em um corpo de prova trincado ....................66

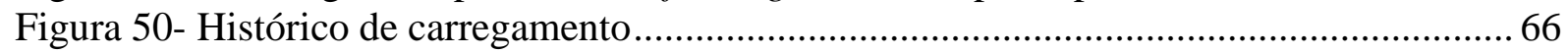

Figura 51- Distribuição das tensões superficiais em um corpo onde não há presença de trincas

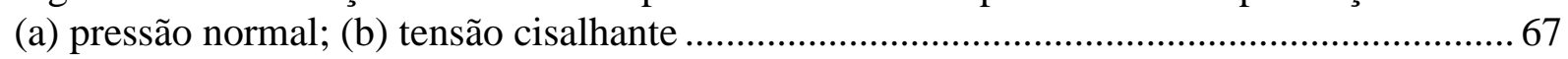

Figura 52- Verificação do cálculo do fator de intensidade de tensão via elementos finitos

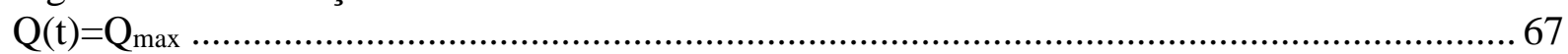

Figura 53- Estimativa do caminho de propagação em trincas em condições de fretting puro. 68

Figura 54- Interpretação geométrica algoritmo de Dang Van.................................................. 74

Figura 55- Inclusão de uma trinca infinitesimal emergindo de uma trinca já existente............ 75 


\section{LISTA DE TABELAS}

Tabela 1- Tensões superficiais cisalhantes para cada região durante a variação do carregamento tangencial com o tempo. 24

Tabela 2- Amplitudes de tensão cisalhante e de tensões normais máximas para ensaios de

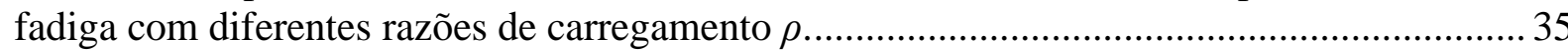

Tabela 3- Parâmetros de carregamento para as ligas de Al4\%Cu e Ti-6Al-4V ........................ 55

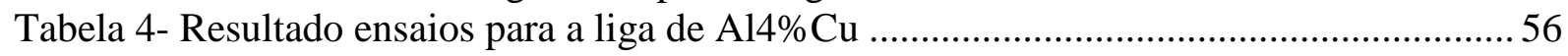

Tabela 5- Resultados ensaios para a liga de Ti-6Al-4V ......................................................... 56

Tabela 6- Propriedades mecânicas das ligas de aços ................................................................ 57

Tabela 7- Resultados para tamanho de trinca obtido nos ensaios para o AISI 1034 (10 6 ciclos)

Tabela 8- Dados dos ensaios para o aço 35NCD16 ............................................................ 58

Tabela 9- Resultados para estimativa do tamanho de trincas que param de crescer AISI 1034, $\theta=0^{\circ}$

Tabela 10- Resultados para estimativa do tamanho de trincas que param de crescer AISI 1034,

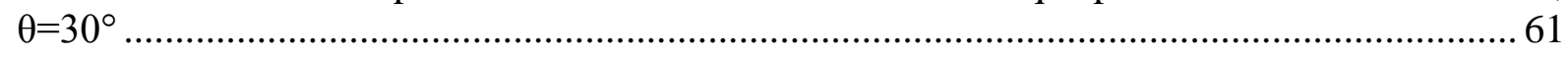

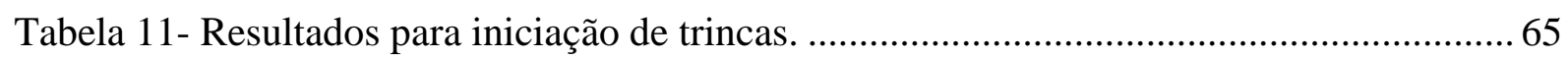




\section{LISTA DE SÍMBOLOS}

\section{Símbolos Latinos}

Complacência composta

$\left[\mathrm{MPa}^{-1}\right]$

Semi-largura do contato

[mm]

$B_{x} \quad$ Densidade de deslocamentos na direção $\mathrm{x}$

$B_{y} \quad$ Densidade de deslocamentos na direção y

$b_{x} \quad$ Deslocamento de uma descontinuidade na direção $\mathrm{x}$

[mm]

$b_{y} \quad$ Deslocamento de uma descontinuidade na direção y

[mm]

$b \quad$ Tamanho da trinca

$b_{0} \quad$ Tamanho crítico ou intrínseco da trinca

c Semi-largura da zona de adesão nos instantes de carga máxima e mínima

[mm]

Semi-largura da zona de adesão durante o carregamento reverso

$[\mathrm{mm}]$

$E \quad$ Módulo de elasticidade

$E^{*} \quad$ Módulo de elasticidade equivalente

[MPa]

$e \quad$ Ponto de colocação de descontinuidade

[MPa]

$F \quad$ Fator geométrico

$f \quad$ Coeficiente de atrito

$G \quad$ Núcleo de uma descontinuidade

$g(x) \quad$ Deslocamento relativo tangencial

$h(x) \quad$ Interpenetração entre dois corpos

$i \quad$ Unidade imaginária

$K \quad$ Fator intensidade de tensão

$[\mathrm{MPa} \sqrt{m}]$

$K_{I} \quad$ Fator intensidade modo I

$[\mathrm{MPa} \sqrt{m}]$

$K_{I I} \quad$ Fator intensidade modo II

$[\mathrm{MPa} \sqrt{m}]$

$K_{\text {eff }} \quad$ Fator intensidade modo efetivo

$[\mathrm{MPa} \sqrt{m}]$

$k \quad$ Constante de Kolosov

L Distância Crítica / Espessura corpo de prova e sapata

m Massa

$N \quad$ Número de ciclos de fadiga

$P \quad$ Carga normal por unidade de comprimento

$p_{0} \quad$ Pressão de pico

$[\mathrm{N} / \mathrm{mm}]$

[MPa]

[MPa]

$p(x) \quad$ Distribuição de pressão no contato

$[\mathrm{N} / \mathrm{mm}]$

Carga normal por unidade de comprimento

$[\mathrm{N} / \mathrm{mm}]$

$Q \quad$ Carga tangencial por unidade de comprimento

$[\mathrm{N} / \mathrm{mm}]$

$Q_{\max } \quad$ Carga tangencial máxima por unidade de comprimento

$[\mathrm{N} / \mathrm{mm}]$

$q(x) \quad$ Distribuição de tensão cisalhante superficial

$q^{\prime}(x) \quad$ Perturbação na distribuição de tensão cisalhante superficial

$q^{\prime \prime}(x) \quad$ Termo de correção para a distribuição de tensão cisalhante superficial

$R \quad$ Raio da sapata cilíndrica

$R^{*} \quad$ Raio equivalente

[mm]

$x, y, z \quad$ Coordenadas do eixo cartesiano

[mm]

\section{Símbolos Gregos}

$\alpha$

Frequência angular 
$\beta \quad$ Expoente de resistência a fadiga

$\Delta \sigma_{\text {eff }} \quad$ Faixa de tensão efetiva $\quad$ [MPa]

$\Delta \sigma_{f l} \quad$ Faixa limite de resistência a fadiga [MPa]

$\Delta K_{\text {eff }} \quad$ Faixa do fator de intensidade de tensão efetivo $\quad[\mathrm{MPa} \sqrt{\mathrm{m}}]$

$\begin{array}{lll}\Delta K_{\text {th }} & \text { Limiar para o fator intensidade de tensão } & {[\mathrm{MPa} \sqrt{m}]}\end{array}$

$\Delta K_{0} \quad$ Limiar para o fator intensidade de tensão em trincas longas $\quad[\mathrm{MPa} \sqrt{m}]$

$\gamma \quad$ Fator de ajuste de Bazant para o limiar de propagação de trincas

$\theta \quad$ Ângulo em coordenadas polares

$\mu \quad$ Módulo de rigidez $\quad$ [MPa]

$v \quad$ Coeficiente de Poisson

$\xi \quad$ Variável de integração

$\sigma \quad$ Tensões normais

$\tau \quad$ Tensões cisalhantes

$\sigma_{u t} \quad$ Tensão última $\quad$ [MPa]

$\sigma_{y} \quad$ Tensão de escoamento $\quad$ [MPa]

$\sigma_{f l} \quad$ Limite de resistência a fadiga $\quad$ [MPa]

$\sigma_{f}^{\prime} \quad$ Coeficiente de resistência a fadiga

$\sigma_{-1} \quad$ Limite de resistência a fadiga totalmente reversível [MPa]

$\sigma_{0} \quad$ Limite de resistência a fadiga para razão de carregamento nula [MPa]

$\Phi \quad$ Função potencial de Muskhelishvili

$\Phi^{\prime} \quad$ Derivada da função potencial de Muskhelishvili

$\phi \quad$ Função desconhecida / Ângulo em coordenadas esféricas

$\rho \quad$ Razão de carregamento

$\omega \quad$ Ângulo de rotação de um sistema de coordenadas.

\section{Subscritos}

$1,2 \quad$ Índices referentes aos corpos 1 e 2

a Amplitude

eff Efetivo

$m \quad$ Médio

$\max \quad$ Máximo

$\min \quad$ Mínimo

xx,yy,xy Componentes que indicam plano normal e sentido da componente de tensão.

\section{Sobrescritos}

$\mathrm{n} \quad$ Componente normal

$\mathrm{t} \quad$ Componente tangencial

- Conjugado 


\section{INTRODUÇÃO}

\subsection{CONTEXTUALIZAÇÃO}

O termo fretting refere-se a um pequeno deslocamento tangencial que pode ocorrer entre duas superfícies em contato (em geral deslocamentos com amplitudes inferiores à $50 \mu m$ ). O movimento tangencial pode surgir oriundo de vibrações devido a fontes externas ou da presença de cargas cíclicas tangencias atuando em um dos corpos, que por sua vez gera um aumento da rugosidade das superfícies, tornando suscetível a nucleação de trincas. Essas trincas são concentradores de tensão e, em presença de cargas externas de fadiga, podem levar a uma falha prematura do componente. Esse fenômeno é conhecido como fadiga por fretting.

Falhas oriundas do processo de fadiga por fretting vêm se mostrando um desafio cada vez maior em projetos de engenharia. Exemplos clássicos desse tipo de falha são observados em cabos de transmissão de energia, Fig. 1, nas conexões do tipo rabo de andorinha entre as pás e o rotor de motores a jato e em juntas rebitadas ou parafusadas da fuselagem de aeronaves, Fig. 2.
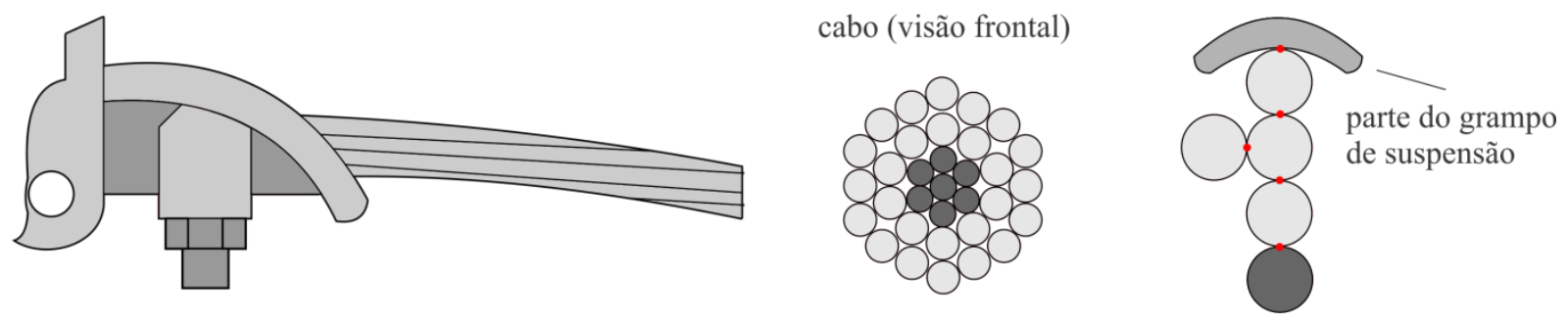

Figura 1- Regiões de contato em cabos condutores

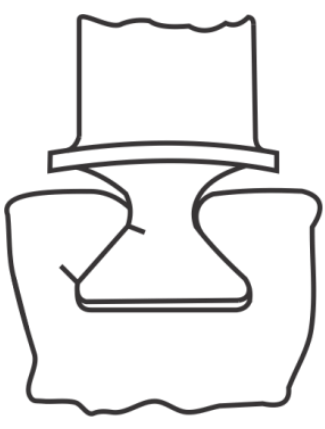

(a)

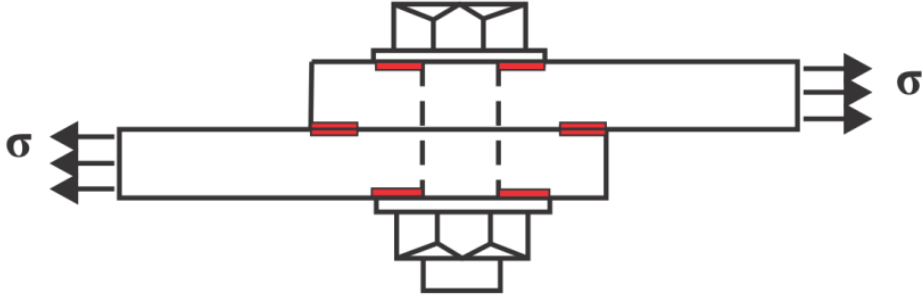

(b)

Figura 2-Configurações ilustrando situações típicas onde ocorre fadiga por fretting na indústria aeronáutica: (a) Conexão tipo rabo de andorinha e (b) Junta parafusada

Os primeiros relatos de falha por fretting ocorreram no início do século XX, por meio da observação de trincas na região de contato entre o corpo de prova e as garras de uma máquina de fadiga (Eden et al. 1911). Na época, o fenômeno foi identificado como um dano superficial, o que hoje é descrito como desgaste por fretting. Warlow-Davis (1941) relatou que os componentes que eram submetidos a condições de fretting e depois a carregamentos cíclicos apresentavam uma redução de 12 a 17\% de sua resistência a fadiga. Experimentos mostraram ainda que a fadiga por fretting pode causar uma redução 
de até $90 \%$ no limite de resistência à fadiga de um material metálico (McDowell, 1953). Segundo Thomson (1998), a fadiga por fretting causa cerca de 17\% das falhas ou contratempos nos sistemas de propulsão aeronáuticos. Nesse contexto, nota-se que entender o processo de fadiga por fretting é fundamental para prevenção e redução de acidentes.

Fatores que influenciam a resistência à fadiga por fretting, como pressão no contato, a amplitude de escorregamento relativo, condições ambientais e materiais não tinham sido avaliados completamente até meados dos anos 60. Entretanto, Nishioka e Hirakawa $(1969,1972)$ avaliaram a influência desses fatores de forma independente e constataram que havia uma faixa de valores de deslocamentos tangenciais que acelerava a fadiga por fretting.

Posteriormente, Bramhall (1973) estudou a influência do tamanho do contato na vida em fadiga, após a realização de sucessivos ensaios onde se mantinha o estado de tensão superficial constante, mas variava-se o tamanho do contato. Dessa forma, concluiu-se que contatos inferiores a um tamanho crítico apresentavam vida infinita ( $>10^{7}$ ciclos), enquanto que para contatos maiores a falha ocorria. Nowell (1988) e Araújo (2000) confirmaram a ocorrência desse efeito.

Várias metodologias para previsão de resistência a fadiga por fretting, conceitualmente bastante distintas entre si, foram desenvolvidas ao longo dos anos. As características comuns entre elas são o fato de serem abordagens simplificadas e/ou empíricas. Nas duas últimas décadas, surgiram métodos promissores nos quais se de destacam a aplicação de critérios baseados na:

i) Analogia com fadiga em entalhes;

ii) Mecânica da fratura linear elástica;

Na primeira abordagem, propõe-se que o problema de fretting é semelhante a um problema de fadiga convencional devido a um concentrador de tensões (entalhes). Essa abordagem simplifica o problema, apesar de dar menos importância ao desgaste superficial. Giannakopoulus et al. (2000) observando semelhanças no campo de tensão no problema de contato entre uma sapata plana com cantos arredondados e um semi-plano com o de corpos entalhados sugeriram que essa característica poderia ser usada para fazer previsão de vida em fadiga por fretting. Neste contexto, trabalhos recentes propõem aplicar um critério de fadiga multiaxial no centro de uma zona de processo a fim de se considerar tanto a influência do gradiente de tensão quanto a multiaxialidade das tensões. Em análises mais convencionais, tem-se a teoria da distância crítica, que propõe que a propagação de trincas pode ser evitada desde que haja uma rápida redução dos níveis de tensão à medida que se adentra o componente (Susmel, 2009). Portanto altos níveis de tensão nas proximidades do contato que ocorrem no problema de fretting podem não ser representativos para a determinação da vida do componente desde que esse campo de tensão severo decaia rapidamente.

Já a segunda abordagem, Araújo e Nowell (1999), baseia-se no fato que, em contatos sob condições de fadiga por fretting, uma trinca pode-se propagar por uma certa distância e parar (condição 
essa considerada segura). Esse fenômeno ocorre porque à medida que a trinca avança, a intensidade das tensões em sua vizinhança diminui. Caso essa intensidade atinja um valor abaixo do limiar para propagação, a trinca para. Basicamente, as metodologias baseadas na parada de trincas quantificam o fator de intensidade tensão ao longo de uma trajetória prescrita e comparam esse valor com um valor limite para propagação de trincas.

No entanto, apesar dos avanços acerca do assunto e da utilização de modelos numéricos e analíticos para prever parâmetros de fadiga, muitos problemas, principalmente no campo industrial permanecem desconhecidos, o que leva a se adotar medidas paliativas (Beard, 2004). O objetivo maior ao se realizar pesquisas na área de fadiga por fretting, sob dadas condições de contato, carregamentos e de um conjunto de parâmetros materiais é transportar esses conhecimentos e resultados para condições mais complexas com aplicação industrial.

\subsection{OBJETIVO}

O objetivo deste trabalho é avaliar o fenômeno de iniciação e propagação de trincas em condições de fretting. Uma metodologia para avaliar a parada de trincas curtas em condições de fretting foi proposta baseada na curva de ajuste de Bazant para o limiar do fator de intensidade de tensão. A influência de se adotar em uma primeira análise a propagação de uma trinca apenas em modo I de forma perpendicular à superfície de contato também foi verificada, embora se saiba que em condições de fretting, as trincas geralmente se iniciam em modo misto.

Em uma segunda análise duas diferentes metodologias baseadas na Teoria das Distâncias Críticas foram utilizadas para estimar a direção de iniciação de trincas. Posteriormente duas outras metodologias foram testadas para estimar o caminho de propagação de trincas em condições de fretting. Todas as metodologias avaliadas neste trabalho foram confrontadas com resultados experimentais para contatos do tipo cilindro no plano em condições de escorregamento parcial. Teorias clássicas como o método da distribuição das discordâncias e um software comercial em elementos finitos (ABAQUS) foram utilizados para extrair os principais parâmetros mecânicos (campo de tensão e fatores de intensidade de tensão) para conduzir as análises. 


\section{MECÂNICA DO CONTATO}

\subsection{TEORIA DO CONTATO}

Em geral, problemas reais de fretting envolvem contato entre componentes de grande complexidade, que associam geometrias e históricos de carregamento complexos. Nesses casos, a modelagem do problema é complicada e se faz o uso de métodos numéricos, sendo o principal deles o método dos elementos finitos.

Sendo assim, no estudo do problema de fadiga por fretting, costuma-se utilizar testes experimentais que empreguem geometrias idealizadas e bem definidas de forma que a natureza do contato, bem como as tensões e deformações induzidas pelo contato, sejam bem definidas, de fácil controle, possuam repetibilidade e baixa sensibilidade às imperfeições de fabricação (Hills e Nowell, 1994).

Neste capítulo uma configuração clássica do problema de fretting será estudada, contato entre cilindros, configuração esta que possui solução analítica bem definida para determinadas condições de carregamento (Hills e Nowell, 1994), e uma gama de resultados experimentais presentes na literatura.

O primeiro passo na análise de contatos mecânicos é a caracterização do contato. Na Figura 3 é apresentada a classificação do contato segundo sua natureza.

a)

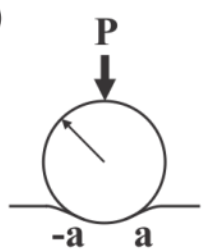

b)

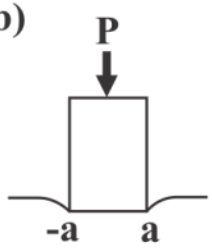

c)

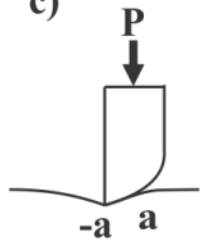

d)

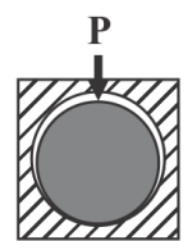

Figura 3- Caracterização de contatos: (a) Incompleto e não-conforme; (b) Completo; (c) Incompleto com singularidade; (d) Incompleto e conforme.

A Figura 3 (a) ilustra um cilindro pressionado contra um semi-plano, formando um contato do tipo incompleto, uma vez que a extensão do contato depende da carga normal aplicada, e não conforme já que para valores pequenos de $\mathrm{P}$ a semi-largura do contato "a" é muito inferior ao raio do cilindro, $\mathrm{R}$. Isso implica que, quando a $<<\mathrm{R}$, a deformação do cilindro será restrita a um pequeno segmento de arco e, portanto o cilindro pode ser aproximado por um semi-plano. Nesse tipo de contato a pressão nas extremidades do contato é nula. Em caso de contatos completos Fig. 3 (b), o tamanho do contato não é influenciado pela carga $\mathrm{P}$ aplicada. A distribuição de pressão ao longo do contato apresenta singularidades nas extremidades do contato, onde a pressão assume valores muito altos. A distribuição 
das tensões nesse tipo de contato é modificada de forma brusca por falhas geométricas. No caso de contato incompleto e com singularidade Fig. 3 (c), o tamanho do contato depende da carga P aplicada, tem distribuição de pressão singular em uma das extremidades e uma distribuição que cai continuamente até zero na outra.

Para o caso da Fig. 3 (d) há conformabilidade do contato, nesse caso, ao contrário do que ocorre na Fig. 3 (a), o semi-tamanho do contato passa a não ser muito menor que o raio do cilindro, tornando inviável a aproximação dos corpos por um semi-pano.

Supondo agora o contato normal entre dois corpos similares (mesmo módulo de elasticidade, E), conforme mostrado na Fig. 4. Quando uma carga de contato é exercida, as partículas na superfície de cada um dos corpos além de serem comprimidas sofrem um deslocamento paralelo. No entanto, como os corpos são elasticamente similares, as partículas correspondentes dos corpos sofrerão o mesmo deslocamento relativo, ou seja, mesmo que haja um coeficiente de atrito diferente de zero entre as superfícies, não haverá tensões cisalhantes.

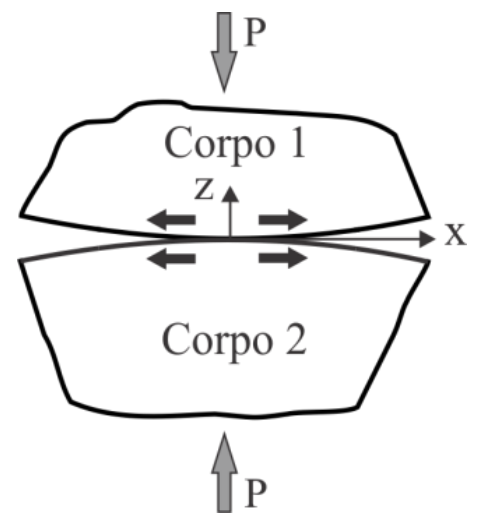

Figura 4-Contato normal entre corpos elasticamente similares

Considere agora a aplicação de uma força tangencial suficientemente grande para causar escorregamento entre os corpos em contato. Nesse caso irão surgir tensões de cisalhamento que são limitadas em toda a extensão do contato, pelo coeficiente de fricção $f$, ou seja:

$$
|q(x, y)|=-f p(x, y)
$$

onde $q(x, y)$ e $p(x, y)$ são as distribuições de tensão cisalhante e de pressão ao longo do contato, respectivamente. A presença das tensões cisalhantes provocará um deslocamento normal nos pontos correspondentes dos corpos em contato. No entanto, como as tensões cisalhantes atuam em direções opostas e os corpos são elasticamente similares, o deslocamento normal dos pontos correspondentes nas superfícies dos dois corpos é o mesmo, fazendo com que a pressão contato permaneça inalterada. Em geral, na região do contato, assume-se que a força de cisalhamento aplicada é suficientemente pequena para não causar deslizamento total, ou seja:

$$
|Q|<f P
$$


onde $Q$ é a carga tangencial de contato e $\mathrm{P}$ a carga normal. Isso resulta no aparecimento de duas zonas distintas, uma de aderência e outra de escorregamento, ilustradas na Fig. 5. A existência da zona de adesão é de fácil compreensão, uma vez que as forças tangenciais não são suficientes para causar escorregamento. No caso da zona de escorregamento, à medida que se afasta do centro do contato a tensão normal tende a zero e, portanto seria necessário um coeficiente de atrito infinito para prevenir o escorregamento. Sendo assim, na zona de escorregamento, as tensões cisalhantes são iguais em magnitude ao limite onde há escorregamento, Eq. (2.1). Já para a zona de adesão:

$$
|q(x, y)|<-f p(x, y)
$$

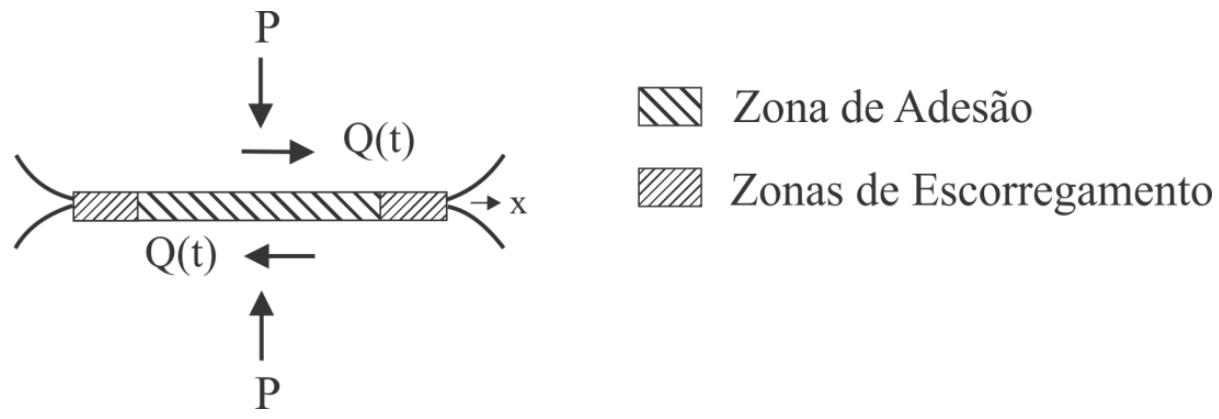

Figura 5-Zona de adesão e escorregamento

Como as tensões cisalhantes nos corpos são iguais em módulo, porém com sentido contrário, os deslocamentos normais induzidos serão os mesmos. Portanto a distribuição de pressão continua sem ser afetado pelas tensões cisalhantes, o que torna o problema desacoplado.

\subsection{FORMULAÇÃO ANALÍTICA DE PROBLEMAS PLANOS}

Para se obter o campo de tensão sub-superficial é preciso determinar o campo de tensões cisalhantes e a distribuição de pressão ao longo do contato. Para isso é preciso resolver as equações integrais que relacionam a distribuição de pressão $p(x)$ com o deslocamento normal $h(x)$ conforme ilustrado no Fig. 6 , e a distribuição das tensões cisalhantes com o deslocamento tangencial relativo $g(x)$. Detalhes referentes ao desenvolvimento dessas equações podem ser encontrados em Hills e Nowell (1994).

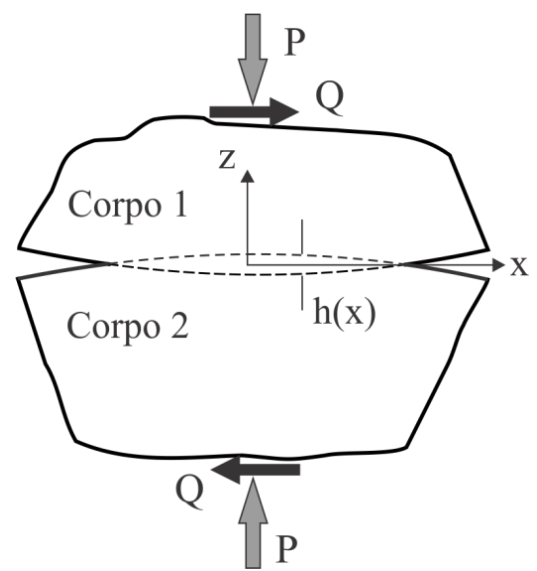

Figura 6-Contato entre corpos elasticamente similares 
Quando os dois corpos são elasticamente similares a solução pode ser obtida pela integração ao longo de todo o contato das Eq. (2.4) e (2.5):

$$
\frac{1}{A} \frac{\partial h}{\partial x}=\frac{1}{\pi} \int \frac{p(\xi)}{x-\xi} d \xi
$$

e,

$$
\frac{1}{A} \frac{\partial g}{\partial x}=\frac{1}{\pi} \int \frac{q(\xi)}{x-\xi} d \xi
$$

onde $A$ é a complacência composta que é definida como:

$$
A=2\left(\frac{k+1}{4 \mu}\right)
$$

sendo $k=3-4 v$, em estado plano de deformação, $v$ a razão de Poisson e $\mu$ é o módulo de rigidez.

\subsection{POTENCIAL DE MUSKHELISHVILI}

Em fretting, é importante compreender o campo de tensão na superfície de contato e como esse se comporta à medida que se adentra no material. Uma forma eficiente de se calcular esse campo de tensões é utilizando a formulação potencial de Muskhelishvilli (1953), Hills, Nowell e Sackfield (1993).

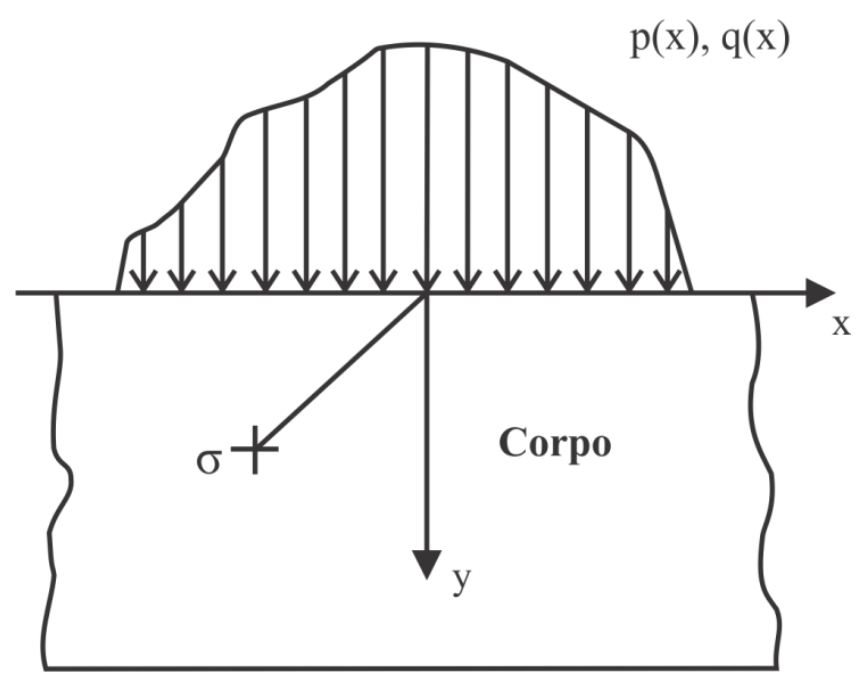

Figura 7 - Semi-plano submetido a uma distribuição de tensão arbitrária

Nessa formulação, onde a coordenada das posições é dada na forma complexa $(z=x+y i)$, Fig. 7 , o potencial pode ser escrito como mostrado na Eq. (2.7):

$$
\Phi(z)=\frac{1}{2 \pi i} \int \frac{p(t)-i q(t)}{t-z} d t
$$


onde $p(t)$ e $q(t)$, são distribuições de tensões normais e cisalhantes arbitrárias. Em condições de escorregamento, essas distribuições são relacionadas pela Eq. (2.1). Assim a Eq. (2.7) pode ser escrita como:

$$
\Phi(z)=\frac{1-i f}{2 \pi i} \int \frac{p(t)}{t-z} d t
$$

Uma vez determinado o potencial, as componentes de tensão podem ser relacionadas através das seguintes equações:

$$
\begin{aligned}
& \sigma_{x x}+\sigma_{y y}=2(\Phi(z)+\bar{\Phi}(\bar{z})) \\
& \sigma_{y y}-\sigma_{x x}+2 i \tau_{x y}=2\left((\bar{z}-z) \Phi^{\prime}(z)+\bar{\Phi}(z)-\Phi(z)\right)
\end{aligned}
$$

onde $\Phi^{\prime}(z)$ é a derivada da função potencial em relação z, $\bar{\Phi}(z)$ o conjugado da função potencial e $\bar{\Phi}(\bar{z})$ é o conjugado da função potencial aplicado a conjugado de z.

\subsection{TEORIA DO CONTATO DE HERTZ}

\subsubsection{CARGA NORMAL}

A configuração estudada neste trabalho, que é comumente aplicada por outros pesquisadores (Nowell, 1988, Araújo, 2000) é mostrada na Fig. 8 (contato entre cilindros). O raio da sapata, R, e o carregamento normal por unidade de comprimento, $\mathrm{P}$, foram definidos considerando cada corpo como um semi-plano elástico e a solução para a distribuição de pressão é a solução de Hertz. Os resultados de Hertz (1882) preveem que devido à força normal estática, uma distribuição de pressão elíptica é desenvolvida ao longo do contato:

$$
p(x)=-p_{0} \sqrt{1-\left(\frac{x}{a}\right)^{2}}
$$

onde $p_{0}$ é o valor máximo da pressão no contato, obtida a partir da condição de equilíbrio.

$$
p_{0}=\frac{2 P}{\pi a}
$$

e $a$ é a metade do tamanho do contato

$$
a=\sqrt{\frac{4 P R^{*}}{\pi E^{*}}}
$$

sendo $R^{*}$, o raio equivalente, dado por:

$$
R^{*}=\left(\frac{1}{R_{1}}+\frac{1}{R_{2}}\right)^{-1}
$$


e finalmente

$$
E^{*}=\left(\frac{1-v_{1}^{2}}{E_{1}}+\frac{1-v_{2}^{2}}{E_{2}}\right)^{-1}
$$

os subscritos 1 e 2 referem-se aos corpos 1 e 2 respectivamente, "E" é o módulo de elasticidade, e $v$ é a razão de Poisson.

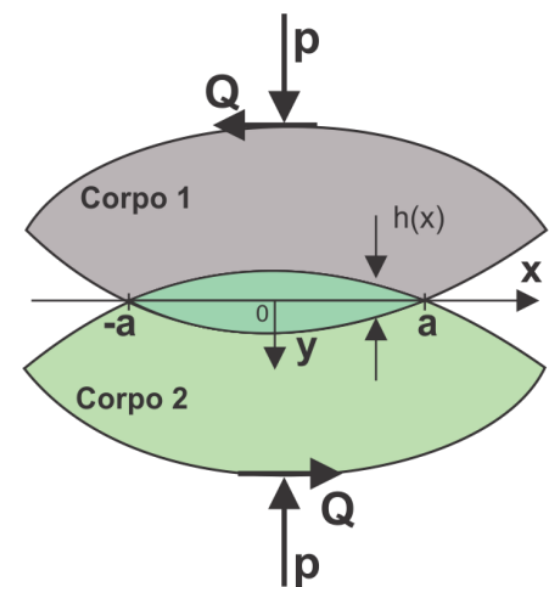

Figura 8- Contato entre dois corpos elasticamente similares, submetidos a uma força normal P, e uma carga tangencial Q.

\subsubsection{CARGA TANGENCIAL}

Por outro lado, a carga tangencial dá origem às tensões cisalhantes. Em fadiga por fretting, o carregamento cisalhante aplicado geralmente é menor que o limite para escorregamento total. Então, como descrito anteriormente, um regime de escorregamento parcial é desenvolvido, onde ocorre escorregamento em duas regiões simétricas $c<|x| \leq a$ que circundam uma região central de adesão $|x| \leq c$, Fig. 9 .

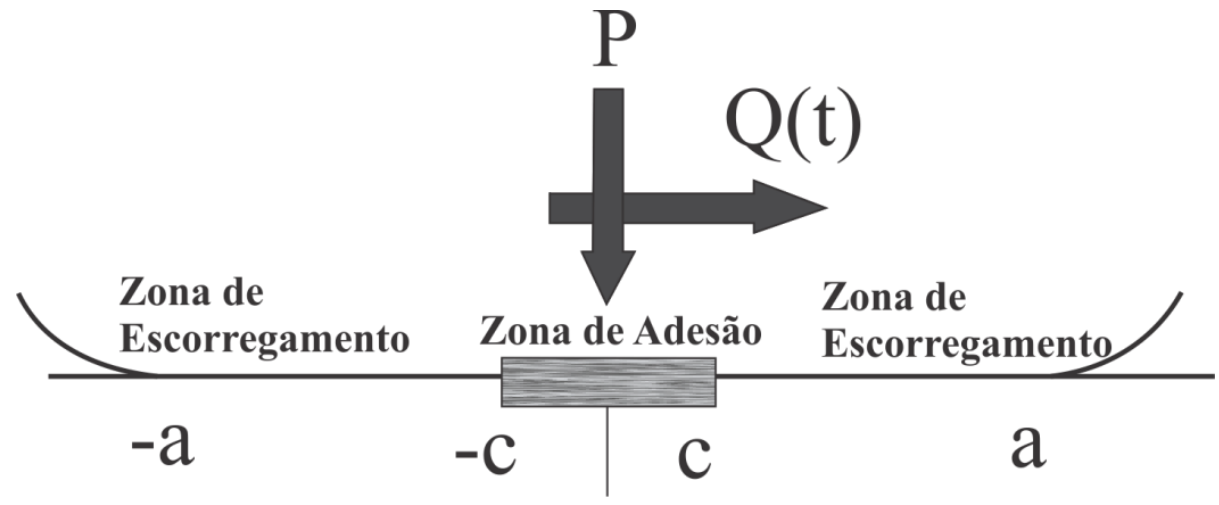

Figura 9- Regiões de escorregamento e de adesão para o contato entre cilindros em regime de escorregamento parcial.

É conveniente modelar as tensões cisalhantes superficiais como uma perturbação da solução de escorregamento total: 


$$
q(x)=f p_{0} \sqrt{1-\left(\frac{x}{a}\right)^{2}}-q^{\prime}(x)
$$

onde $f$ é o coeficiente de atrito.

Na zona de adesão, pode-se obter $q^{\prime}(x)$ resolvendo-se a Eq. (2.5), Hills et al. (1993), levando-se em conta o fato de não haver movimento relativo na direção x entre os pontos correspondentes da região de adesão $\left(g^{\prime}(x)=0,|x| \leq c\right)$.

$$
q^{\prime}(x)=f p_{0} \frac{c}{a} \sqrt{1-\left(\frac{x}{c}\right)^{2}} \quad|x| \leq c
$$

Na zona de escorregamento $(c<|x| \leq a)$ não há perturbação da solução de escorregamento total, sendo assim:

$$
q^{\prime}(x)=0 \quad c<|x| \leq a
$$

O tamanho da zona de adesão, $c$, é encontrado considerando-se equilíbrio tangencial.

$$
\frac{c}{a}=\sqrt{1-\left(\frac{Q}{f P}\right)}
$$

A Figura 10 ilustra essa solução para uma condição típica de carregamento, onde a razão $p(x) / p_{0}$ é descontada da perturbação $q^{\prime}(x)$ na zona de adesão.

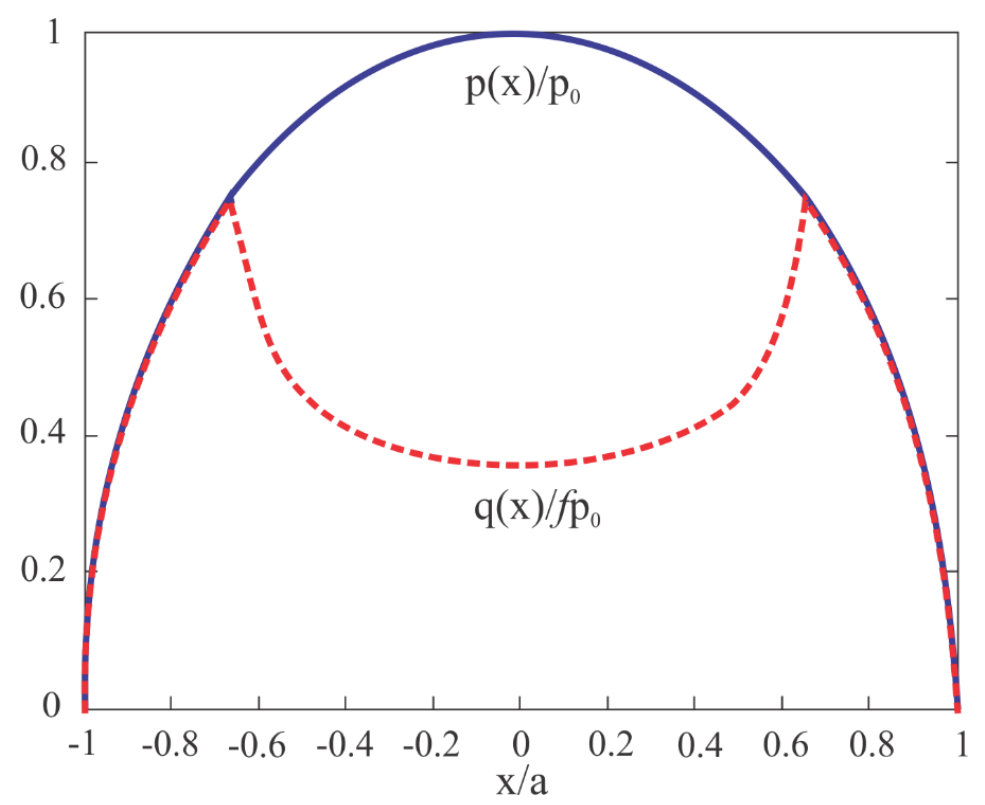

Figura 10- Perfil de distribuição de tensões normais e cisalhantes para uma configuração de carregamento com $\mathrm{Q} / \mathrm{P}=0.59$

As expressões desenvolvidas até agora para a distribuição de tensão cisalhante na superfície são válidas apenas quando a força tangencial está em seu valor máximo em um ciclo de carregamento. Para 
analisar as tensões superficiais ao longo do tempo é necessário avaliar o que ocorre no carregamento reverso, Hills et al. (1993).

Para essa análise é importante recordar as condições de cisalhamento superficial nas zona de escorregamento e de adesão, que são descritas pelas Eq. (2.1) e Eq. (2.3). Além disso, as tensões cisalhantes sempre apontam na direção oposta ao movimento da sapata:

$$
\operatorname{sgn}(q(x))=-\operatorname{sgn}\left(\frac{\partial g}{\partial t}\right)
$$

Para compreender melhor o fenômeno de escorregamento reverso assumiremos um carregamento tangencial com comportamento senoidal ao longo do tempo descrito pela Fig. 11. Durante a primeira fase do carregamento, ou seja, quando a tensão cisalhante atinge o valor máximo (ponto A, Fig. 11), as Eq. (2.16) a (2.18) descrevem $q(x)$.

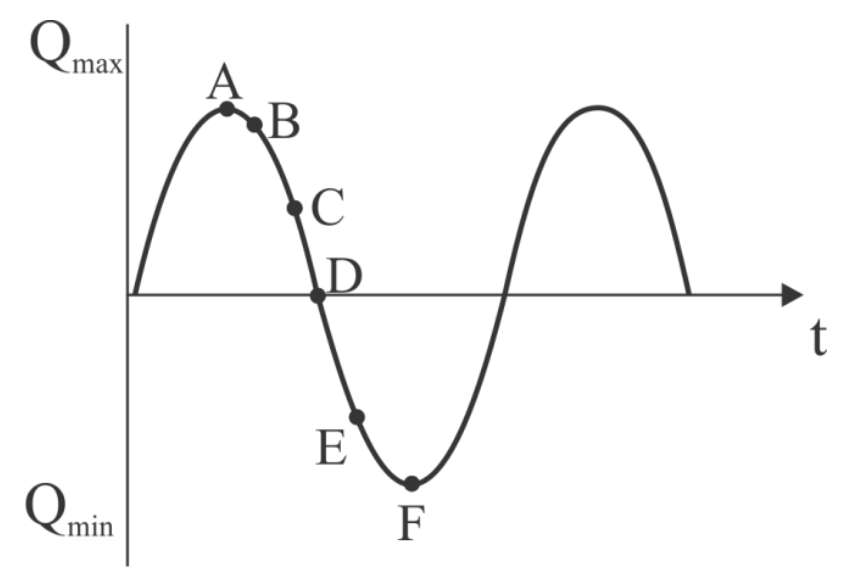

Figura 11- Variação da carga Q com o tempo

Durante o descarregamento do ponto A para o ponto B, o deslocamento relativo muda de sinal provocando uma violação da Eq. (2.20) e há adesão em todo o contato.

Prosseguindo com o descarregamento até o ponto $\mathrm{C}$, verifica-se escorregamento reverso nas extremidades do contato. Nessa nova zona de escorregamento formada $\left(c^{\prime}<x \leq a\right)$, as tensões cisalhantes superficiais terão mudado de direção, ou seja, passarão de $f p(x) \sqrt{1-\left(\frac{x}{a}\right)^{2}}$ para $-f p(x) \sqrt{1-\left(\frac{x}{a}\right)^{2}}$. Dessa forma, por analogia, pode-se concluir que a perturbação necessária para evitar escorregamento na nova zona de adesão é dada por:

$$
q^{\prime \prime}(x)=2 f p_{0} \frac{c^{\prime}}{a} \sqrt{1-\left(\frac{x}{c^{\prime}}\right)^{2}}
$$

O fator 2, que aparece na Eq. (2.21), deve cancelar o movimento relativo quando as tensões superficiais na zona de escorregamento mudam de $f p(x)$ para menos $-f p(x)$. A Tabela 1 apresenta as distribuições de tensões cisalhantes superficiais para cada região na fase de descarregamento. 
Tabela 1- Tensões superficiais cisalhantes para cada região durante a variação do carregamento tangencial com o tempo.

\begin{tabular}{cc}
\hline$q(x) / f p_{0}$ & Zona de aplicação \\
$-\sqrt{1-\left(\frac{x}{a}\right)^{2}}$ & $c^{\prime}<|x| \leq a$ \\
$-\sqrt{1-\left(\frac{x}{a}\right)^{2}}+2 \frac{c^{\prime}}{a} \sqrt{1-\left(\frac{x}{c^{\prime}}\right)^{2}}$ & $c<|x| \leq c^{\prime}$ \\
$-\sqrt{1-\left(\frac{x}{a}\right)^{2}}+2 \frac{c^{\prime}}{a} \sqrt{1-\left(\frac{x}{c^{\prime}}\right)^{2}}-\frac{c}{a} \sqrt{1-\left(\frac{x}{c}\right)^{2}}$ & $|x| \leq c$ \\
\hline
\end{tabular}

O tamanho da nova zona de adesão em escorregamento reverso pode ser calculado utilizando-se a condição de equilíbrio:

$$
\frac{c^{\prime}}{a}=\sqrt{1-\left|\frac{Q_{\max }-Q(t)}{2 f P}\right|}
$$

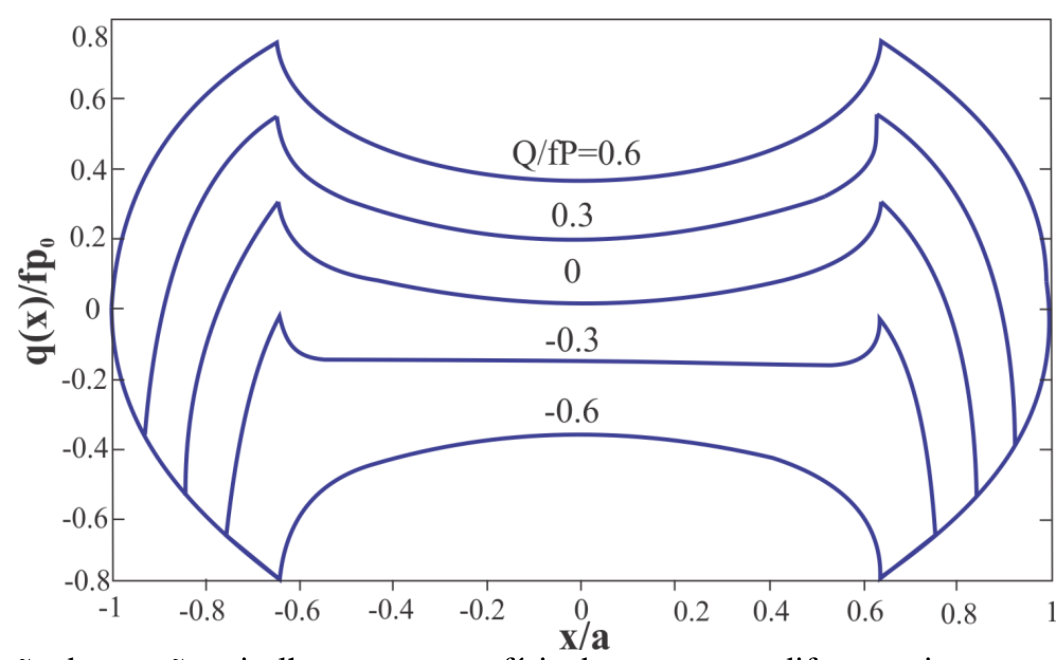

Figura 12- Variação das tensões cisalhantes na superfície do contato em diferentes instantes de tempo para um carregamento Q cíclico.

A Figura. 12 mostra a variação das tensões cisalhantes ao longo da superfície para diferentes valores de $Q$, correspondentes aos pontos A, C, D, E e F de um ciclo de fretting como mostrado na Fig. 11. Nota-se que para as cargas cisalhantes máximas, $Q_{\max }$ e $Q_{\min }$, as distribuições de tensões cisalhantes são iguais em módulo, mas com sinais opostos. Nota-se também, que após remoção total da carga $Q$, ponto $\mathrm{D}$, a tensão cisalhante não é nula, mas está em equilíbrio, o que significa que a distribuição de tensões cisalhantes ao longo do tempo não é linear. Portanto, tanto as tensões cisalhantes quanto as 
tensões e deformações dos corpos em contato dependem da história de carregamento. Desta forma, a aplicação do princípio da superposição tem que ser aplicado de forma cuidadosa em problemas de contato com atrito.

\subsubsection{CAMPO DE TENSÃO CÍCLICO NO INTERIOR DA REGIÃO DO CONTATO}

O campo de tensão sub-superficial resultante das cargas de contato pode ser obtido pela superposição dos campos de tensões provocados por $p(x)$ e $q(x)$ em escorregamento total e pelas perturbações $q^{\prime}(x)$ e $q^{\prime \prime}(x)$. É importante notar que quatro combinações de superposição serão necessárias para descrever o campo de tensão, sendo que estas devem ser feitas nos estados de carga máxima, mínima, descarregamento e recarregamento. As componentes de tensão são descritas pelas equações abaixo:

Nas cargas máxima e mínima:

$$
\frac{\sigma_{i j}}{p_{0}}(x, y)=\left(\frac{\sigma_{i j}^{n}\left(\frac{x}{a}, \frac{y}{a}\right)}{p_{0}}\right) \pm f\left(\frac{\sigma_{i j}^{t}\left(\frac{x}{a}, \frac{y}{a}\right)}{f p_{0}}\right) \mp f \frac{c}{a}\left(\frac{\sigma_{i j}^{t}\left(\frac{x}{c}, \frac{y}{c}\right)}{f p_{0}}\right)
$$

onde a combinação de sinais + - são para carga máxima. Já nos casos de descarregamento e recarregamento têm-se:

$$
\begin{aligned}
& \frac{\sigma_{i j}}{p_{0}}(x, y)=\left(\frac{\sigma_{i j}^{n}\left(\frac{x}{a}, \frac{y}{a}\right)}{p_{0}}\right) \mp f\left(\frac{\sigma_{i j}^{t}\left(\frac{x}{a}, \frac{y}{a}\right)}{f p_{0}}\right) \pm 2 f \frac{c^{\prime}}{a}\left(\frac{\sigma_{i j}^{t}\left(\frac{x}{c^{\prime}}, \frac{y}{c^{\prime}}\right)}{f p_{0}}\right) \\
& \mp f \frac{c}{a}\left(\frac{\sigma_{i j}^{t}\left(\frac{x}{c}, \frac{y}{c}\right)}{f p_{0}}\right)
\end{aligned}
$$

onde a combinação de sinais -+- são para descarregamento. Os sobrescritos $n$ e $t$ referem-se às componentes de tensão produzidas pelos carregamentos normais e tangencias, respectivamente.

Essas tensões podem ser obtidas na condição de estado plano de deformação usando-se os potenciais de Muskhelishvilli, apresentados no seção 2.3, Hills e Nowell (1994). 


\section{FADIGA UNIAXIAL E MULTIAXIAL}

\subsection{FADIGA UNIAXIAL}

\subsubsection{CURVAS S-N}

As leis ou equações que definem o comportamento de um material em condições de fadiga são geralmente relações empíricas obtidas em laboratório ensaiando-se corpos de prova do material que se deseja estudar. Nessas leis, relaciona-se a amplitude de tensão ou deformação com o número de ciclos até a falha.

Métodos para caracterização da vida em termos de tensão nominal surgiram a partir do trabalho de Wöhler (1860), que analisou o fenômeno de fadiga em eixos de máquinas ferroviárias. Esses métodos são baseados no diagrama de Wöhler (curva S-N). Essa curva relaciona a amplitude de tensão nominal aplicada em um corpo de prova com o número de ciclos até a falha resistida por este. Esses dados geralmente são obtidos em carregamentos de flexão, torção ou tração/compressão.

Basquin (1910) observou estes dados e verificou que eles poderiam ser interpolados por meio da Eq. (3.1), a chamada relação de Basquin, Fig. 13.

$$
\frac{\Delta \sigma_{a}}{2}=\sigma_{f}^{\prime}\left(2 N_{f}\right)^{\beta}
$$

onde $\Delta \sigma_{a} / 2$ é a amplitude de tensão, $N_{f}$ é o número de ciclos de vida, $\sigma_{f}^{\prime}$ é o coeficiente de resistência a fadiga e $\beta$ é o expoente de resistência a fadiga.

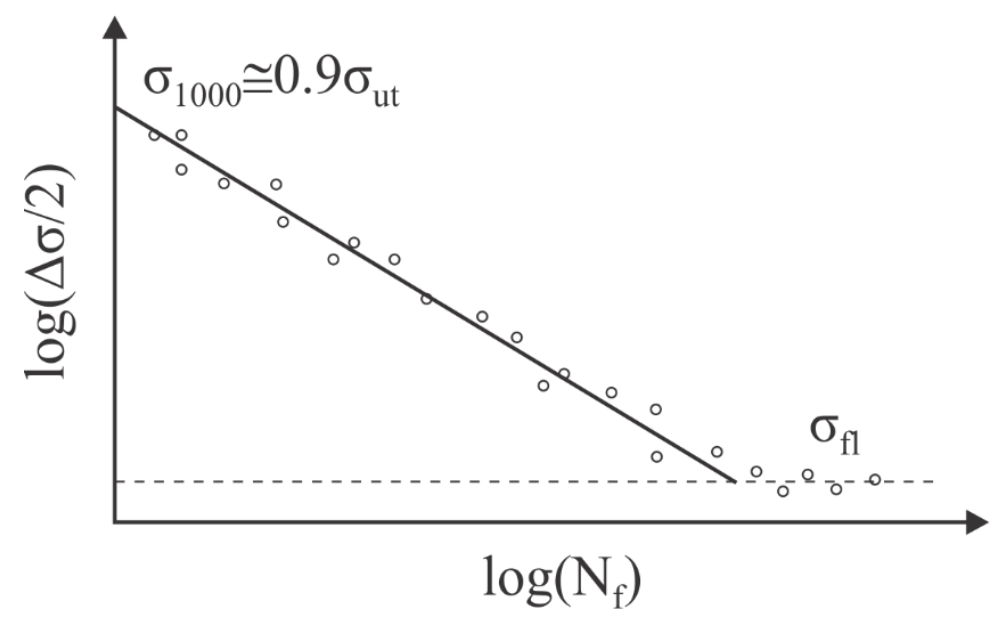

Figura 13- Construção esquemática da curva S-N

Alguns materiais, como ligas de aço, quando submetidos a amplitudes de tensão constante, apresentam um limite inferior de amplitude de tensão abaixo do qual não se observa mais a falha do componente mesmo com um número muito elevado de ciclos $\left(\mathrm{N}_{\mathrm{f}} \geq \mathrm{N}_{0}\right)$. Essa amplitude de tensão é conhecida como limite de resistência à fadiga, $\sigma_{f l}$, e seu valor geralmente varia entre $35 \%$ a 55\% do 
limite de resistência a tração, $\sigma_{u t}$, para a maioria dos aços e ligas de cobre. O primeiro ponto da curva, em geral para metais, corresponde ao limite de resistência à fadiga para uma vida de aproximadamente $10^{3}$ ciclos e corresponde a aproximadamente $0.9 \sigma_{u t}$.

Os metais não ferrosos, tais como o alumínio, o cobre e aços de alta resistência, não apresentam um limite de fadiga bem definido. Nesses casos, o limite de resistência à fadiga, $\sigma_{f l}$, continua a decrescer com o aumento do número de ciclos. Um limite de resistência a fadiga para esses casos é adotado como a amplitude de tensão em que o corpo de prova suporta um determinado número ciclos sem falhar, Fig. 14.

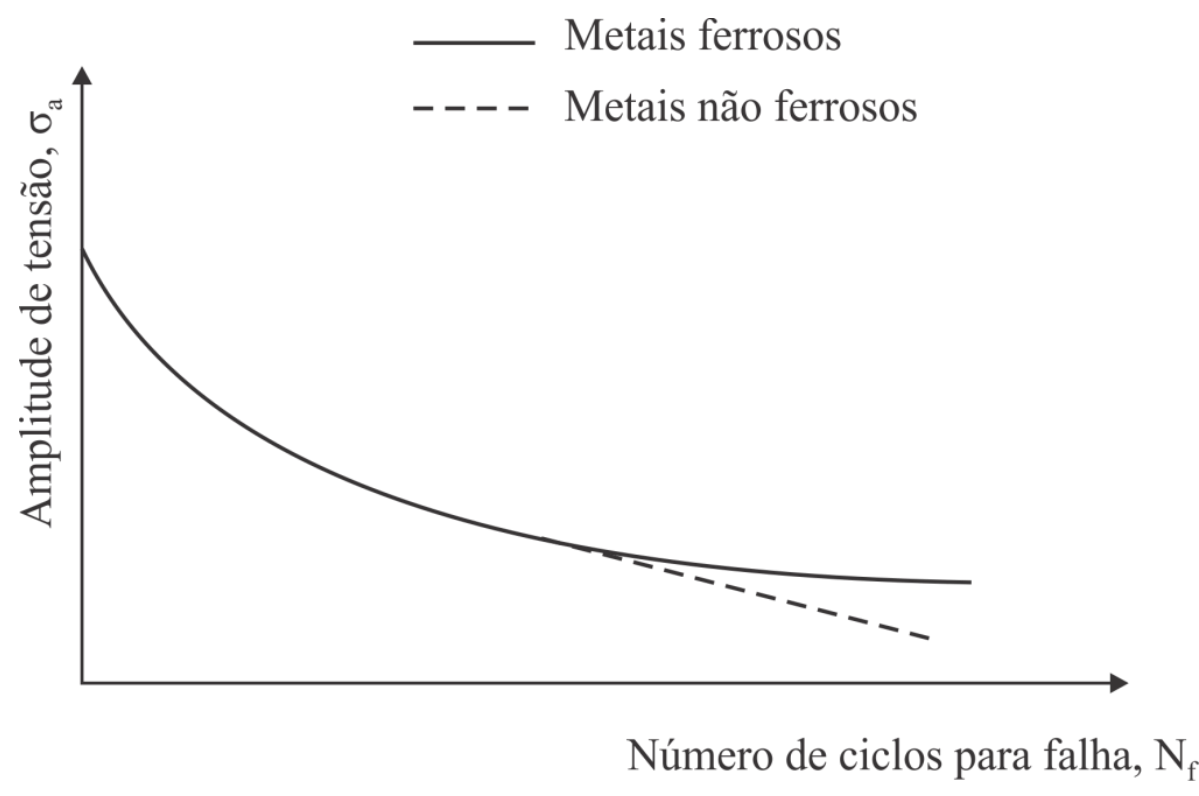

Figura 14- Curva SxN para metais ferrosos e não ferrosos

\subsubsection{EFEITO DA TENSÃO MÉDIA}

Embora a maioria dos ensaios disponíveis na literatura correspondam a ensaios conduzidos com tensão média igual à zero, existem muitas aplicações práticas onde isso não ocorre. O efeito da tensão média é de fundamental importância no comportamento à fadiga de materiais. A Figura 15 ilustra um ciclo de fadiga senoidal com uma tensão média diferente de zero. Nesse caso, a faixa de tensão, a amplitude de tensão e a tensão média são definidas como:

$$
\begin{gathered}
\Delta \sigma=\sigma_{\text {max }}-\sigma_{\text {min }} \\
\sigma_{a}=\frac{\sigma_{\max }-\sigma_{\min }}{2} \\
\sigma_{m}=\frac{\sigma_{\max }+\sigma_{\min }}{2}
\end{gathered}
$$

A tensão média também pode ser caracterizada pela razão de tensões, $\rho$ :

$$
\rho=\frac{\sigma_{\min }}{\sigma_{\max }}
$$




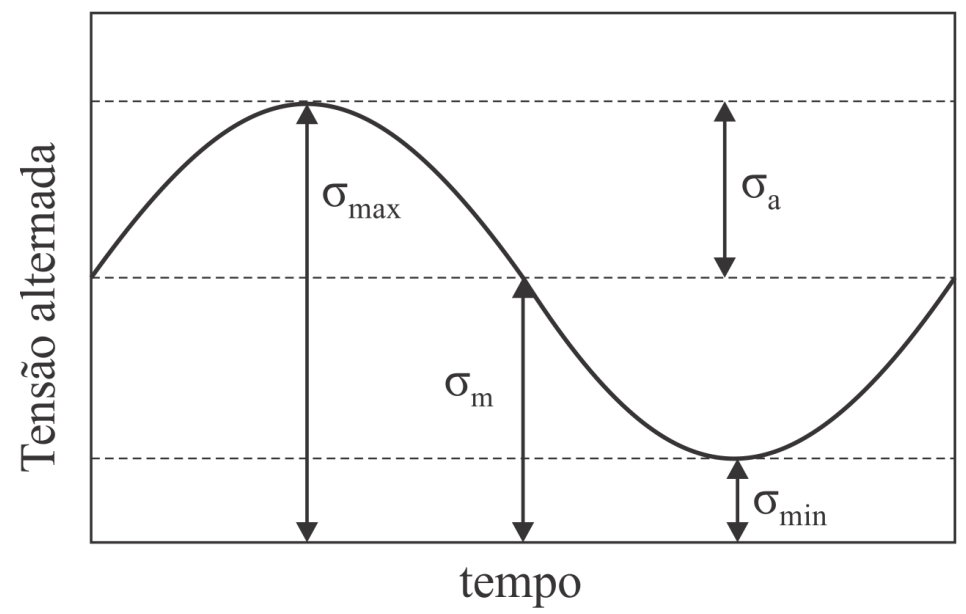

Figura 15- Carregamento cíclico

Quando gráficos de amplitude de tensão contra o número de ciclos em um teste de fadiga uniaxial são gerados, nota-se que a curva $\mathrm{SxN}$ resultante é fortemente influenciada pelo nível de tensão média trativa aplicada. A Figura 16 representa esquematicamente o comportamento típico de um material metálico para diferentes valores de tensão média aplicados com $\sigma_{\mathrm{m} 4}>\sigma_{\mathrm{m} 3}>\sigma_{\mathrm{m} 2}>\sigma_{\mathrm{m} 1}$. Pode-se observar graficamente uma redução da vida em fadiga do material com o aumento da tensão trativa média.

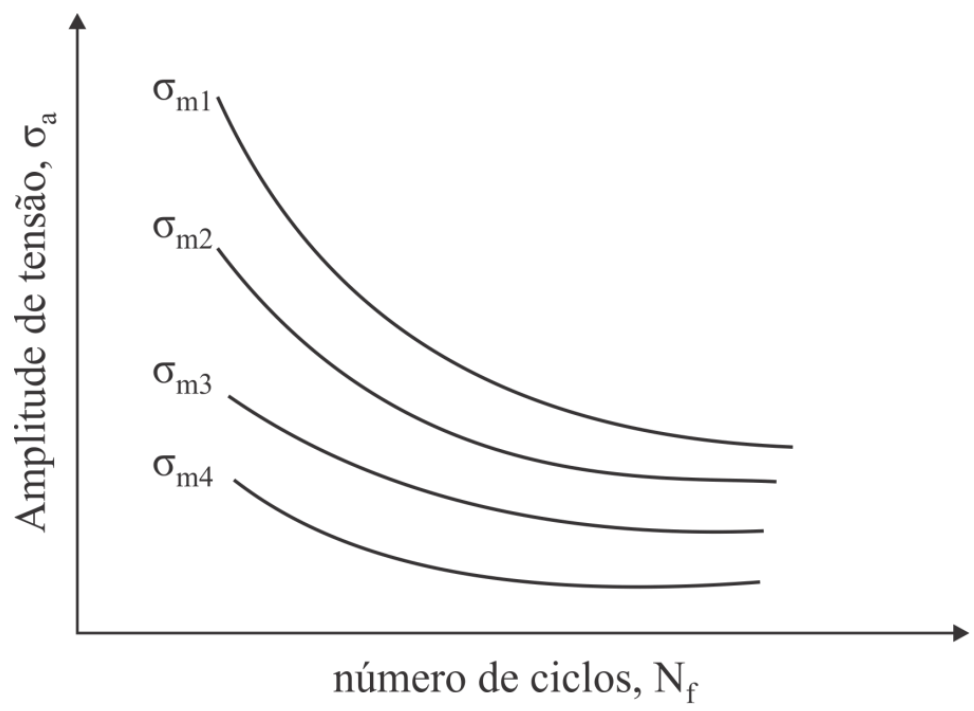

Figura 16- Efeito da tensão média

De forma geral, as tensões médias de compressão são benéficas e as de tração prejudiciais na vida em fadiga. Tal fenômeno pode ser explicado devido ao fato de as tensões de tração $\left(\sigma_{m}>0\right)$ favorecem a abertura e consequentemente a propagação de trincas, enquanto que as tensões médias compressivas provocam efeito contrário.

O efeito da tensão média em fadiga pode ser representado através de diagramas de vida constante, conforme ilustrado na Fig. 17. Nesses gráficos são mostrados diferentes combinações de amplitudes de tensão e tensão média conduzindo a vida em fadiga de forma constante. Alguns dos modelos mais 
difundidos para capturar esses efeitos foram propostos por Gerber (1874), Goodman (1899) e Sodeberg em 1939. As equações matemáticas que descrevem esses três métodos são:

$$
\begin{array}{ll}
\text { Goodman: } & \frac{\sigma_{a}}{\sigma_{-1}}+\frac{\sigma_{m}}{\sigma_{u t}}=1 \\
\text { Soderberg: } & \frac{\sigma_{a}}{\sigma_{-1}}+\frac{\sigma_{m}}{\sigma_{y}}=1 \\
\text { Gerber: } & \frac{\sigma_{a}}{\sigma_{-1}}+\left(\frac{\sigma_{m}}{\sigma_{u t}}\right)^{2}=1
\end{array}
$$

onde $\sigma_{-1}$ é o limite de resistência a fadiga para uma carregamento totalmente reversível $(\rho=-1)$.

Vale lembrar que não há uma unanimidade entre qual desses modelos é o melhor, mas sim que cada um deles funciona melhor para certos tipos de materiais.

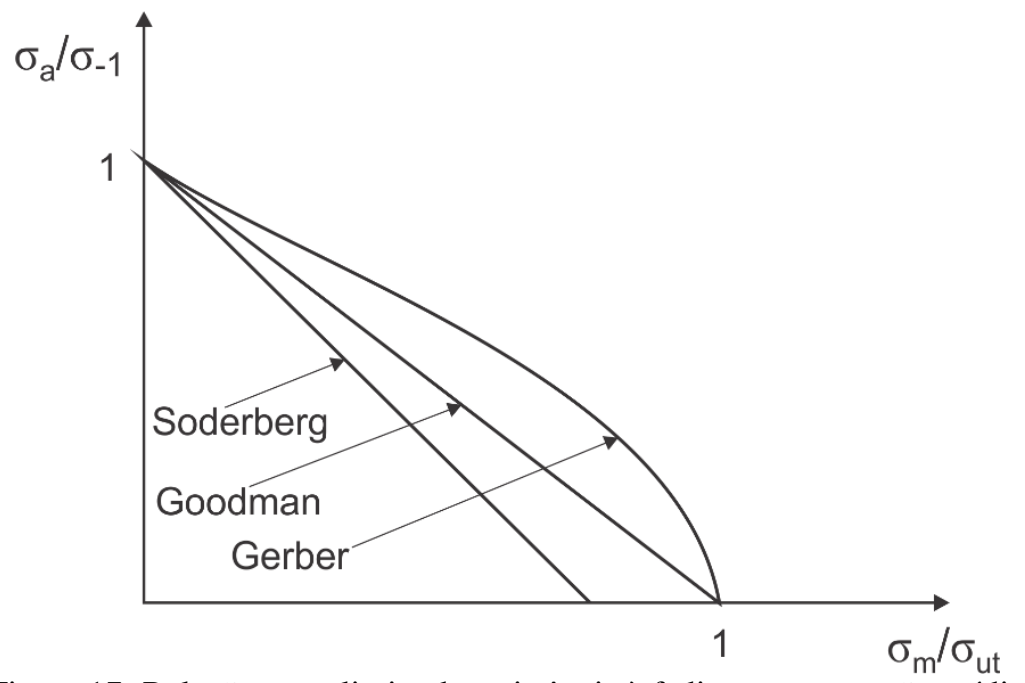

Figura 17- Relação entre limite de resistência à fadiga contra tensão média

\subsection{FADIGA MULTIAXIAL}

Na seção anterior conceituou-se a analisou-se a fadiga laboratorial e caracterizada por carregamentos uniaxiais. Contudo, em problemas práticos de fadiga é mais comum que componentes e mecanismos estejam sujeitos a estados multiaxiais de tensão. Isso é verificado em componentes aeronáuticos, problemas de contato, eixos de automobilísticos, cabos condutores de energia e etc. Uma história de tensões genéricas para um carregamento cíclico multiaxial pode ser representada da seguinte forma:

$$
\boldsymbol{T}(t)=\left[\begin{array}{ccc}
\sigma_{x x}(t) & \sigma_{x y}(t) & \sigma_{x z}(t) \\
& \sigma_{y y}(t) & \sigma_{y z}(t) \\
& & \sigma_{z z}(t)
\end{array}\right], \quad \sigma_{i j}(t)=\sigma_{i j, m}+\sigma_{i j, a} g\left(\alpha_{i j} t-\beta_{i j}\right)
$$

$\sigma_{i j, a}:$ amplitude de tensão

$\sigma_{i j, m}:$ componente de tensão média 
$\alpha_{i j}$ : frequência angular

$\beta_{i j}$ : ângulo de fase

$g(*)$ é um função periódica

As histórias de tensões podem ser classificadas como proporcionais ou não proporcionais. Uma história de carregamento é dita proporcional quando as componentes de tensão geradas por essas cargas mantém uma relação fixa de proporcionalidade ao longo de um ciclo de carregamento, isto é:

$$
\sigma_{k l}=\kappa \sigma_{i j}, \quad k l \neq i j
$$

onde $\kappa \in \mathbb{R}$ representa o coeficiente de proporcionalidade. Carregamentos não proporcionais não respeitam a condição expressa pela Eq. (3.10).

Os critérios de fadiga multiaxiais surgem diretamente da tentativa de se avaliar a resistência à fadiga de componentes sujeitos a estados complexos de tensão utilizando-se dados experimentais uniaxiais, haja vista que a realização de experimentos com cargas combinadas não é vantajoso para aplicações em engenharia. Assim, um dos grandes desafios a cerca desse tema é justamente incorporar o conhecimento e os resultados da fadiga uniaxial em problemas mais complexos.

Os primeiros critérios de fadiga multiaxial foram de natureza totalmente empírica e amparados pelos vastos trabalhos experimentais produzidos por Gough e Pollard (1935) e Nishihara e Kawamoto (1945). Sines (1955) analisou o efeito das tensões médias sobre a amplitude limite das tensões cíclicas e a partir daí propôs um critério baseado nos invariantes do tensor tensão. Nesta abordagem, uma amplitude de tensão equivalente é calculada e usada para prever a vida em fadiga a partir de curvas SxN convencionais. Crossland (1956) desenvolveu um modelo similar ao de Sines, mas que considerava o valor máximo da pressão hidrostática, e não o seu valor médio, como variável fundamental no processo de nucleação da trinca. Mais recentemente, Deperrois (1991), Bin Li et al. (2000) e Mamiya e Araújo (2002) também apresentaram critérios baseados nos invariantes do tensor tensão. Já as abordagens de plano crítico, muitas vezes utilizadas em problemas multiaxiais, consideram que as trincas de fadiga têm origem em determinados planos materiais, onde as combinações de tensões ou deformações cisalhantes e normais são suficientemente severas. Esses critérios são capazes de prever não apenas a resistência à fadiga do material e o local de iniciação da trinca, mas também sua orientação. Modelos de plano crítico foram propostos por Brawn e Miller (1973), McDiarmid (1974 e 1997), Matake (1977), Socie (1987), Fatemi e Socie (1988), e Susmel e Lazarin (2002).

\subsubsection{AMPLITUDE DE TENSÃO CISALHANTE EM CARREGAMENTOS MULTIAXIAS}

Ao contrário da tensão normal, a definição de uma amplitude de tensão cisalhante, $\tau_{a}$, e uma tensão cisalhante média, $\tau_{m}$, relativa a um plano genérico é muito mais complexa, principalmente pelo fato de 
o vetor tensão cisalhante $\boldsymbol{\tau}(t)$ mudar sua direção e magnitude ao longo de um ciclo de carregamento. Devido essa complexidade, diferentes abordagens foram propostas e validadas ao longo dos anos para lidar com esse problema, entretanto nenhuma delas é universalmente aceita. Apenas duas dessas abordagens serão consideradas nesse trabalho, o método do maior retângulo circunscrito (MRC) e o método do mínimo círculo circunscrito (MCC).

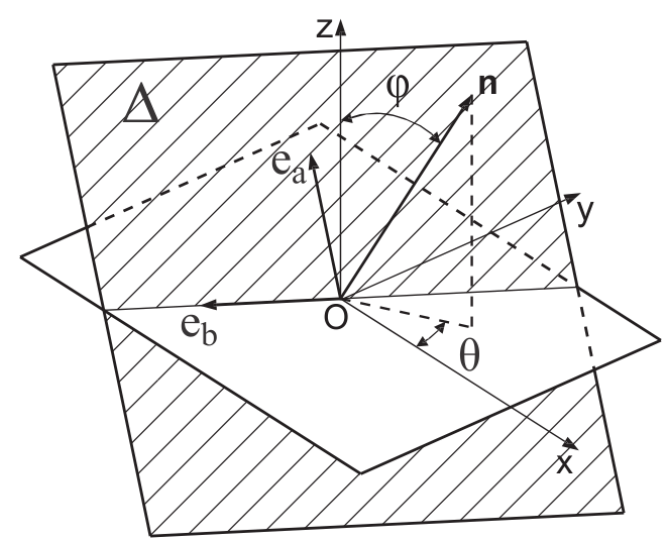

Figura 18- Plano material em coordenadas esféricas

Considere então um ponto material $O$, pertencendo a um corpo qualquer submetido a cargas externas. Esse ponto é também o centro de um sistema de coordenadas Oxyz. A orientação do plano material $\Delta$ possuindo um vetor normal unitário $\boldsymbol{n}$ pode ser descrito utilizando-se coordenadas esféricas $\phi$ e $\theta$, Fig. 18.

Dessa forma o vetor normal no sistema de coordenadas $O x y z$ pode ser escrito como:

$$
\boldsymbol{n}=\left[\begin{array}{c}
\sin (\phi) \cos (\theta) \\
\sin (\phi) \sin (\theta) \\
\cos (\phi)
\end{array}\right]
$$

Em problemas multiaxiais torna-se viável descrever o tensor das tensões em um sistema de coordenadas ortonormal, onde uma das bases é o vetor normal $\boldsymbol{n}$, e os outros dois estão contidos no plano $\Delta$. Dentre um infinito conjunto de opções para as duas bases ortonormais contidas no plano, escolhe-se o conjunto de vetores $\boldsymbol{e}_{\boldsymbol{a}}$ e $\boldsymbol{e}_{\boldsymbol{b}}$, nas direções a e b, Fig. 18, respectivamente, tal que:

$$
\begin{aligned}
& \boldsymbol{e}_{\boldsymbol{a}}=\left[\begin{array}{c}
-\sin (\theta) \\
\cos (\theta) \\
0
\end{array}\right] \\
& \boldsymbol{e}_{\boldsymbol{b}}=\left[\begin{array}{c}
-\cos (\phi) \cos (\theta) \\
-\cos (\phi) \sin (\theta) \\
\sin (\phi)
\end{array}\right]
\end{aligned}
$$

Durante um ciclo de carregamento, em carregamentos multiaxiais, a tensão cisalhante, $\boldsymbol{\tau}(t)$, varia sua direção e magnitude, sendo assim a ponta do vetor tensão cisalhante forma no plano $\Delta$ uma curva fechada, $\psi$, Fig. 19. 


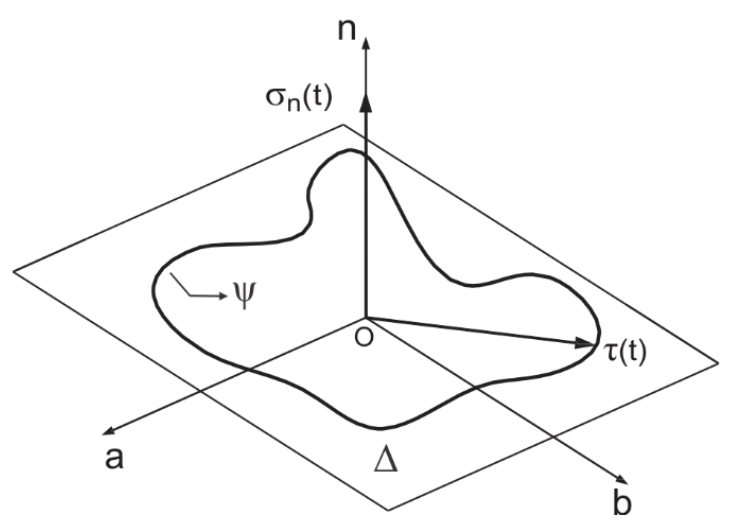

Figura 19- Histórico de tensão cisalhante

Para calcular a amplitude de tensão cisalhante em um histórico de carregamento como o mostrado na Fig. 19, podemos usar o MCC, Fig. 20, onde o objetivo é encontrar a menor circunferência que circunscreve a curva fechada $\psi$. O raio dessa circunferência é a amplitude de tensão cisalhante, $\tau_{a}$ e o centro dessa circunferência é a tensão cisalhante média, $\tau_{m}$. Uma forma eficaz de se encontrar essa circunferência é através do método da hiperesfera (Dang Van, 1989), ver anexo A.1.

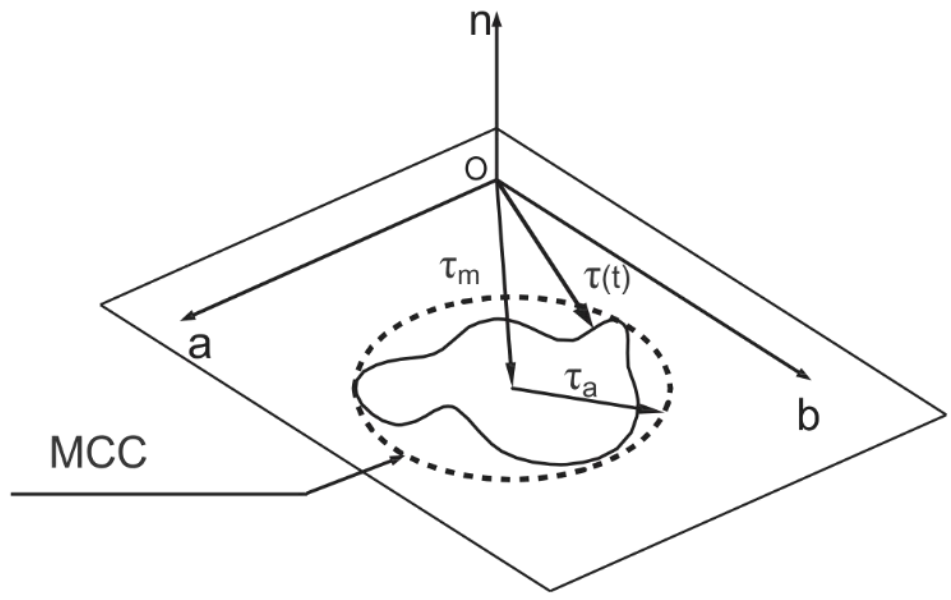

Figura 20- Método da mínima circunferência circunscrita

Recentemente, Mamiya et al. (2009), desenvolveram o MRC. Considere uma figura geométrica retangular com orientação arbitrária circunscrevendo a história de carregamento $\psi$ das tensões cisalhantes, Fig. 21.

O retângulo é tangente à história de tensões nos pontos:

$$
\begin{aligned}
& p_{i}(\omega)=\arg \left(\max _{t} \tau_{i}(\omega, t)\right), \quad i=1,2 \\
& q_{i}(\omega)=\arg \left(\min _{t} \tau_{i}(\omega, t)\right), \quad i=1,2
\end{aligned}
$$

pertencentes a curva $\psi$, onde $\tau_{i}(\omega, t)$ representa a i-ésima componente da tensão cisalhante $\boldsymbol{\tau}(t)$ projetada no plano de corte no instante $t$, descrita em termos de uma base com orientação $\omega$, Fig. 21. 


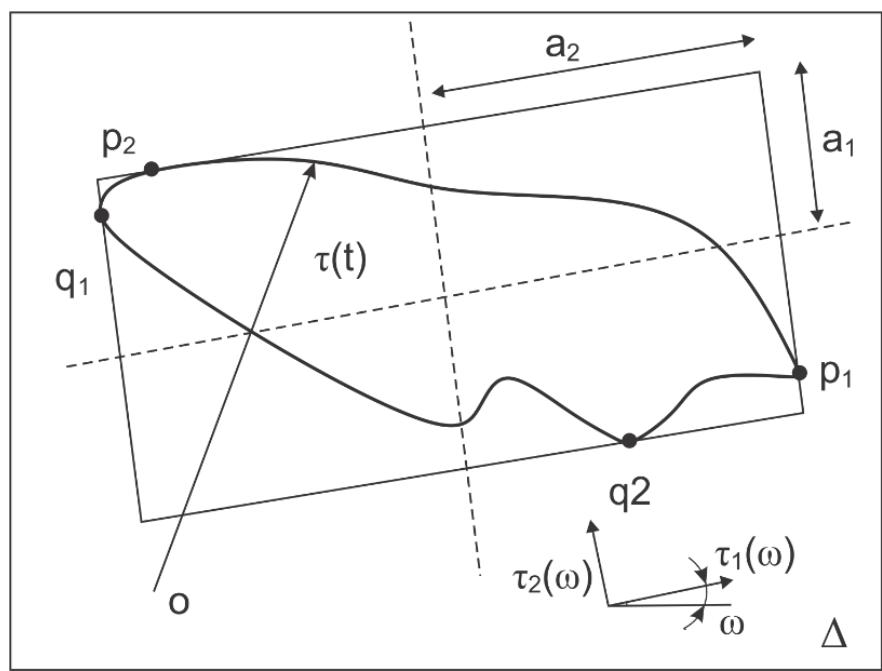

Figura 21- Método do maior retângulo circunscrito

Para cada orientação $\omega$ do retângulo, define-se a amplitude da i-ésima componente $a_{i}(\omega)$ da história de carregamento com sendo a metade do lago do retângulo:

$$
a_{i}(\omega)=\frac{1}{2}\left[\max _{t} \tau_{i}(\omega, t)-\min _{t} \tau_{i}(\omega, t)\right], \quad i=1,2
$$

e a amplitude de tensão cisalhante é então definida como:

$$
\tau_{a}=\max _{\omega} \sqrt{a_{1}(\omega)^{2}+a_{2}(\omega)^{2}}
$$

\subsubsection{MÉTODO DA CURVA DE WÖHLER MODIFICADA}

De acordo com a abordagem do plano crítico, em nível de tamanho de grão, o estado de tensão cíclico leva à formação de bandas de escorregamento persistente paralelas a um plano material denominado plano de escorregamento. Após certo número de ciclos, devido aos efeitos de concentração de tensão causados pela presença de intrusões, ocorre a iniciação de micro-trincas, causadas predominantemente por tensões cisalhantes. Considerando-se agora um agregado de grãos é possível assumir que, de um ponto de vista estatístico, o plano material de iniciação da trinca, denominado plano crítico, coincide com o plano de escorregamento. Com base nessa hipótese, e considerando-se que tensões macroscópicas são puramente elásticas, assume-se que o plano crítico é aquele que possui a maior amplitude te tensão cisalhante associada à história do vetor tensão cisalhante em um plano material.

Susmel e Lazzarin (2002) observaram ainda que no plano crítico, a tensão normal máxima, $\sigma_{n, \max }$, considera efeitos de tensão média na resistência a fadiga. Desta forma, Susmel e Lazzarin propõem em seu modelo que a falha ocorrerá quando a seguinte equação for violada:

$$
\tau_{a}\left(\phi^{*}, \theta^{*}\right)+m_{1} \frac{\sigma_{n, \max }}{\tau_{a}}\left(\phi^{*}, \theta^{*}\right) \leq \lambda
$$


onde, $\lambda$ e $m_{1}$ são parâmetros matérias que serão quantificados mais à frente. Já os parâmetros $\theta^{*}$ e $\phi^{*}$ são os ângulos em coordenadas esféricas que descrevem o plano crítico.

As grandezas $\tau_{a}(\phi, \theta)$ e $\sigma_{n, \max }(\phi, \theta)$ são calculados plano a plano. Desta forma, seja um plano material $\Delta$ qualquer descrito pelos ângulos $(\phi, \theta)$, Fig. 22.

O vetor tensão de Cauchy atuando no plano é definido por:

$$
\boldsymbol{t}(t, \phi, \theta)=\boldsymbol{T}(t) \boldsymbol{n}
$$

onde $\boldsymbol{T}$ é o tensor tensão de Cauchy em um instante de tempo $t$ e o vetor normal $\boldsymbol{n}$ em coordenadas retangulares é dado pela Eq. (3.11). As componentes de tensão normal e cisalhante atuando no plano $\Delta$ são dadas, respectivamente, por:

$$
\begin{aligned}
\sigma_{n} & =(\boldsymbol{T} \boldsymbol{n}) \cdot \boldsymbol{n} \\
\boldsymbol{\tau} & =\boldsymbol{T} \boldsymbol{n}-\sigma_{n} \boldsymbol{n}
\end{aligned}
$$
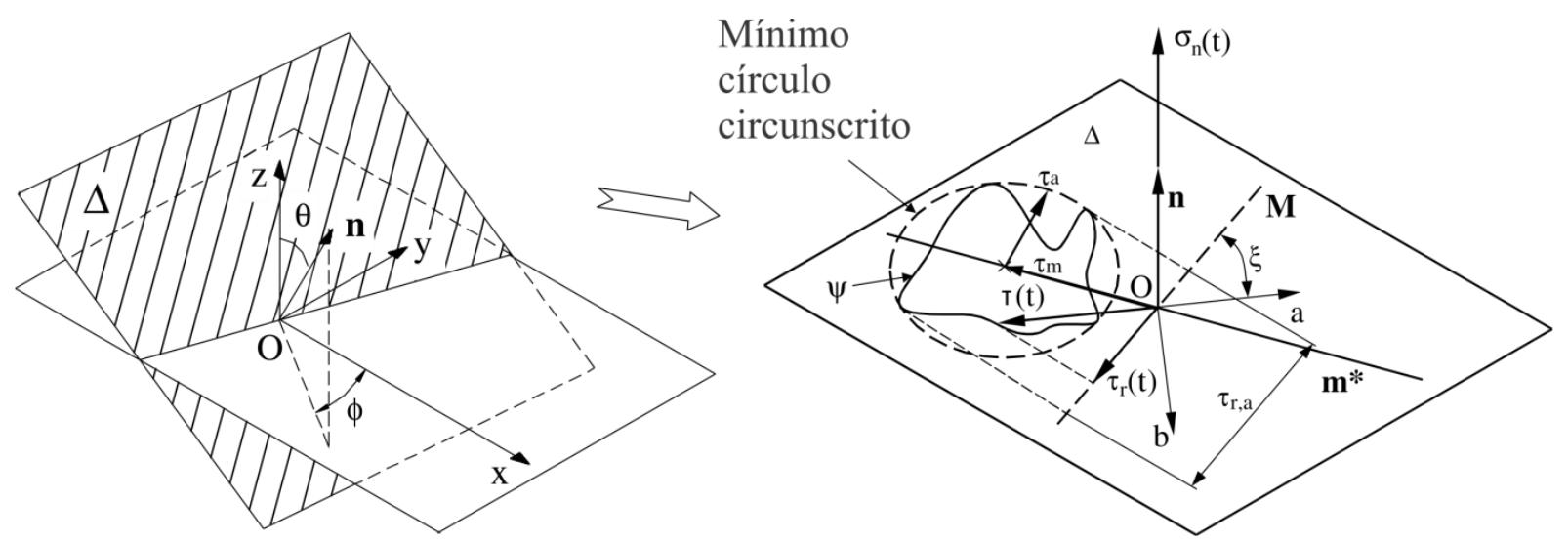

Figura 22- Distribuição das tensões no plano material $\Delta$, Susmel et al. (2004)

O vetor tensão cisalhante, $\boldsymbol{\tau}$, pode ser decomposto na base ortonormal contida no plano $\Delta$ dada pelas Eq. (3.12) e (3.13) de forma a capturamos a trajetória da tensão cisalhante ao longo do tempo, Fig. 22. O parâmetro $\tau_{a}(\phi, \theta)$ na Eq. (4.9) pode ser calculado de diversas maneiras, a representada na Fig. 22 é o método do mínimo círculo circunscrito (Dang Van, 1989).

O critério proposto por Susmel e Lazzarin (2002) considera que o plano mais solicitado é aquele em que $\tau_{a}$ atinge seu valor máximo. Logo:

$$
\tau_{a}\left(\phi^{*}, \theta^{*}\right)=\max _{\phi, \theta}\left(\tau_{a}(\phi, \theta)\right)
$$

Dentre os planos críticos, determina-se o que atinge maior tensão normal máxima ao longo de um ciclo de carregamento, fornecendo então a grandeza $\sigma_{n, \max }$.

Para avaliar os parâmetros $m_{1}$ e $\lambda$ considerara-se os resultados obtidos para dois ensaios distintos de fadiga. No caso de um ensaio de fadiga para flexão alternada com limite de resistência a fadiga dado por $\sigma_{-1}$ e outro para flexão repetida dado por $\sigma_{0}$ temos no plano crítico, Tab. 2: 
Tabela 2- Amplitudes de tensão cisalhante e de tensões normais máximas para ensaios de fadiga com diferentes razões de carregamento $\rho$.

\begin{tabular}{ccc}
\hline $\begin{array}{c}\text { Limite de resistência à } \\
\text { fadiga }\end{array}$ & $\tau_{a}\left(\phi^{*}, \theta^{*}\right)$ & $\sigma_{n, \max }\left(\phi^{*}, \theta^{*}\right)$ \\
\hline$\sigma_{-1}(\rho=-1)$ & $\sigma_{-1} / 2$ & $\sigma_{-1} / 2$ \\
$\sigma_{0}(\rho=0)$ & $\sigma_{0} / 2$ & $\sigma_{0}$ \\
\hline
\end{tabular}

Substituindo os valores presentes na Tab. 2 na Eq. (3.18) formamos um sistema com duas equações e duas incógnitas de onde podem ser extraídas as propriedades matérias $m_{1}$ e $\lambda$ :

$$
\begin{aligned}
& m_{1}=\frac{\sigma_{1}-\sigma_{0}}{2} \\
& \lambda=\frac{2 \sigma_{1}-\sigma_{0}}{2}
\end{aligned}
$$

Para avaliar os modelos, foi convencionado um índice de resistência em fadiga que mede o quanto a situação de carregamento imposta nos testes está distante da condição de falhar (limite de fadiga) que é calibrado através dos parâmetros $m_{1}$ e $\lambda$. Assim, para se avaliar a qualidade dos resultados estimados pelo critério de Susmel e Lazzarin define-se o índice $S U$ :

$$
S U=\frac{\tau_{a}\left(\phi^{*}, \theta^{*}\right)+m_{1} \frac{\sigma_{n, \max }}{\tau_{a}}\left(\phi^{*}, \theta^{*}\right)-\lambda}{\lambda}
$$

onde $S U<0$ implica em vida segura e $S U>0$ implica em falha do componente, segundo o critério adotado. 


\section{MECÂNICA DA FRATURA}

\subsection{CONCEITOS FUNDAMENTAIS}

Fratura devido a cargas cíclicas é conhecida como fadiga e esta é reconhecidamente a maior causa de falha de componentes mecânicos. O fenômeno de fratura por fadiga é convenientemente dividido em três etapas: (i) Iniciação de trincas; (ii) propagação da trincas, onde se avalia a trinca até um tamanho crítico suportado pelo componente; e (iii) a ruptura catastrófica do componente. A mecânica da fratura é a ciência que estuda as duas últimas etapas desse fenômeno.

\subsubsection{TENSÕES NAS VIZINHANÇAS DA TRINCA}

Uma trinca em um sólido pode se propagar em diferentes modos, como ilustrado na Fig. 23. Os modos I, II e III são denominados de "modo de abertura", "modo de cisalhamento" e "modo de rasgamento", respectivamente.

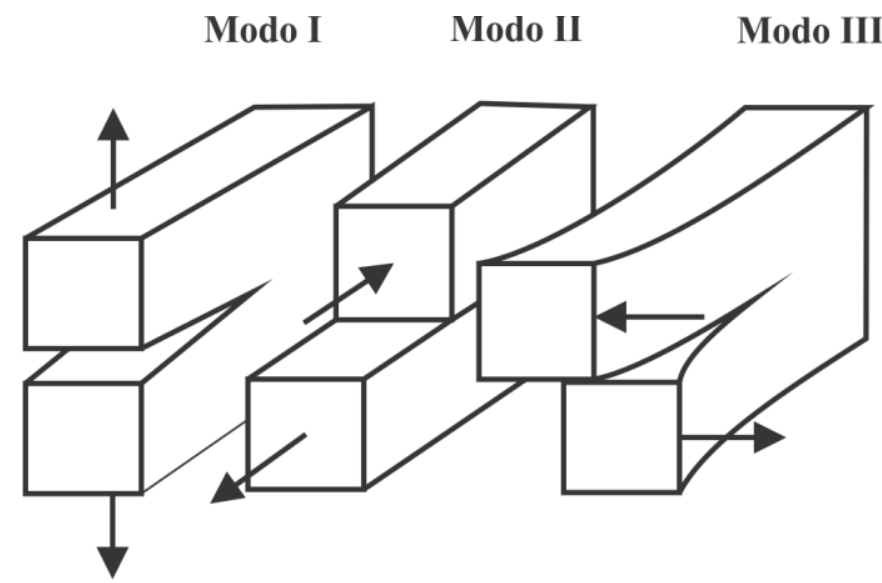

Figura 23- Modos de propagação de trincas

Considere uma trinca de comprimento $2 b$ em um plano infinito sujeita a uma tensão $\sigma$ de abertura da trinca. Um elemento de área $d x d y$, a uma distância $r$ da ponta da trinca e a um ângulo $\theta$ em relação à trinca, Fig. 24, experimenta tensões normais $\sigma_{x x}$ e $\sigma_{y y}$ e uma tensão cisalhante $\sigma_{x y}$. Fazendo-se uso da teoria da elasticidade pode se mostrar que estas tensões são dadas por:

$$
\begin{aligned}
& \sigma_{x x}=\frac{\sigma \sqrt{\pi b}}{\sqrt{2 \pi r}} \cos \left(\frac{\theta}{2}\right)\left(1-\sin \left(\frac{\theta}{2}\right) \sin \left(\frac{3 \theta}{2}\right)\right)+\ldots \\
& \sigma_{y y}=\frac{\sigma \sqrt{\pi b}}{\sqrt{2 \pi r}} \cos \left(\frac{\theta}{2}\right)\left(1+\sin \left(\frac{\theta}{2}\right) \sin \left(\frac{3 \theta}{2}\right)\right)+\ldots \\
& \sigma_{x y}=\frac{\sigma \sqrt{\pi b}}{\sqrt{2 \pi r}} \sin \left(\frac{\theta}{2}\right) \cos \left(\frac{\theta}{2}\right) \cos \left(\frac{3 \theta}{2}\right)+\ldots
\end{aligned}
$$




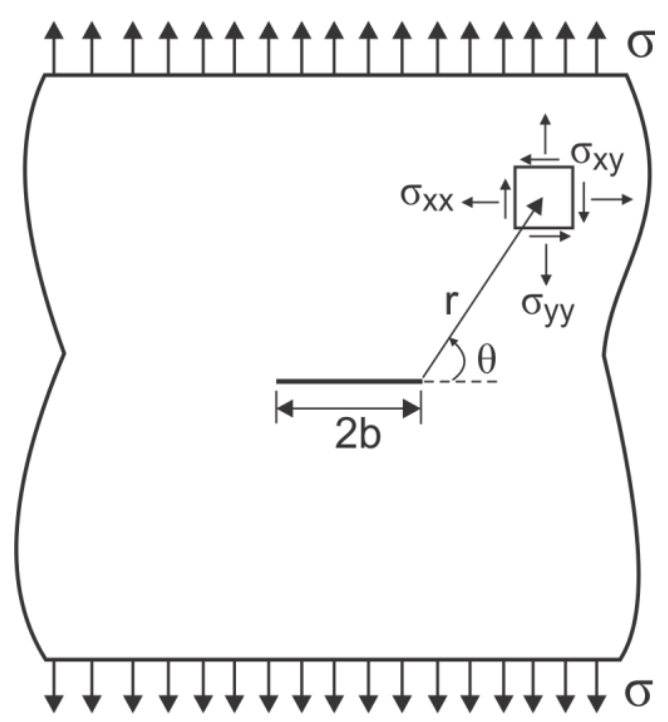

Figura 24- Trinca em um plano infinito sujeito a tensão normal

As Equações (4.1) são os primeiros termos de uma expansão de séries, somente aplicáveis para $r \ll$ $b$. Estas também evidenciam uma singularidade em $r=0$. Na ponta da trinca, $r \rightarrow 0$, as tensões $\sigma_{i j} \rightarrow$ $\infty$. Em outros termos, a tensão nas proximidades da raiz da trinca é produto da posição geométrica $(1 / \sqrt{2 \pi r}) f(\theta)$ e de um fator $\sigma \sqrt{\pi b}$ que é chamado de fator intensidade de tensão, $K$. O fator intensidade de tensão é um indicador da magnitude das tensões nas proximidades da ponta da trinca. Vale ressaltar que o fator de intensidade $K$ foi obtido considerando (i) apenas o primeiro termo de uma série (para os termos subsequentes, a tensão é proporcional a potências de $r$ ) e (ii) para uma análise linear elástica. Portanto, a aplicabilidade de $K$ está restrita a regiões próximas da ponta da trinca onde $r \ll b$ e a condições de escoamento de pequena escala, ou seja, a região plastificada na ponta da trinca deve ser muito menor que a região de dominância de $K$, Fig . 25 .

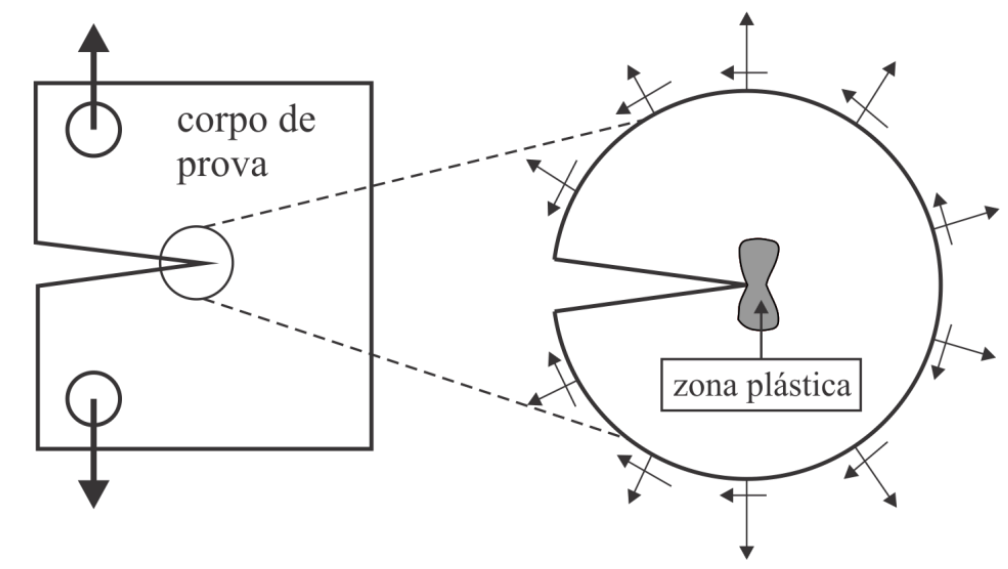

Figura 25- Zona plástica e de dominância de K na ponta da trinca

\subsubsection{INTEGRAL $J$}

A integral J (Rice, 1968) é amplamente utilizada como um parâmetro de mecânica da fratura. A integral J está relacionada com a taxa de liberação de energia associada ao crescimento de trincas e é 
uma medida da intensidade das deformações na ponta da trinca. Se a resposta do material for linear, ela pode ser relacionada com os fatores de intensidade de tensão.

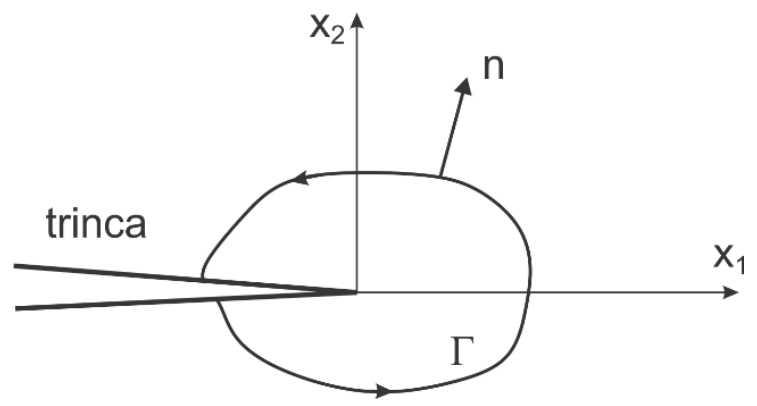

Figura 26- Integral J na proximidades da ponta da trinca

Considere agora um corpo homogêneo constituído de um material elástico, linear ou não, livre de forças de campo e sujeito a um campo de deformação bidimensional, ou seja, o campo de tensão é função apenas das coordenadas $x_{1}$ e $x_{2}$, Fig. 26. Considere também a existência de um concentrador de tensão (nesse caso uma trinca).

A integral $\mathrm{J}$ no caso 2D é definida como:

$$
\int_{\Gamma}\left(W d x_{2}-t_{i} \frac{\partial u_{i}}{\partial x_{1}} d \Gamma\right)
$$

onde $\mathrm{W}$ é a densidade de energia de deformação:

$$
W=\int_{0}^{\varepsilon_{i j}} \sigma_{i j} d \varepsilon_{i j}
$$

onde $\sigma_{i j}$ são as componentes do tensor das tensões e $t_{i}=\sigma_{i j} n_{j}$ ao longo do contorno, onde $\boldsymbol{n}$ é o vetor normal ao contorno, Fig. 28.

Para o caso de uma comportamento linear do material, a integral J e os fatores intensidades de tensão se relacionam da seguinte forma:

$$
J=\frac{1}{\bar{E}}\left(K_{I}^{2}+K_{I I}^{2}\right)
$$

onde $\bar{E}=E$ em estado plano de tensão e $\bar{E}=E /\left(1-v^{2}\right)$ para estado plano de deformação.

\subsubsection{PROPAGAÇÃO DE TRINCAS EM CARREGAMENTOS CÍCLICOS}

O fator de intensidade de tensão é uma medida dos campos de tensão e de deformação elástica nas proximidades da ponta da trinca, portanto é esperado que este controle a taxa de propagação da trinca dentro de uma escala de pequenas deformações plásticas. Paris et al. (1961) sugeriram que para uma 
variação cíclica do campo de tensão a taxa de propagação de trincas está relacionada com a faixa do fator de intensidade de tensão, $\Delta K$.

$$
\frac{d b}{d N}=f(\Delta K)
$$

onde $d b / d N$ é a taxa de crescimento da trinca, $N$ é o número de ciclos de fadiga. A Figura 27 mostra um diagrama esquemático que revela a taxa de propagação da trinca contra a faixa do fator de intensidade de tensão $\Delta K$ em escala logarítmica. Para valores de $\Delta K$ inferiores a $\Delta K_{t h}$ a taxa de propagação da trinca é muito pequena, sendo esse denominado de limiar do fator de intensidade de tensão. No estágio 1, há uma forte variação na taxa de propagação da trinca com a variação de $\Delta K$. Já o estágio 2, parte aproximadamente linear do gráfico, pode ser descrito por:

$$
\frac{d b}{d N}=B(\Delta K)^{\zeta}
$$

em que $B$ e $\zeta$ são constantes que dependem de propriedades materiais como, temperatura e condições de carregamento. No estágio 3, a taxa de propagação da trinca já elevada apresenta uma zona plástica na ponta da trinca que começa a predominar nessa região levando o componente a falha com o incremento de $\Delta K$.

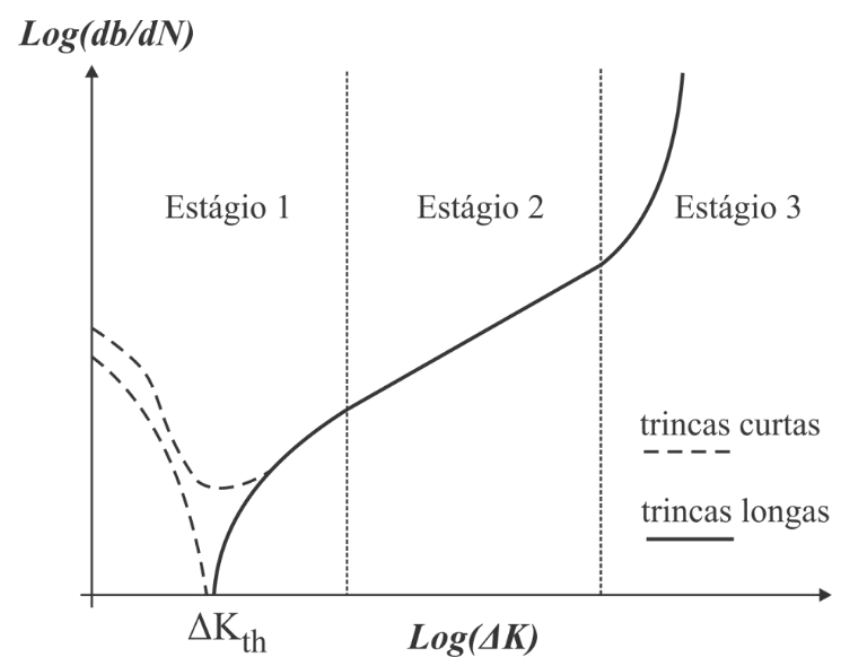

Figura 27- Taxa de crescimento da trinca em função de $\Delta K$

\subsubsection{PROPAGAÇÃO DE TRINCAS CURTAS}

A caracterização do problema de crescimento de trincas em componentes sujeitos a cargas de fadiga em termos da Mecânica da fratura Linear Elástica apoia-se em dados experimentais de fadiga obtidos de corpos de prova contendo trincas relativamente longas. Entretanto, em projetos de engenharia frequentemente se lida com trincas de dimensões bastante reduzidas.

A taxa e crescimento de trincas mais curtas podem ser significativamente maiores que a taxa de crescimento para trincas longas submetidas ao mesmo estado de carregamento. Observa-se também que 
trincas curtas crescem a taxas consideráveis quando o $\Delta K$ nominal é menor que limiar do fator intensidade de tensão $\Delta K_{t h}$ para trincas longas.

A primeira observação relatada de crescimento acelerado de trincas curtas de fadiga é atribuída a Pearson (1975), que examinou os efeitos do tamanho da trinca nas taxas de propagação para uma liga de alumínio endurecida. Ele notou que trincas curtas superficiais ( 0.006 até $0.5 \mathrm{~mm}$ ) cresciam 100 vezes mais rápido que trincas longas, quando submetidas ao mesmo $\Delta K$ nominal. Esta investigação também mostrou indícios da possibilidade do crescimento de trincas curtas submetidas a faixas de tensão nominal abaixo do limiar para trincas longas. Estudos posteriores (Lankford, 1882 e 1986, Miller et al. 1986, e Kitagawa e Tanaka, 1990) consideraram diferentes materiais mostrando várias acelerações e desacelerações transitórias associadas com o crescimento subcrítico de trincas curtas de fadiga. Smith et al. (1996) estudou o comportamento de trincas curtas em uma superliga de níquel. Acelerações e retardos na taxa de crescimento são observados com o crescimento do seu comprimento até que essa se torne uma trinca longa, cujo comportamento é descrito pela Mecânica da Fratura Linear Elástica tradicional.

\subsection{METODOLOGIA PARA O CALCULO DO FATOR DE INTENSIDADE DE TENSÃO EM PROBLEMAS DE FRETTING}

O problema de fretting possui uma grande complexidade em seu campo de tensão, sendo assim não existem soluções fechadas para o cálculo do fator de intensidade de tensão neste tipo de problema. Uma metodologia eficaz para determinação do fator de intensidade de tensão nesse caso é o método dos elementos finitos, porém em alguns casos o elevado custo computacional torna essa prática inviável. Uma técnica numérica para a obtenção de $K$ é o método da distribuição das discordâncias, que é descrito detalhadamente por Hills e Nowell (1994). Uma breve descrição do método será apresentada neste trabalho.

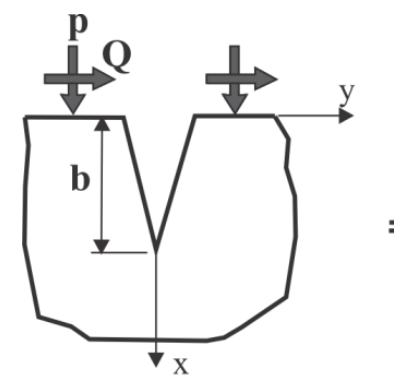

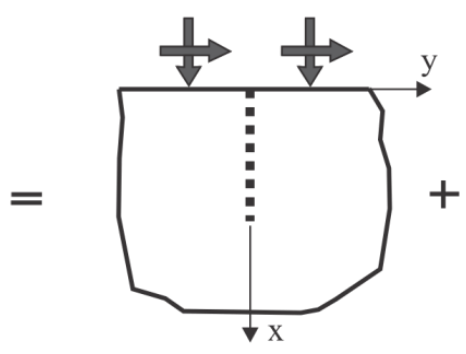

(a)

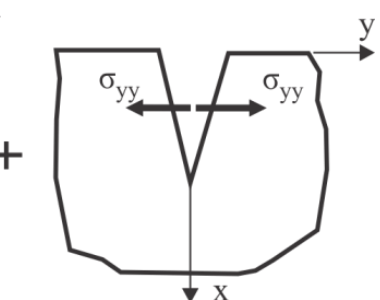

(b)

Figura 28-Princípio de Bueckner: (a) Corpo sem a trinca sujeito a cargas de contato; (b) corpo trincado na ausência de cargas externas, mas com as tensões ao longo da trinca iguais e postas as tensões do problema (a).

A técnica se baseia no princípio de Bueckner (1958), que é basicamente um princípio de superposição. Suponha um corpo com uma trinca sujeito a cargas de contato como mostrado na Fig. 28. Um problema equivalente ao original pode ser obtido com a superposição de (a) e (b), onde (a) 
representa o corpo sem a trinca submetido às cargas de contato e (b) representa um corpo trincado na ausência de cargas externas, mas com as tensões na linha da trinca iguais em intensidade, mas opostas em relação às tensões na linha da trinca devido às cargas de contato, de forma que ao se somar os dois problemas, as faces da trinca estejam livre de tensões.

As equações (2.23) e (2.24) fornecem as componentes de tensão normais à trinca, $\sigma_{N}$, ao longo da linha da trinca para o caso (a). Como as tensões nas faces da trinca no problema original devem ser nulas, distribui-se discordâncias de descontinuidades ('dislocations') ao longo da linha da trinca para produzirmos (b), assim as tensões induzidas cancelam as tensões do problema de contato, (a) + (b). Esse procedimento resulta em uma equação integral em relação à desconhecida densidade de deslocamentos longo da linha da trinca.

O primeiro passo é determinar o estado de tensão, $\sigma_{y y}$, induzido em um ponto $(x, 0)$ por um único deslocamento de largura $b_{y}$ (vetor de Burguer) colocado em um ponto $(e, 0)$ na geometria a ser modelada, nesse caso um semi-plano. A solução desse problema foi obtida por Dundurs e Sendeckyj (1965):

$$
\sigma_{y y}=\frac{2 \mu b_{y}}{\pi(k+1)} G(x, e)
$$

onde $\mu$ é o módulo de rigidez do material, $k$ é a constante de Kolosov ( $k=3-4 v$ ) em estado plano de deformação, $v$ é razão de Poisson, e o núcleo $G(x, e)$ é dado por:

$$
G(x, e)=\frac{1}{x-e}-\frac{1}{x+e}-\frac{2 e}{(x+e)^{2}}+\frac{4 e^{2}}{(x+e)^{3}}
$$

Uma distribuição contínua de deslocamento com densidade $B_{y}(e)$ é agora considerada ao longo da trinca, atendendo a condição de que as faces da trinca devem estar livres de tensão em todo seu domínio, assim temos:

$$
\sigma_{N}+\frac{2 \mu}{\pi(k+1)} \int_{0}^{b} B_{y}(e) G(x, e) d e=0
$$

onde

$$
B_{y}(e)=\frac{\partial b_{y}}{\partial e}
$$

$b$ é o comprimento da trinca e $\sigma_{N}$ são as tensões normais a trinca devido a um carregamento externo. Essa equação integral em relação à função desconhecida $B_{y}(e)$ contem um núcleo de Cauchy. Uma discretização utilizando a quadratura de Gauss-Jacobi produz um sistema algébrico linear com $n$ equações e $n$ incógnitas, Eq. (4.11), que pode ser resolvido com métodos numéricos padrões. O fator de intensidade de tensão pode então ser calculado diretamente através da densidade de discordâncias. 


$$
\begin{aligned}
& \frac{\mu}{\pi(k+1)} \sum_{i=1}^{n} \frac{2 \pi\left(1+r_{j}\right)}{2 n+1} G\left(s_{i}, r_{j}\right) \phi\left(r_{j}\right)=-\sigma_{N}\left(s_{i}\right) \\
& r_{j}=\cos \left(\frac{2 j-1}{2 n+1} \pi\right), \quad j=1,2, \ldots, n \\
& s_{i}=\cos \left(\frac{2 j}{2 n+1} \pi\right), \quad i=1,2, \ldots, n
\end{aligned}
$$

onde $s_{i}$ e $r_{j}$ são as componentes $x$ e $e$ respectivamente normalizadas e discretizadas e $\phi$ é uma função desconhecida. A relação matemática para encontrar o fator intensidade de tensão é dada por:

$$
K_{I}=2 \sqrt{2} \sqrt{\pi b} \frac{\mu}{k+1} \phi(1)
$$

Os valores de $\phi$ obtidos pela Eq. (4.11), são revelados apenas para os pontos de integração, $r_{j}$, e para sua definição em outros pontos precisamos examinar a definição do polinômio de interpolação fundamental de Jacobi. Através disso, pode-se então deduzir a fórmula para avaliar $\phi$ ao longo de todo o domínio. Isso foi feito por Krenk (1975):

$$
\phi(1)=\frac{2}{2 n+1} \sum_{j=1}^{n} \cot \left(\frac{2 j-1}{2 n+1} \frac{\pi}{2}\right) \sin \left(\frac{n}{2 n+1}(2 j-1) \pi\right) \phi\left(r_{j}\right)
$$

No entanto, normalmente uma trinca se inicia em modo II e assim essa se propaga como mostrado na Fig. 29. Trincas inclinadas produzem uma série de complicações adicionais na modelagem do problema. A primeira delas é que ambos os deslocamentos $b_{\hat{x}}$ e $b_{\hat{y}}$ induzem tanto tensões cisalhantes quanto tensões normais ao longo da linha da trinca $(\hat{y}=0)$, ou seja, há uma ligação entre cargas modo I e II.
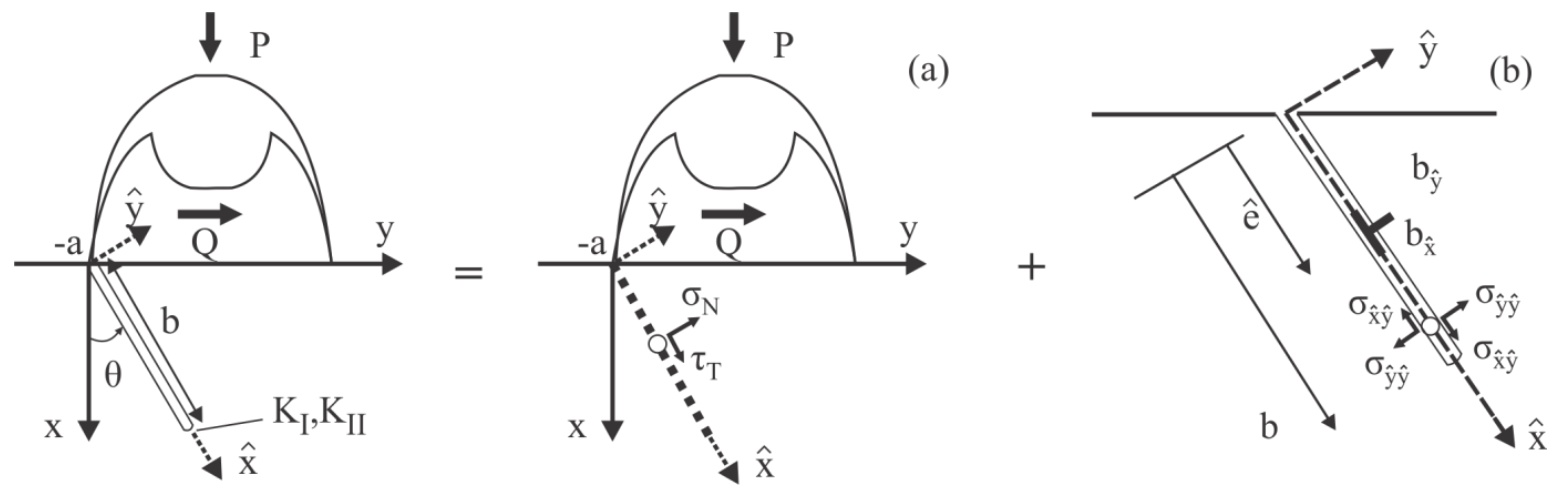

Figura 29- Princípio de Bueckner: (a) Corpo sem a trinca sujeito a cargas externas, (b) corpo trincado na ausência de cargas externas, mas com tensões ao longo da linha da trinca iguais em módulo, mas opostas as do problema (a)

O ponto de partida para o cálculo dos fatores intensidades de tensão é encontrar o estado de tensão induzido pelos deslocamentos, Dundurs e Mura (1964). Para um deslocamento contendo componentes $\left(b_{x}, b_{y}\right)$ localizado em $(e, 0)$ em coordenadas globais, o estado de tensão induzido é dado por: 


$$
\left[\begin{array}{l}
\sigma_{x x} \\
\sigma_{y y} \\
\sigma_{x y}
\end{array}\right]=\frac{\mu}{\pi(k+1)}\left\{\left[\begin{array}{l}
G_{x x x}(x, y, e) \\
G_{x y y}(x, y, e) \\
G_{x x y}(x, y, e)
\end{array}\right] b_{x}+\left[\begin{array}{l}
G_{y x x}(x, y, e) \\
G_{y y y}(x, y, e) \\
G_{y x y}(x, y, e)
\end{array}\right] b_{y}\right\}
$$

onde as funções definidas como, $G_{i j k}$ são dadas explicitamente em Hills e Nowell (1994), ver anexo A.2. Essas equações relacionadas aos vetores de Burguer estão em coordenadas globais $(x, y)$, no entanto com o objetivo de escrever uma equação expressando a imposição de que as tensões ao longo das faces das trinca devem ser nulas, se faz conveniente transformar o estado de tensão para coordenadas locais $(\hat{x}, \hat{y})$, Fig. 29 (a). Também é conveniente expressar os vetores de Burguer em coordenadas locais, Fig. 29 (b). Então:

$$
\begin{aligned}
& \sigma_{\hat{x} \hat{y}}=\frac{1}{2}\left(\sigma_{x x}-\sigma_{y y}\right) \sin (2 \theta)+\sigma_{x y} \cos (2 \theta) \\
& \sigma_{\hat{y} \hat{y}}=\frac{1}{2}\left(\sigma_{x x}+\sigma_{y y}\right)-\frac{1}{2}\left(\sigma_{x x}-\sigma_{y y}\right) \cos (2 \theta)+\sigma_{x y} \sin (2 \theta) \\
& {\left[\begin{array}{l}
b_{x} \\
b_{y}
\end{array}\right]=\left[\begin{array}{cc}
\cos \theta & \sin \theta \\
-\sin \theta & \cos \theta
\end{array}\right]\left[\begin{array}{l}
b_{\hat{x}} \\
b_{\hat{y}}
\end{array}\right]}
\end{aligned}
$$

Substituindo a Eq. (4.15) na Eq. (4.14) podemos encontrar um novo conjunto de funções, que se tornaram núcleos de equações integrais, expressas exclusivamente em coordenadas locais:

$$
\left[\begin{array}{c}
\sigma_{\hat{x} \hat{y}} \\
\sigma_{\hat{y} \hat{y}}
\end{array}\right]=\frac{\mu}{\pi(k+1)}\left\{\left[\begin{array}{c}
G_{\hat{x}}^{S}(\hat{x}, \hat{e}) \\
G_{\hat{x}}^{N}(\hat{x}, \hat{e})
\end{array}\right] b_{\hat{x}}(\hat{e})+\left[\begin{array}{c}
G_{\hat{y}}^{S}(\hat{x}, \hat{e}) \\
G_{\hat{y}}^{N}(\hat{x}, \hat{e})
\end{array}\right] b_{\hat{y}}(\hat{e})\right\}
$$

onde os subscritos nos núcleos, $G$, denotam a direção dos vetores de Burguer e os sobrescritos a direção das tensões.

Podemos agora formar duas integrais simultâneas análogas a Eq. (4.9), distribuindo deslocamentos ao longo da linha da trinca de forma a anular as tensões induzidas por cargas externas ao longo dessa linha:

$$
\begin{aligned}
& \tau_{T}(\hat{x})+\frac{\mu}{\pi(k+1)}\left\{\int_{0}^{b} B_{\hat{x}}(\hat{e}) G_{\hat{x}}^{S}(\hat{x}, \hat{e}) d \hat{e}+\int_{0}^{b} B_{\hat{y}}(\hat{e}) G_{\hat{y}}^{S}(\hat{x}, \hat{e}) d \hat{e}\right\}=0 \\
& \sigma_{N}(\hat{x})+\frac{\mu}{\pi(k+1)}\left\{\int_{0}^{b} B_{\hat{x}}(\hat{e}) G_{\hat{x}}^{N}(\hat{x}, \hat{e}) d \hat{e}+\int_{0}^{b} B_{\hat{y}}(\hat{e}) G_{\hat{y}}^{N}(\hat{x}, \hat{e}) d \hat{e}\right\}=0
\end{aligned}
$$

onde $\sigma_{N}(\hat{x}), \tau_{T}(\hat{x})$ são os valores das tensões normais e cisalhante, respectivamente, em coordenadas locais devido as cargas externas e $B_{\hat{x}}, B_{\hat{y}}$ são as densidades de deslocamento, definidas como:

$$
B_{\hat{\imath}}=\frac{\partial b_{\hat{\imath}}(\hat{e})}{\partial \hat{x}} \quad i=x \text { ou } y
$$

Novamente, as integrais das Eq. (4.17) e (4.18) podem ser discretizadas utilizando quadratura de Guass-Jacobi, fornecendo um sistema algébrico linear 2n por 2n: 


$$
\begin{aligned}
& \frac{\mu}{\pi(k+1)} \sum_{i=1}^{n} \frac{2 \pi\left(1+r_{i}\right)}{2 n+1}\left(G_{\hat{x}}^{S}\left(s_{i}, r_{j}\right) \phi_{\hat{x}}\left(r_{j}\right)+G_{\hat{y}}^{S}\left(s_{i}, r_{j}\right) \phi_{\hat{y}}\left(r_{j}\right)\right)=-\tau_{T}\left(s_{i}\right) \\
& \frac{\mu}{\pi(k+1)} \sum_{i=1}^{n} \frac{2 \pi\left(1+r_{i}\right)}{2 n+1}\left(G_{\hat{x}}^{N}\left(s_{i}, r_{j}\right) \phi_{\hat{x}}\left(r_{j}\right)+G_{\hat{y}}^{N}\left(s_{i}, r_{j}\right) \phi_{\hat{y}}\left(r_{j}\right)\right)=-\sigma_{N}\left(s_{i}\right)
\end{aligned}
$$

os pontos de integração $r_{j}$ e $s_{i}$ são dados pela Eq.(4.11) e os fatores intensidades de tensão são dados por:

$$
\begin{aligned}
& K_{I}=2 \sqrt{2} \sqrt{\pi b} \frac{\mu}{k+1} \phi_{y}(1) \\
& K_{I I}=2 \sqrt{2} \sqrt{\pi b} \frac{\mu}{k+1} \phi_{x}(1)
\end{aligned}
$$

onde os valores das funções $\phi_{x}$ e $\phi_{y}$ na ponta da trinca podem ser obtidos através da Eq. (5.13) . 


\section{METODOLOGIAS}

\subsection{METODOLOGIAS PARA PREVER PARADA DO PROPAGAÇÃO DE TRINCAS CURTAS EM CONDIÇÕES DE FRETTING}

Considerando dados para trincas curtas obtidas para uma variedade de materiais, Kitagawa e Takahashi (1976) verificaram que existe um tamanho crítico $b_{0}$ abaixo do qual $\Delta K_{t h}$, o limiar de propagação de trincas, decresce com o decrescimento do tamanho da trinca. Na Fig. 30 (a) observa-se que para $b<b_{0}$ a condição limiar de propagação de trinca é caracterizada por uma faixa de tensão crítica $\Delta \sigma_{t h}$, a qual se aproxima do limite de fadiga para corpos lisos $\Delta \sigma_{f l}$. Para $b>b_{0}$, Fig. 30 (b) observa-se que $\Delta K_{t h}$ é independente do tamanho da trinca. Esse valor de $\Delta K$ será então denominado desse ponto em diante de limiar do fator intensidade de tensão para trincas longas, $\Delta K_{0}$.

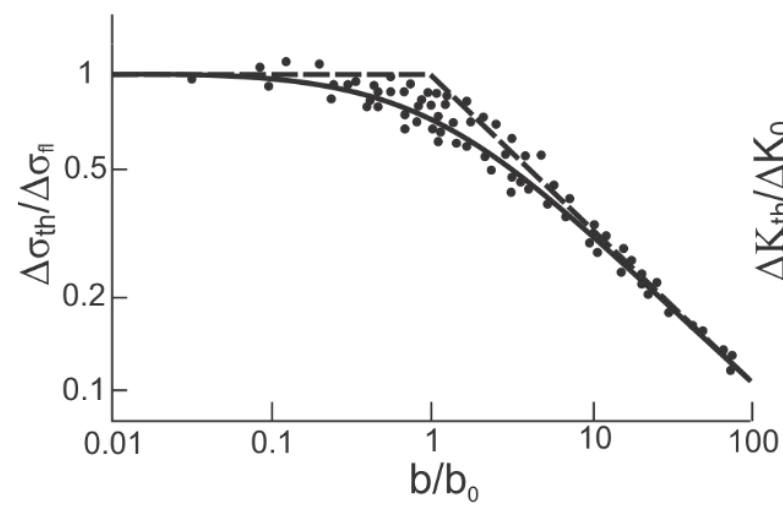

(a)

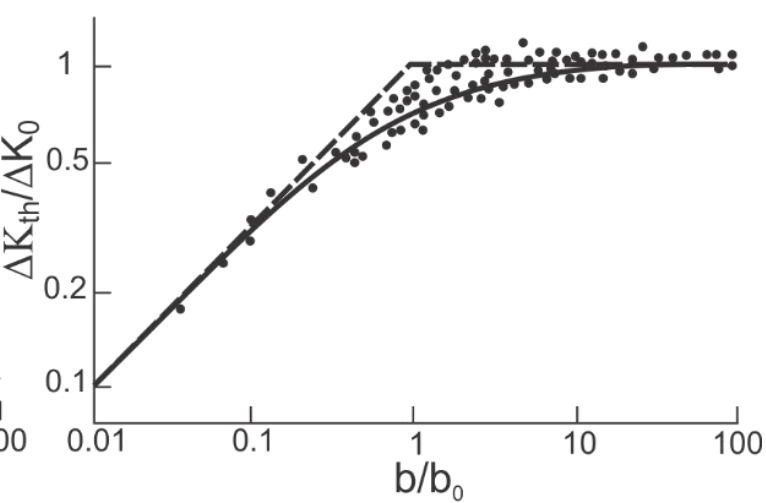

(b)

Figura 30- Efeito do tamanho da trinca (a) tensão limiar e (b) no fator intensidade de tensão para uma grande variedade de ligas de engenharia (Kitagawa-Takahashi, 1976).

El Haddad et al. (1979) propuseram a seguinte expressão para o fator de intensidade de tensão de uma trinca de comprimento efetivo $b+b_{0}$.

$$
\Delta K=\Delta \sigma \sqrt{\pi\left(b+b_{0}\right)}
$$

onde $\Delta \sigma$ é a faixa de tensão aplicada, e $b_{0}$ é o tamanho intrínseco da trinca, uma constante para um dado material.

A Eq. (5.1) é uma formulação empírica, que prediz maiores valores de $\Delta K$ para trincas curtas. Note que para comprimentos de trincas inferiores a $b_{0}$, Fig. 30 (a), a tensão limiar para trincas curtas passa a se aproximar do limite de fadiga do material $\Delta \sigma_{f l}$, sendo assim:

$$
\Delta K_{0}=F \Delta \sigma_{f l} \sqrt{\pi b_{0}}
$$

em que $F$ é um fator geométrico. Isolando-se então $b_{0}$ na Eq. (5.2): 


$$
b_{0}=\frac{1}{\pi}\left(\frac{\Delta K_{0}}{F \Delta \sigma_{f l}}\right)^{2}
$$

Em todo caso, a modificação empírica de El-Haddad produz um limiar de propagação de trincas descrito por:

$$
\frac{\Delta K_{t h}}{\Delta K_{0}}=\sqrt{\frac{b}{b+b_{0}}}
$$

Já o diagrama Kitagawa-Takahashi (K-T), sugere a seguinte aproximação:

$$
\begin{aligned}
& \frac{\Delta K_{t h}}{\Delta K_{0}}=\sqrt{\frac{b}{b_{0}}}, \quad b<b_{0} \\
& \frac{\Delta K_{t h}}{\Delta K_{0}}=1, \quad b \geq b_{0}
\end{aligned}
$$

\subsubsection{MODELO DE ARAÚJO E NOWELL (1999)}

O cálculo do fator de intensidade de tensão em problemas de fretting não possui solução analítica devido à complexidade da distribuição do campo de tensão nos corpos em estudo, no entanto, como já mostrado, o fator de intensidade de tensão pode ser obtido fazendo-se uso do método da distribuição das discordâncias, ou através do método dos elementos finitos.

Um primeiro modelo, onde o fator intensidade de tensão foi obtido para carregamentos de fretting via distribuição das discordâncias e feito posterior comparação com curvas para limiar de propagação de trincas curtas, foi realizado por Araújo e Nowell (1999) para estimativa de resistência a fadiga em ligas aeronáuticas, Fig. 31.

O fator intensidade de tensão modo I foi calculado para uma trinca se propagando perpendicular à superfície de contato. Para obter-se a variação do fator intensidade de tensão, $\Delta K_{I}$, fez-se o uso da seguinte equação:

$$
\Delta K_{I}=K_{I}^{\max }-K_{I}^{\min }
$$

onde $K_{I}^{\max }$ e $K_{I}^{\min }$ são respectivamente os valores máximos e mínios do fator de intensidade de tensão em um ciclo completo de carregamento. Observou-se que $K_{I}^{\text {min }}$ assumia valores negativos nos carregamentos em estudo, e como fatores de intensidade de tensão modo I negativos não contribuem para a abertura de trincas, foi assumido que esse é igual à zero, sendo assim:

$$
\Delta K_{I}=K_{I}^{\max }
$$

A variação do fator intensidade de tensão modo II, $\Delta K_{I I}$, assume valores significativamente menores que $\Delta K_{I}$ no caso em estudo, portanto como aproximação apenas esse é considerado na análise. 


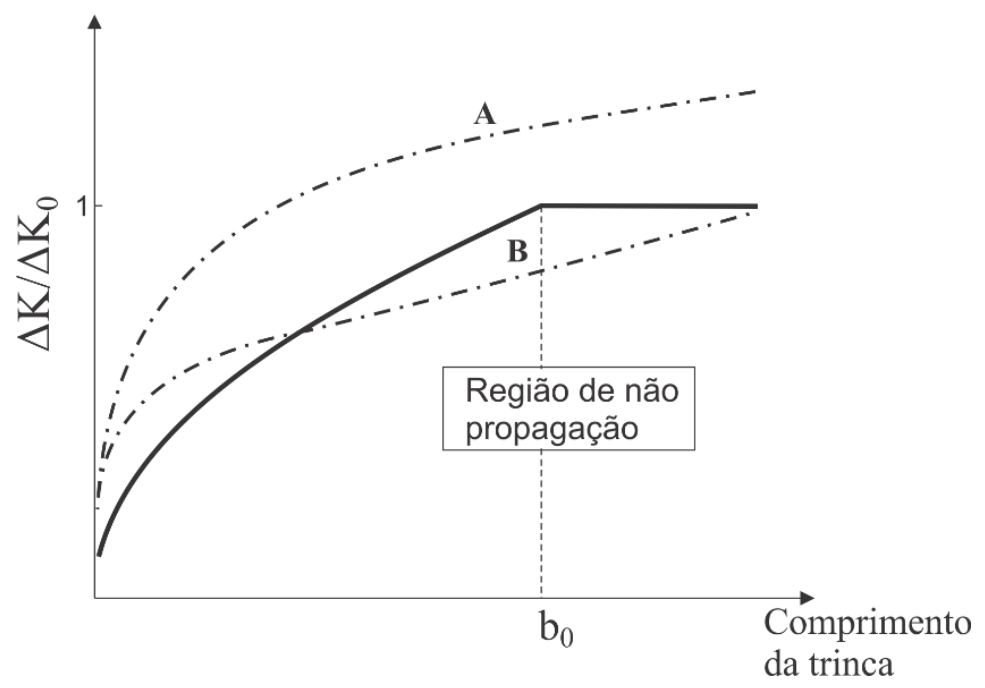

Figura 31- Metodologia proposta por Araújo e Nowell (1999)

Analisando a Fig. 31, tem-se que curvas acima do diagrama Kitagawa-Takahashi, indicam falha do material, curva (A), ou seja, a trinca se propaga até o rompimento desse, já as curvas que cruzam o diagrama possuem vida infinita, curva (B). Essa metodologia foi aplicada e comparada com dados de vida em fadiga Nowell (1988), fornecendo bons resultados.

\subsubsection{METODOLOGIA DINI ET AL. (2006)}

Um modelo semelhante ao de Araújo e Nowell (1999) foi aplicado por Dini el al., (2006) para prever resistência a fadiga em ligas aeronáuticas, no entanto, o modelo propôs o uso dos diagramas KitagawaTakahashi e da curva de El-Haddad.

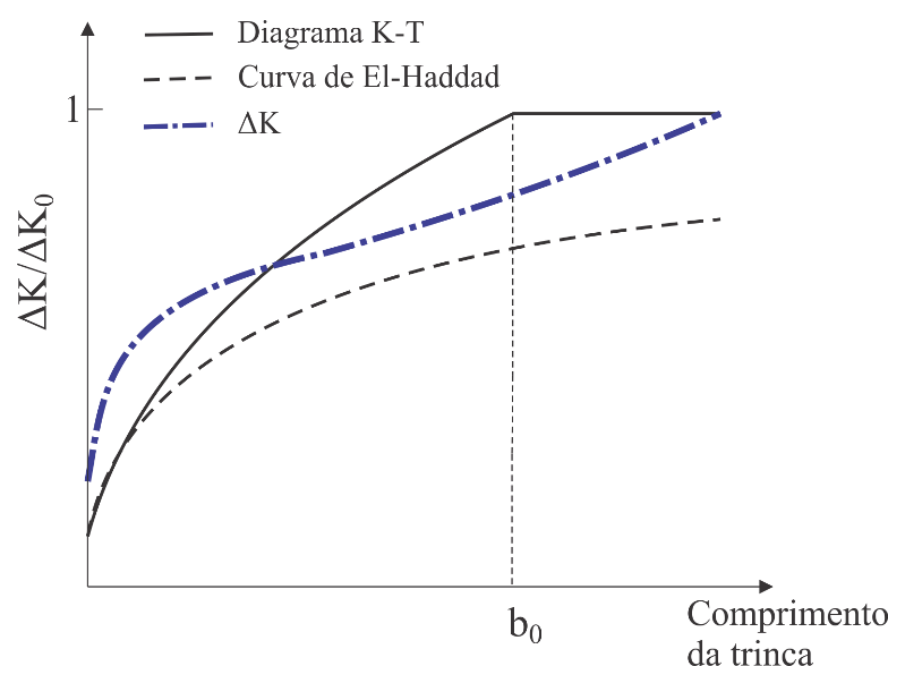

Figura 32- Metodologia proposta por Dini el Al., (2006)

Verificou-se que a curva de Kitagawa-Takahashi previa vida infinita para alguns ensaios enquanto que a curva de El-Haddad acusava falha do componente, Fig. 32. Para os dados experimentais utilizados, Dini (2006), o modelo apresentou maior acurácia quando fez-se o uso da curva de El-Haddad, levando 
a conclusão de que esta curva previa melhores resultados que a aproximação de Kitagawa-Takahashi para o material em estudo (liga de titânio).

\subsubsection{METODOLOGIA PROPOSTO POR FOUVRY ET AL. (2008)}

Aplicando um metodologia semelhante a que originalmente foi proposta por Araújo e Nowell (1999), Fouvry (2008) em seu trabalho estimou o comprimento de trincas curtas que param de crescer em condições de fretting. Em seu trabalho ele considerou que a trinca se propagava de forma inclinada (observação experimental) e comparou a evolução da faixa do fator de intensidade de tensão efetivo com o digrama K-T, Fig. 33.

Ao considerar a propagação de um trinca inclinada, o fator de intensidade de tensão modo II já não é mais desprezível, sendo assim, o uso de um fator de intensidade de tensão efetivo foi utilizado, $\Delta K_{e f f}$.

$$
\Delta K_{e f f}=\sqrt{\Delta K_{I}^{2}+\Delta K_{I I}^{2}}
$$

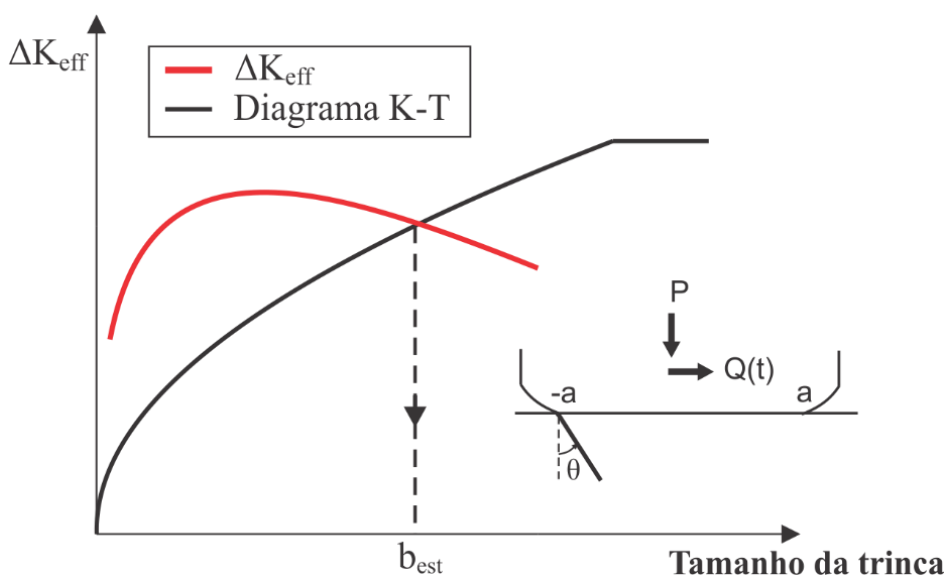

Figura 33- Metodologia utilizada por Fouvry pra estimar comprimento de trincas paradas

Na Equação (5.8), novamente foram considerados apenas valores positivos para o cálculo de $\Delta K_{I}$. Uma representação esquemática da metodologia aplicada por Fouvry é mostrada na Fig. 33. No gráfico o cruzamento entre as duas curvas representa a parada de crescimento da trinca, assim como a projeção no eixo das abscissas fornece o comprimento da trinca estimado.

\subsubsection{METODOLOGIA PROPOSTA NESTE TRABALHO}

Tendo em vista que Araújo (1999) e Fouvry (2008) obtiveram bons resultados utilizando o diagrama K-T como limiar de propagação de trincas, enquanto que, Dini et al. (2006) obteve melhores resultado utilizando a curva de El-Haddad, neste trabalho será utilizada uma curva mais genérica levando em conta propriedades materiais para avaliar o fenômeno de parada de crescimento de trincas curtas. 
Seguindo o raciocínio de Bazant (1997), uma curva mais genérica pode ser proposta para descrever o limiar de propagação de trincas, Eq. (5.9). Nesse caso o parâmetro material $\gamma$ é introduzido de forma a melhor se ajustar aos dados experimentais.

$$
\Delta K_{t h}(b)=\Delta K_{0}\left(1+\left(\frac{b_{0}}{b}\right)^{\frac{\gamma}{2}}\right)^{-\frac{1}{\gamma}}
$$

Fica claro na Eq. (5.9) que para um $\gamma=2$ temos a curva de El-Haddad. Já considerando um $\gamma \rightarrow \infty$ essa mesma equação colapsa no digrama K-T. Um série de dados experimentais Tanaka et al. (1981) e Livieri e Tovo (2004) são apresentados na Fig. 34, junto com diferentes parâmetros $\gamma$ para ajustar os dados experimentais.

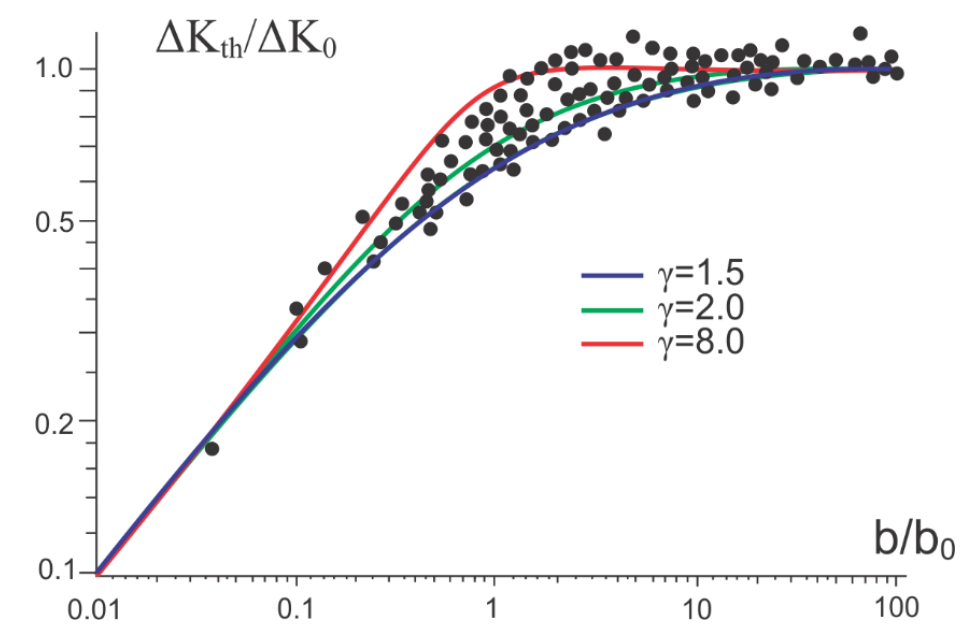

Figura 34- Limiar de propagação de trincas através da curva de Bazant

Além da influência da escolha da curva para descrever o limiar de propagação de trincas, a influência da direção de propagação da trinca também será avaliada, uma vez que nos problemas reais, a princípio não se sabe a direção inicial de propagação da trinca. O objetivo é verificar se a consideração preliminar de uma trinca se propagando apenas em modo I de forma perpendicular à superfície de contato é uma boa aproximação para estudar a propagação de trincas curtas.

\subsection{CRITÉRIOS PARA ESTIMAR A DIREÇÃO DE INICIAÇÃO DE TRINCAS EM CONDIÇÕES DE FRETTING}

Como extensivamente mostrado na literatura, a iniciação e a posterior propagação de trincas em metais é normalmente caracterizada por dois estágios distintos, Fig. 35. O estágio I, estágio inicial, normalmente governado por modo II de propagação e o estágio II, geralmente caracterizado por trincas em modo I de propagação. Entretanto, de acordo com Dubourg e Lamacq (2000), o estágio I pode ser dividido em dois grupos: tipo 1 quando a iniciação de trincas é fortemente influenciada pela faixa de tensão cisalhante, $\Delta \tau$, e tipo 2 quando é a faixa de tensão normal, $\Delta \sigma_{n}$, que governa o processo. 


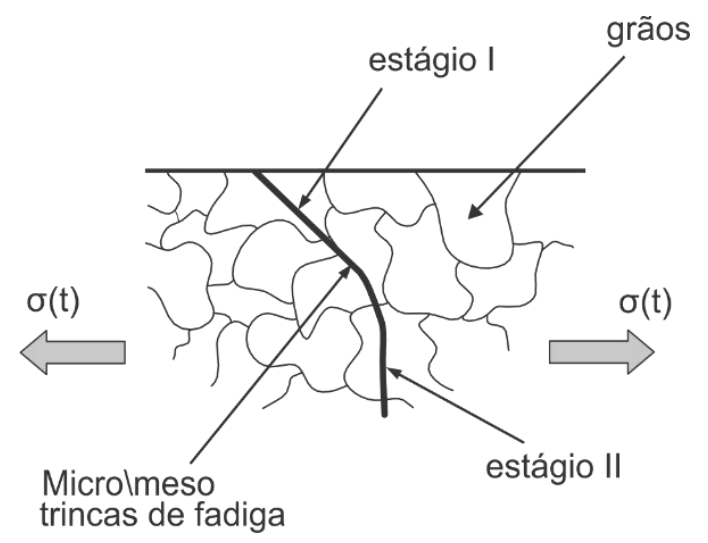

Figura 35- Estágios de propagação de trincas

Susmel e Taylor (2007), realizaram testes em aços de baixo carbono entalhados a fim de se estudar o comportamento de trincas em elevados ciclos de fadiga. Foi então verificado que nesse tipo de concentrador de tensão, o estágio I é governado por um modo misto de propagação, uma vez que o perfil das trincas observadas nunca eram paralelas ao plano de bissecção do entalhe. Notou-se também que o caminho irregular das trincas no estágio I ficavam confinados dentro de um região da ordem do comprimento característico do material, L.

Considerando essas hipóteses, dois critérios multiaxiais baseados na teoria das distâncias críticas serão aplicados para estimar a iniciação de trincas.

\subsubsection{TEORIA DAS DISTÂNCIAS CRÍTICAS}

A Teoria das Distâncias Críticas (TDC) é capaz de estimar com certa precisão o dano por fadiga em componentes contendo não somente trincas, mas também qualquer tipo de entalhe. Antes de considerar com detalhes as diferentes formalizações da TDC é importante salientar que essa teoria estima o dano por fadiga diretamente pelo pós-processamento do campo de tensão linear elástico agindo sobre a zona de processo de fadiga. Este aspecto é muito importante porque a TDC permite que componentes reais sejam estudados sem a necessidade de análises elasto-plásticas.

Vários pesquisadores têm tentando explicar o comportamento do aparente ganho de resistência em componentes com entalhes agudos devido ao fato da concentração de tensão ocorrer somente em um pequeno volume do material, Sheppard (1991), Taylor e O’Donnell (1994). A TDC tem como ideia inicial o fato de que o dano por fadiga na presença de concentradores de tensão pode ser estimado usando uma quantidade de tensão a qual é representativa de todo o campo de tensão linear elástico na zona de processo. Em particular, os entalhes são assumidos na condição de limite de fadiga quando a tensão efetiva, $\Delta \sigma_{e f f}$, se iguala ao limite à fadiga do material, $\Delta \sigma_{f l}$, ou seja:

$$
\Delta \sigma_{e f f}=\Delta \sigma_{f l}
$$


A tensão efetiva acima é comumente calculada simplesmente definindo-se uma distância crítica conveniente e um domínio de integração onde o campo de tensão é representativo do fenômeno de fadiga. Particularmente, independentemente da definição adotada para $\Delta \sigma_{e f f}$, todas as modernas formalizações da distância crítica assumem que a mesma é uma propriedade do material que pode ser calculada como (Tanaka, 1983; Atzori et al. 1992; Lazzarin et al. 1997; Taylor, 1999):

$$
\mathrm{L}=\frac{1}{\pi}\left(\frac{\Delta K_{t h}}{\Delta \sigma_{f l}}\right)^{2}
$$

onde $\Delta K_{t h}$ é a faixa do limiar de propagação de trincas longas e $\Delta \sigma_{f l}$ a faixa do limite de resistência a fadiga, sendo ambos propriedades materiais para uma mesma razão de carregamento $\rho$.

Para simplificar os cálculos, o campo de tensão representativo geralmente é avaliado em um único ponto ou é feita uma média ao longo de uma linha ou de uma área, já que a consideração de um volume eleva muito o custo computacional. Essas aproximações podem ser denominadas de método do ponto, linha e área, Fig. 36.

\section{Método do ponto}

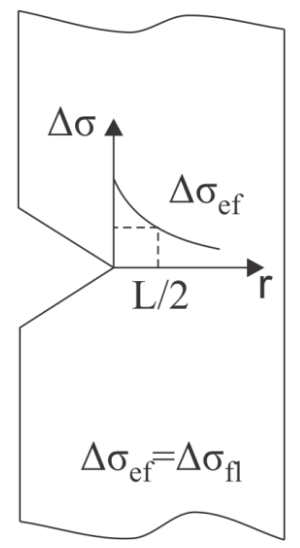

( a )
Método da Linha

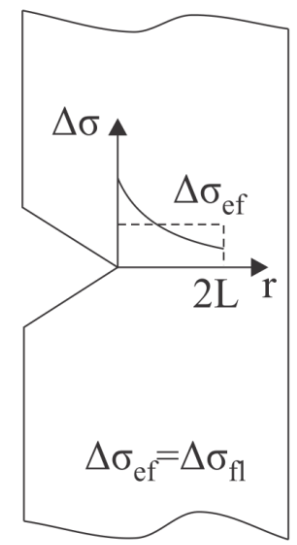

( b )
Método da Área

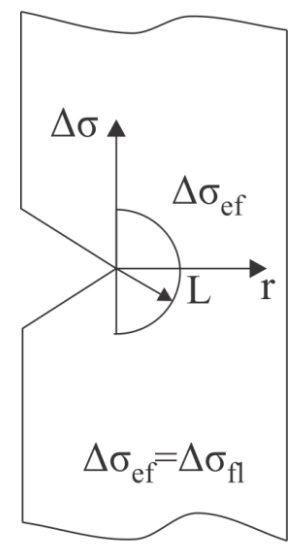

( c )

Figura 36- Diferentes formalizações da Teoria das Distâncias Críticas: (a) Método do Ponto; (b) Método da Linha; (c) Método da Área.

Analisando cada caso em particular temos que $\Delta \sigma_{e f f}$ de acordo com o Método do Ponto (Tanaka, 1983; Taylor, 1999) é dado por:

$$
\Delta \sigma_{e f f}=\Delta \sigma\left(\theta=0, r=\frac{L}{2}\right)
$$

No método da linha (Tanaka, 1983; Lazzarin et al. 1997; Taylor, 2007):

$$
\Delta \sigma_{e f f}=\frac{1}{2 L} \int_{0}^{2 L} \Delta \sigma(\theta=0, r) d r
$$

Já para o método da área (Sheppard, 1991; Taylor, 1999): 


$$
\Delta \sigma_{e f f}=\frac{2}{\pi L^{2}} \int_{0}^{\pi} \int_{0}^{L} \Delta \sigma(\theta, r) r d r d \theta
$$

Vale salientar que as diferentes formulações da TDC são capazes de estimativas dentro de um intervalo de erro de $\pm 20 \%$ independente do material e das características geométricas do mesmo (Taylor e Wang, 2000; Susmel e Taylor, 2003). É importante lembrar que erros dessa magnitude são aceitáveis, devido aos erros advindos de trabalhos experimentais e das análises de tensões numéricas (Taylor e Wang, 2000).

\subsubsection{METODO DA DIREÇÃO CRÍTICA ASSOCIADO COM A TDC}

A teoria das distâncias críticas (TDC) pode ser utilizada em associação com qualquer critério de fadiga (Susmel e Taylor, 2006). Então baseado na hipótese que no estágio I pode-se ter trincas dominadas pela máxima faixa de tensão normal (trinca tipo 2), a orientação da trinca será definida aqui por um linha de comprimento $2 \mathrm{~L}$, inclinada de um ângulo $\theta_{\sigma}$ em relação ao eixo y, que maximiza $\theta$ na Eq. (5.15), Fig. 37 (a). Portanto, um aspecto importante que deve ser notado na Eq. (5.15) é que a máxima faixa de tensão normal calculada é sempre perpendicular à linha definida pelo ângulo, $\theta$, i.e. a linha de comprimento $2 \mathrm{~L}$ (inclinada de $\theta$ ) é discretizada em muitos pontos materiais e a máxima faixa de tensão normal é calculada para o mesmo plano $\theta$ para todos esses pontos. Esse procedimento fornece a orientação crítica $\theta_{\sigma}$ que uma trinca de tamanho $2 \mathrm{~L}$ teria em teoria em seu estágio inicial. Uma abordagem similar pode ser usada de forma a minimizar a faixa de tensão cisalhante, $\Delta \tau$, Eq. (5.16). A base física para dar suporte a essa hipótese é o fato que, nesses planos, menos energia é desperdiçada por atrito e consequentemente mais energia é disponibilizada para propagar a trinca (Giner, 2014).

$$
\theta_{\sigma}=\max _{\theta}\left(\int_{0}^{2 L} \Delta \sigma_{\theta}(r, \theta) d r\right)
$$

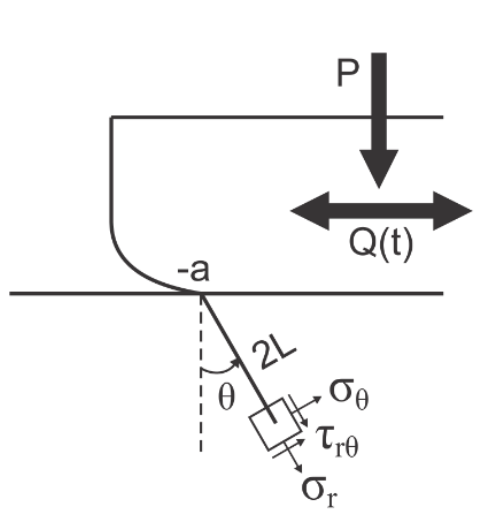

(a) sapatas cilíndricas

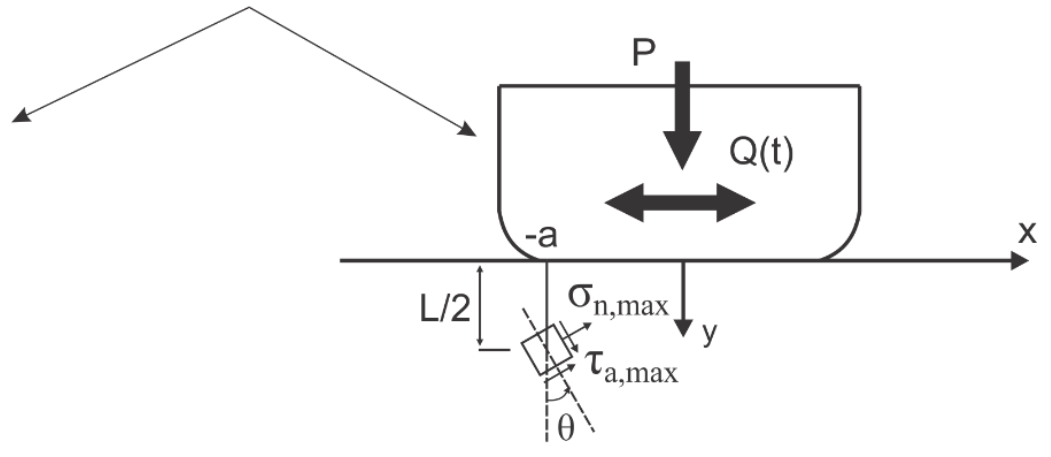

(b)

Figura 37- (a) Campo de tensão nas proximidades da zona crítica em termos do método da linha em coordenadas cilíndricas; (b) Plano crítico em termos do método do ponto 


$$
\theta_{\tau}=\min _{\theta}\left(\int_{0}^{2 L} \Delta \tau_{r \theta}(r, \theta) d r\right)
$$

Nas equações (5.15) e (5.16) as integrais são avaliadas em um distância 2L, como definido pelo Método da Linha (Taylor, 2007).

\subsubsection{MODELO DE PLANO CRÍTICO APLICADO EM TERMOS DA TDC}

Nesse caso, assume-se que o processo de iniciação da trinca é governado pela faixa de tensão cisalhante $\Delta \tau$ (trinca tipo 1). Considerando uma abordagem de plano crítico, tal como o Método das Curvas de Whöler modificada, espera-se que a iniciação da trinca ocorra no plano material que experimenta a maior amplitude de tensão cisalhante. Como a tensão cisalhante sempre possui a mesma magnitude em dois planos mutuamente ortogonais, o plano crítico entre esses dois é aquele que experimenta a maior tensão normal ao longo de um ciclo de carregamento. A Figura 37 (b) ilustra o modelo de pano crítico associado com o método do ponto (MP) para se estimar a direção de propagação preferencial da trinca.

\subsection{CRITÉRIOS PARA ESTIMAR O CAMINHO DE PROPAGAÇÃO DE TRINCAS}

Em fretting, as condições de carregamento são complexas e não proporcionais, o que torna o processo de estimar a direção de propagação de trincas difícil. Modelos clássicos como a Máxima Tensão Tangencial (Erdogan e Sih, 1963), Máxima Densidade de Energia de Deformação (Sih, 1972) ou a Máxima Taxa de Energia de Liberação (Palaniswamy e Knauss, 1972) não são adequadas para carregamentos não proporcionais. Levando em conta essa não proporcionalidade do problema de fretting, dois modelos distintos serão avaliados a fim de se estimar o perfil de propagação das trincas em tais condições:

(i) A trinca irá se propagar na direção que maximiza $\Delta k_{1}(\theta)$ ao longo de um ciclo (Dubourg e Lamacq, 2000), $\max \left(\Delta K_{1}\right)$.

(ii) A trinca irá se propagar na direção que minimiza $\Delta \tau$ na ponta da trinca ao longo de um ciclo (Giner et al. 2014), $\min (\Delta \tau)$.

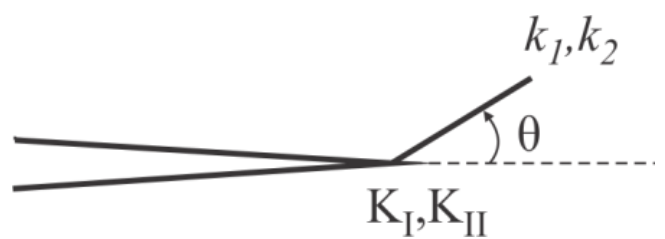

Figura 38- Trinca infinitesimal emergindo da trinca original 


$$
\left[\begin{array}{l}
k_{1}(\theta, t) \\
k_{2}(\theta, t)
\end{array}\right]=\left[\begin{array}{ll}
K_{11}(\theta) & K_{12}(\theta) \\
K_{21}(\theta) & K_{22}(\theta)
\end{array}\right]\left[\begin{array}{l}
K_{I}(t) \\
K_{I I}(t)
\end{array}\right]
$$

onde $k_{1}$ e $k_{2}$ são os fatores de intensidade de tensão modos I e II, respectivamente, de uma trinca infinitesimal emergindo da trinca já existente na direção $\theta$, Fig. 38. As expressões que relacionam $k_{1} \mathrm{e}$ $k_{2}$ com os fatores de intensidade de tensão modo I e II $\left(K_{I}\right.$ e $\left.K_{I I}\right)$ da trinca original são dadas pela Eq. (5.17), onde as funções angulares $K_{i j}(\theta)$ são reportadas em (Ribeaucourt et al. 2007) e (Amestoy et al. 1979), ver anexo A.3.

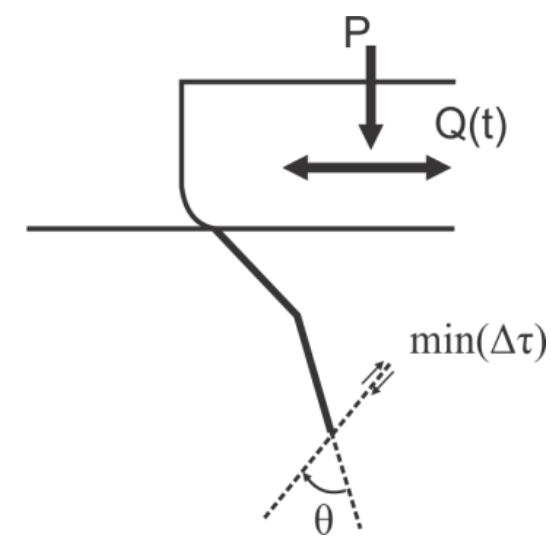

Figura 39- Critério da mínima faixa de tensão cisalhante aplicado na ponta da trinca

Recentemente, Giner et al. (2014) propuseram o critério da mínima faixa de tensão cisalhante para prever a direção de propagação de trincas em problemas de fretting. Esse critério consiste em encontrar o plano que minimiza a faixa de tensão cisalhante, $\Delta \tau$, na ponta da trinca, Fig. 39 . Sabendo que a tensão cisalhante é sempre igual em dois planos mutuamente ortogonais escolhe-se aquele onde a faixa de tensão normal $\Delta \sigma_{n}$ é máxima (menos perda de energia por fricção). 


\section{DADOS EXPERIMENTAIS}

\subsection{DADOS DISPONÍVEIS NA LITERATURA}

Ensaios de fretting puro e de fadiga por fretting provenientes da literatura serão utilizados nesse trabalho para confrontar algumas das metodologias previamente descritas. Todos os ensaios considerados neste trabalho são do tipo contato cilindro no plano na condição de escorregamento parcial, i.e. $Q / P<f$, onde o raio da sapata cilíndrica em todos os casos analisados é muito menor que a semilargura do contato.

Os ensaios em condições de fadiga por fretting foram conduzidos em ligas de Al4\%Cu e Ti-6Al$4 \mathrm{~V}$. As sapatas e os corpos de provas nesse caso foram fabricadas em mesmo material. As propriedades mecânicas desses materiais são: módulo de elasticidade, $E=74 \mathrm{GPa}$ e tensão de escoamento $\sigma_{y}=465$ MPa para a liga de alumínio e $E=115 \mathrm{GPa}$ e $\sigma_{y}=974 \mathrm{MPa}$ para a liga de Ti-6Al-4V. O coeficiente de Poisson é 0.33 para ambas as ligas. Esses experimentos são descritos e discutidos detalhadamente em, Araújo et al. (2004), Nowell (1988) e Araújo (2000), sendo assim, apenas as informações necessárias para conduzir as análises serão apresentadas aqui.

Nos casos de fadiga por fretting, em que há a presença de uma carga remota de fadiga, o histórico de carregamento pode ser descrito da seguinte forma: primeiramente uma carga normal estática (por unidade de comprimento), $\mathrm{P}$, é aplicada nas sapatas mantendo-as pressionadas contra o corpo de prova. Então uma carga tangencial oscilatória variando entre $\pm Q_{\max }$ é aplicada em fase com uma carga remota de fadiga variando entre $0.9 \mathrm{MPa}$ e $\sigma_{b, \max }$ para o Ti-6Al-4V e entre $\pm \sigma_{b, \max }$ para a liga de $\mathrm{Al}$, onde $\sigma_{b, \max }$ e $Q_{\max }$ são os valores máximos atingidos pela tensão remota e pela carga tangencial ao longo de um ciclo de carregamento, respectivamente. O coeficiente de atrito nas zonas de escorregamento para o Al4\%Cu é 0.75 e para o Ti-6Al-4V é 0.55 . Uma série de ensaios para a liga de $\mathrm{Al}$ e outra para a liga de Ti-6Al-4V foram analisadas, onde o raio da sapata era diferente para cada ensaio da série. A Tabela 3 relata os principais parâmetros de carregamento utilizados nos ensaios para as ligas de $\mathrm{Al}$ e Ti, enquanto que as Tab. 4 e 5 relatam os resultados dos ensaios considerando os diferentes raios de sapata.

Tabela 3- Parâmetros de carregamento para as ligas de Al4\%Cu e Ti-6Al-4V

\begin{tabular}{rrrc}
\hline Material & $p_{0}(M P a)$ & $Q_{\max } / P$ & $\sigma_{b, \max }(M P a)$ \\
\hline $\mathrm{Al} 4 \% \mathrm{Cu}$ & 143 & 0.45 & 92.7 \\
Ti-6Al-4V & 650 & 0.16 & 280 \\
\hline
\end{tabular}

Vale lembrar que nesses ensaios, a magnitude das tensões na superfície era a mesma independentemente do raio da sapata, apesar dos gradientes de tensão serem distintos em cada caso. 


\begin{tabular}{ccc}
\hline \multicolumn{3}{c}{$\mathrm{Al} \% \mathrm{Cu}$} \\
\hline $\mathrm{R}(\mathrm{mm})$ & $\mathrm{N}^{\circ}$ de ciclos & Status do CP \\
12.5 & 10.000 .000 & Interrompido \\
25 & 10.000 .000 & Interrompido \\
37.5 & 4.040 .000 & Falha \\
50 & 1.500 .000 & Falha \\
\hline
\end{tabular}

\begin{tabular}{ccc}
\multicolumn{3}{c}{ Tabela 5- Resultados ensaios para a liga de Ti-6Al-4V } \\
\hline Ti-6Al-4V \\
12.5 & 1.400 .000 & Interrompido \\
37.5 & 521.000 & Falha \\
50 & 374.000 & Falha \\
60 & 196.000 & Falha \\
\hline
\end{tabular}

A faixa limiar de propagação para trincas longas e a faixa limite de resistência a fadiga para a liga de Al4\% $\mathrm{Cu}$ valem respectivamente: $\Delta K_{0}=4.2 \mathrm{MPa} \sqrt{\mathrm{m}}$ e $\Delta \sigma_{-1}=248 \mathrm{MPa}$. No caso da liga de Ti6Al-4V $\Delta K_{0}=4.5 \mathrm{MPa} \sqrt{\mathrm{m}}$ e $\Delta \sigma_{0}=565 \mathrm{MPa}$, para um razão de carregamento igual a zero, Dini. (2004).

Os ensaios em condições de fretting puro foram conduzidos em corpos de prova fabricados em ligas de aço 35NCD16 e AISI 1034. Em ambos os testes as sapatas cilíndricas são fabricadas de materiais diferentes, aço 100C6 e aço cromo 52100, respectivamente. As propriedades mecânicas desses materiais são apresentadas na Tab. 6 e maiores detalhes são encontrados em Baietto et al. (2013) e Fouvry et al. (2008). Tanto o aço AISI 1034 quanto o aço 35NCD16 possuem coeficiente de Poisson $v=0.3$, e nos ensaios com ambos os materiais o coeficiente de atrito $f$ nas zonas de escorregamento é 0.9 , segundo esses autores. Deve-se notar que o histórico de carregamento nesses casos é semelhante ao que foi aplicado nos corpos de prova de $\mathrm{A} 14 \% \mathrm{Cu}$ e Ti-6Al-4V, exceto pela inexistência da carga remota de fadiga. 


\begin{tabular}{crrrccc}
\hline Material & $E(G P a)$ & $\sigma_{y}(M P a)$ & $\sigma_{u}(M P a)$ & $\sigma_{-1}(M P a)$ & $\tau_{-1}(M P a)$ & $\Delta K_{0}(M P a \sqrt{m})$ \\
\hline AISI 1034 & 200 & 350 & 600 & 270 & - & 7 \\
52100 & 210 & 1700 & 2000 & - & - & - \\
35 NCD16 & 200 & 1127 & 1270 & 590 & 460 & - \\
$100 \mathrm{C} 6$ & 195 & 1500 & - & - & - & - \\
\hline
\end{tabular}

Para as ligas de aço, mediu-se o comprimento e perfil das trincas por meio de microscopia óptica. Para isso seccionou-se os corpos de prova no centro da zona de contato. No caso do aço AISI 1034 uma bateria de ensaios foi realizada mantendo-se a carga normal P em $227 \mathrm{~N} / \mathrm{mm}$ e variando-se a amplitude carga tangencial $Q_{\max }$, Tab. 7, observando-se a presença de trincas curtas não propagantes. Nestes ensaios, Fouvry et al. (2008) observaram trincas perfazendo um ângulo médio $\theta=30^{\circ} \pm 3$ (ângulo medido entre um vetor normal a superfície de contato e o plano da trinca, Fig. 40).

Tabela 7- Resultados para tamanho de trinca obtido nos ensaios para o AISI $1034\left(10^{6}\right.$ ciclos $)$

\begin{tabular}{cccccccc}
\hline \multicolumn{8}{c}{ Aço AISI 1034} \\
\hline$Q_{\text {max }}(N / m m)$ & 126 & 137 & 144 & 146 & 151 & 164 & 169 \\
$b_{\text {exp }}(\mu m)$ & 24 & 29 & 31 & 52 & 55 & 65 & 68 \\
\hline
\end{tabular}

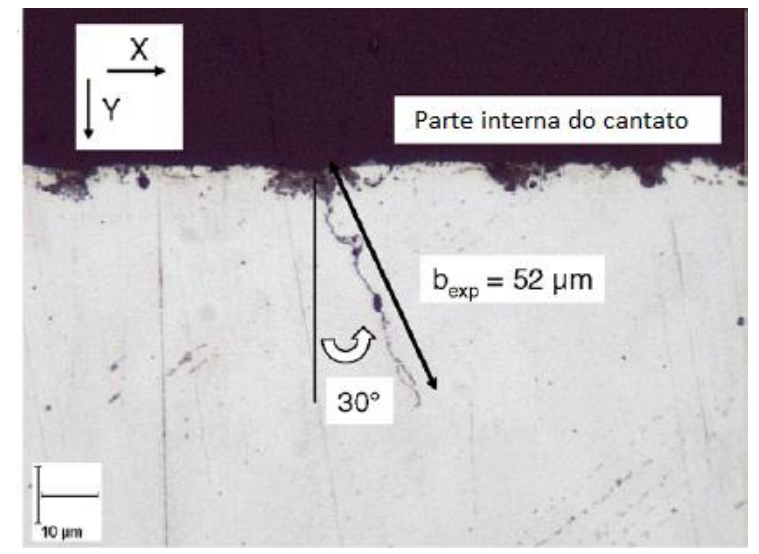

Figura 40- Perfil da trinca em microscópio eletrônico para o aço AISI 1034

Já para o aço 35NCD16 três testes foram realizados sob mesmas condições de carregamento e geométricas $\left(P=1000 \mathrm{~N} / \mathrm{mm}, Q_{\max }=500 \mathrm{~N} / \mathrm{mm}\right.$ e $\left.R=80 \mathrm{~mm}\right)$, mas interrompidos em diferentes instantes (números de ciclos). O comprimento e o perfil da trinca foram então registrados. Os 
resultados para esses testes são mostrados na Tab. 8. O perfil da trinca é descrito como esquematizado na Fig. 41.

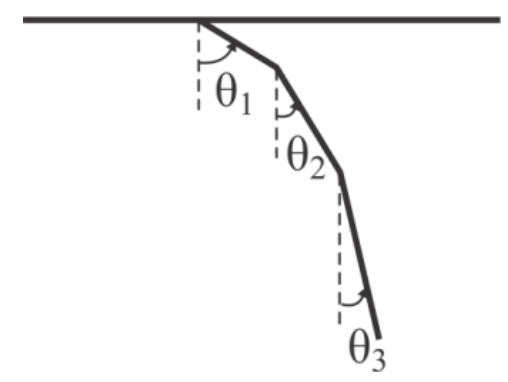

Figura 41- Esquematização do perfil de propagação da trinca

Tabela 8- Dados dos ensaios para o aço 35NCD16

\begin{tabular}{rcc}
\hline & $35 \mathrm{NCD} 16$ & \\
\hline 100.000 ciclos & $a_{1}=68 \mu \mathrm{m}$ & $\theta_{1}=17^{\circ}$ \\
250.000 ciclos & $a_{2}=130 \mu \mathrm{m}$ & $\theta_{2}=13^{\circ}$ \\
500.000 ciclos & $a_{3}=248 \mu \mathrm{m}$ & $\theta_{3}=11^{\circ}$ \\
\hline
\end{tabular}

Para os testes com o Al4\%Cu e com Ti-6Al-4V os autores não seccionaram os corpos de prova dos ensaios de vida infinita para verificação da existência e das características de eventuais trincas não propagantes. Portanto, estes dados não serão utilizados para análises referentes ao caminho de trincas, mas apenas para validação da metodologia de parada de crescimento de trincas curtas. Vale lembrar que apesar dos autores não terem investigado a existência de trincas não propagantes, a ocorrência delas era bastante provável uma vez que os níveis de amplitude de tensão na extremidade anterior do contato (local usual de iniciação das trincas) eram significativamente maiores que o limite de fadiga do material.

Os dados para o aço AISI 1034 serão utilizados para avaliar os modelos que estimam o comprimento trincas curtas que pararam de crescer em condições de fretting e também para testar os modelos que estimam a direção de iniciação de trincas. Já os dados para a liga de aço 35NCD16 serão utilizados para avaliar tanto as metodologias que estimam a direção de iniciação quanto as que estimam o caminho de propagação. 


\section{RESULTADOS}

\subsection{PARADA DE TRINCAS}

Considerando os dados experimentais para as ligas $\mathrm{Al} 4 \% \mathrm{Cu}$ e $\mathrm{Ti}-6 \mathrm{Al}-4 \mathrm{~V}$ a faixa do fator de intensidade de tensão modo I foi calculado via método da distribuição das discordâncias considerandose uma trinca com origem na extremidade anterior do contato $(x / a=-1)$ e perpendicular à superfície uma vez que informações quanto ao perfil da trinca não estão disponíveis nesses casos. Apesar dessa análise ser uma aproximação, ela parece adequada em uma primeira análise já que, na extremidade anterior do contato o estado de tensão é uniaxial. A medida que a trinca evolui tensões de cisalhamento surgem mas são significativamente menores que as tensões normais.

Em seguida comparou-se a evolução do fator de intensidade de tensão com curvas para limiar de propagação de trincas curtas baseadas em um parâmetro material, $\gamma$, fator de Bazant. A Figura 42 ilustra os resultados para a série de ensaios com o Al, e a Fig. 43 ilustra os resultados para os ensaios com a liga de Ti-6Al-4V.

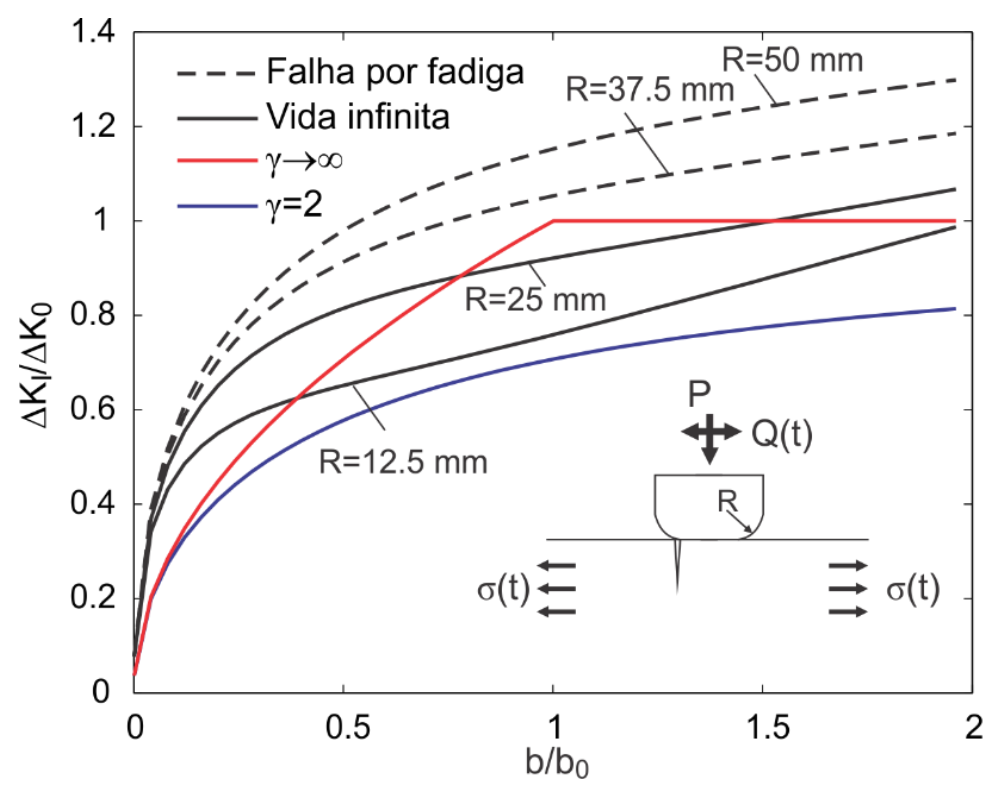

Figura 42- Resultado para parada de trinca $(\mathrm{A} 14 \% \mathrm{Cu})$

Os resultados mostrados na Fig. 42 (A14\%Cu) mostram que para $\gamma \rightarrow \infty$ (diagrama K-T) o modelo prevê exatamente o que ocorre experimentalmente, enquanto que para $\gamma=2$ (curva de El-Haddad) há previsão falha para todos os ensaios. Já os resultados para a liga Ti-6Al-4V, Fig. 43, mostram que um $\gamma=2$ é capaz de descrever corretamente o que ocorreu nos experimentos, enquanto que um $\gamma \rightarrow \infty$ acusa parada de trinca para todos os ensaios, sendo que três deles chegaram a ruptura. Ou seja, o uso do diagrama K-T para a avaliação da para de trincas nesta liga de Ti-6Al-4V fornece resultados não conservativos. 


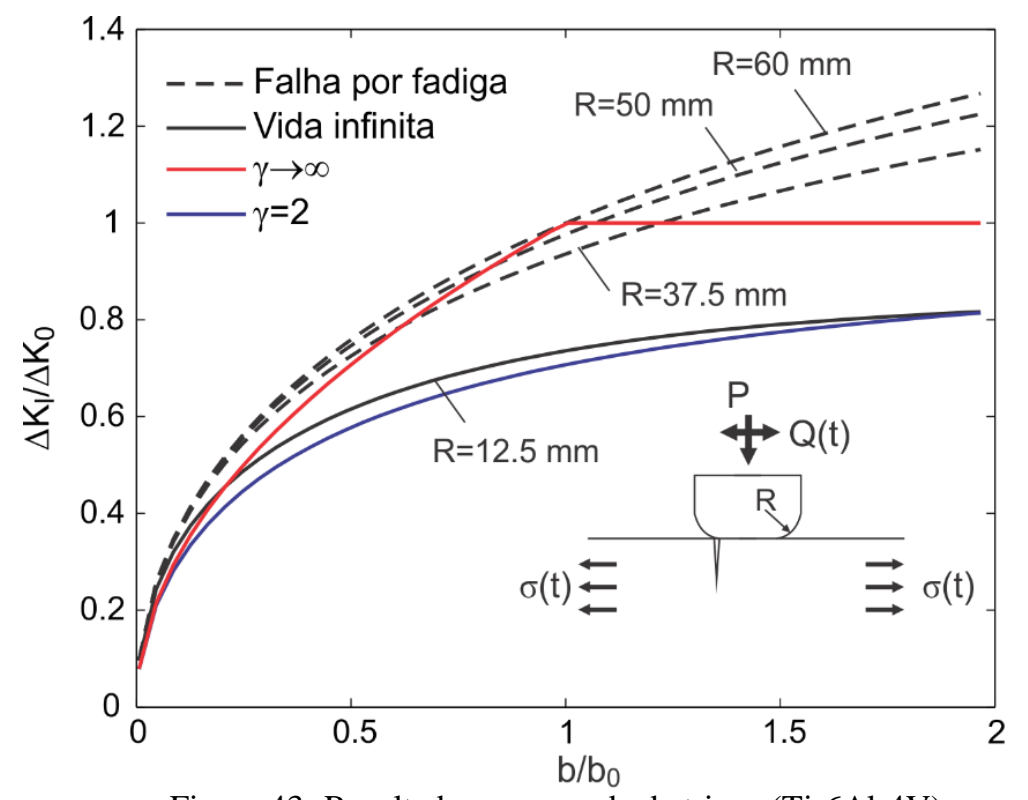

Figura 43- Resultado para parada de trinca (Ti-6Al-4V)

Nos ensaios de Fouvry et al. (2008) os autores não apenas relataram o perfil da trinca mas mediram seu comprimento, Fig. 40. Desta forma, nessa etapa da análise a mesma metodologia já descrita também foi utilizada para estimar o comprimento final de trincas não propagantes. Primeiramente considerou-se a propagação de trincas perpendiculares a superfície de contato, onde a faixa do fator de intensidade de tensão modo I foi comparado com diferentes curvas para limiar de propagação de trincas curtas. Posteriormente a mesma análise foi realizada, entretanto, considerando a propagação de trincas inclinadas por um ângulo $\theta=30^{\circ}$ em relação a superfície de contato (observação experimental), Fig. 40. Lembrando que no caso de se considerar uma trinca inclinada, o fator de intensidade modo II passa a não ser mais desprezível, o que requere o uso da Eq. (5.8) para quantificar um fator intensidade de tensão efetivo.

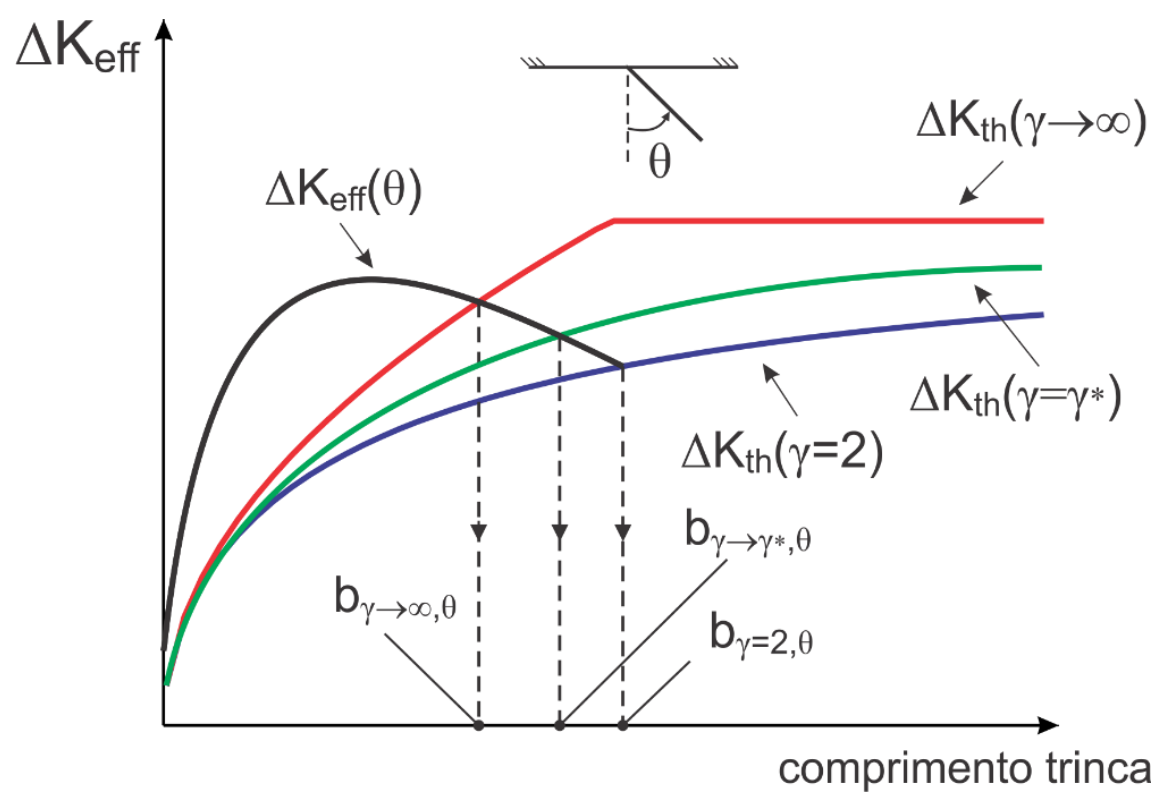

Figura 44- Metodologia para estimar comprimento de trincas que param de crescer 
Os resultados dessas análises e a comparação com as observações experimentais são mostradas nas Tab. 9 e 10. Note que apenas resultados para $\gamma=2$ e $\gamma \rightarrow \infty$ são apresentados, uma vez que no problema analisado, melhores resultados foram obtidos considerando $\gamma=\infty$ e para $\gamma$ menores as estimativas ficavam piores. Um $\gamma=2$ (curva de El-Haddad) também foi considerado apenas para comparação dos resultados. A Figura 44 ilustra a metodologia utilizada e a nomenclatura adotada para os resultados.

Tabela 9- Resultados para estimativa do tamanho de trincas que param de crescer AISI $1034, \theta=0^{\circ}$

\begin{tabular}{cccccc}
\hline$Q_{\max }(N / m m)$ & $b_{\text {exp }}(\mu m)$ & $b_{\gamma \rightarrow \infty, 0^{\circ}}(\mu m)$ & $b_{\gamma=2,0^{\circ}}(\mu m)$ & $\frac{b_{\text {exp }}-b_{\gamma \rightarrow \infty, 0^{\circ}}}{b_{\text {exp }}} \%$ & $\frac{b_{\text {exp }}-b_{\gamma=2,0^{\circ}}}{b_{\text {exp }}} \%$ \\
\hline 126 & 24 & 40 & 49 & 65 & 106 \\
137 & 29 & 47 & 61 & 63 & 110 \\
144 & 31 & 53 & 69 & 69 & 123 \\
146 & 52 & 54 & 72 & 4 & 38 \\
151 & 55 & 58 & 78 & 6 & 42 \\
164 & 65 & 69 & 97 & 6 & 49 \\
169 & 68 & 74 & 105 & 8 & 54 \\
\hline
\end{tabular}

Tabela 10- Resultados para estimativa do tamanho de trincas que param de crescer AISI $1034, \theta=30^{\circ}$

\begin{tabular}{cccccc}
\hline$Q_{\text {max }}(N / m m)$ & $b_{\text {exp }}(\mu m)$ & $b_{\gamma \rightarrow \infty, 30^{\circ}}(\mu m)$ & $b_{\gamma=2,30^{\circ}}(\mu m)$ & $\frac{b_{\text {exp }}-b_{\gamma \rightarrow \infty, 30^{\circ}}}{b_{\text {exp }}} \%$ & $\frac{b_{\text {exp }}-b_{\gamma=2,30^{\circ}}}{b_{\text {exp }}} \%$ \\
\hline 126 & 24 & 37 & 45 & 55 & 88 \\
137 & 29 & 44 & 56 & 53 & 92 \\
144 & 31 & 49 & 63 & 59 & 104 \\
146 & 52 & 51 & 66 & -2 & 26 \\
151 & 55 & 55 & 72 & -1 & 30 \\
164 & 65 & 65 & 91 & 0 & 40 \\
169 & 68 & 70 & 100 & 3 & 48 \\
\hline
\end{tabular}

Considerando os resultados para o aço AISI 1034 apresentados nas Tab. 9 e 10 verifica-se que quando trincas apenas em modo I são consideradas, o comprimento final da trinca estimado é ligeiramente maior do que quando comparado com trincas inclinadas. Isto se dá pois, o fator de intensidade de tensão modo I, em uma trinca perpendicular nas condições de carregamento em estudo, 
é ligeiramente maior que o fator de intensidade de tensão efetivo (dado pela combinação dos modos I e II) em trincas inclinadas. Observa-se também que considerar um $\gamma \rightarrow \infty$ para a curva de limiar de propagação de trincas curtas produz melhores resultados tanto para o caso de trincas apenas em modo I quanto para trincas em modo misto (inclinadas $30^{\circ}$ ), Fig. 45.

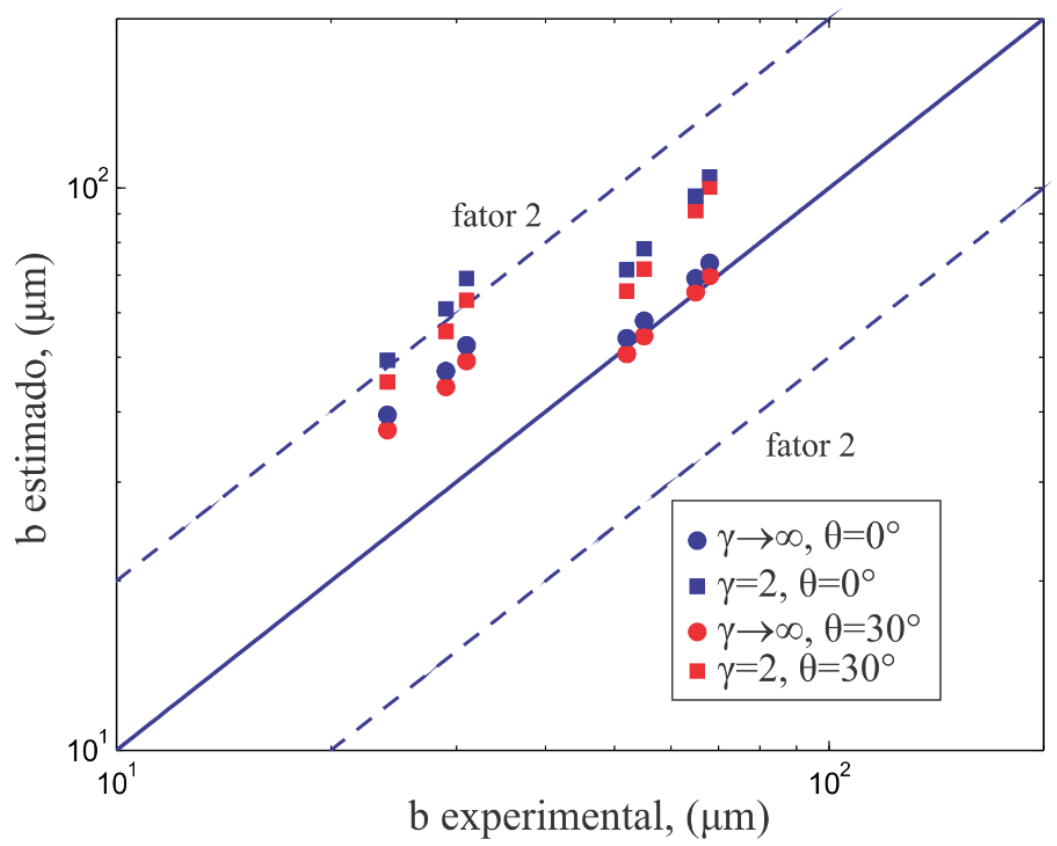

Figura 45- Comparação entre o comprimento final de trincas que param de crescer com a observação experimental (AISI 1034)

Note que os resultados mostrados na Fig. 45 revelam que para trincas menores os erros nas estimativas do comprimento das trincas não propagantes são maiores. Isso pode ocorrer pois nesses casos (trincas menores), a magnitude do campo de tensão ainda é muito alta devido a influência das tensões de contato, o que pode provocar certos níveis de plasticidade, violando as condições de escoamento em pequena escala sobre as quais se apoiam a mecânica da fratura linear elástica.

Resumindo os resultados dessa primeira etapa verificou-se que considerar uma trinca se propagando de forma perpendicular à superfície de contato apenas em modo I se mostrou eficaz na descrição do fenômeno de parada de trincas, uma vez que essa metodologia quando associada a curva limiar adequada (fator de ajuste $\gamma$ ) foi capaz de capturar a severidade do gradiente de tensão nas proximidades do contato.

Pôde-se também notar que, não é possível estabelecer uma curva universal para descrever o limiar de propagação de trincas curtas, sendo que, o que pode funcionar melhor para um determinado material, pode levar a erros consideráveis em outros. Neste trabalho bons resultados foram obtidos com curvas clássicas como o diagrama K-T $(\gamma \rightarrow \infty)$ para as ligas de aço e de Al, enquanto que, a curva de ElHaddad $(\gamma=2)$ forneceu melhores estimativas para a liga de Ti. Entretanto, um valor intermediário de $\gamma$ pode ser mais adequado para outros materiais, o que sugere que para análises mais precisas esse parâmetro deve ser levantado previamente. 


\subsection{ESTIMATIVA DA DIREÇÃO DE INICIAÇÃO DE TRINCAS}

Para conduzir essa análise serão utilizados apenas os dados para as ligas de aço, uma vez que apenas nesses casos informação necessárias quanto ao perfil de propagação das trincas estão disponíveis. Os dois modelos apresentados no capítulo 5 para estimar direção de iniciação de trincas, método da direção crítica e o modelo de plano crítico serão avaliados para os corpos de prova em aço AISI 1034 e em aço $35 \mathrm{NCD} 16$.

\subsubsection{AÇO AISI 1034}

Nesse caso, temos um comprimento característico do material dado por $53 \mu \mathrm{m}$, Eq. (5.11). Os resultados para o método da direção crítica são mostrados na Fig. 46 para uma das condições de carregamento para o aço AISI 1034 (P=227 N/mm e $\left.\mathrm{Q}_{\max }=169 \mathrm{~N} / \mathrm{mm}\right)$.

Como pode ser visto, o ângulo estimado utilizando $\Delta \sigma_{n, \text { eff }}$ (somente valores positivos de tensão normal sendo considerados) é muito menor que o observado experimentalmente ( $\left.30^{\circ}\right)$, enquanto que $\max \left(\Delta \sigma_{n}\right)$ e $\min (\Delta \tau)$ forneceram resultados semelhantes. A faixa de ângulos investigados foi limitada entre $\pm 60^{\circ}$, pelo fato de que (i) não faz sentido fisicamente assumir ângulos de propagação tão rasos e (ii) isso reduz o custo computacional.

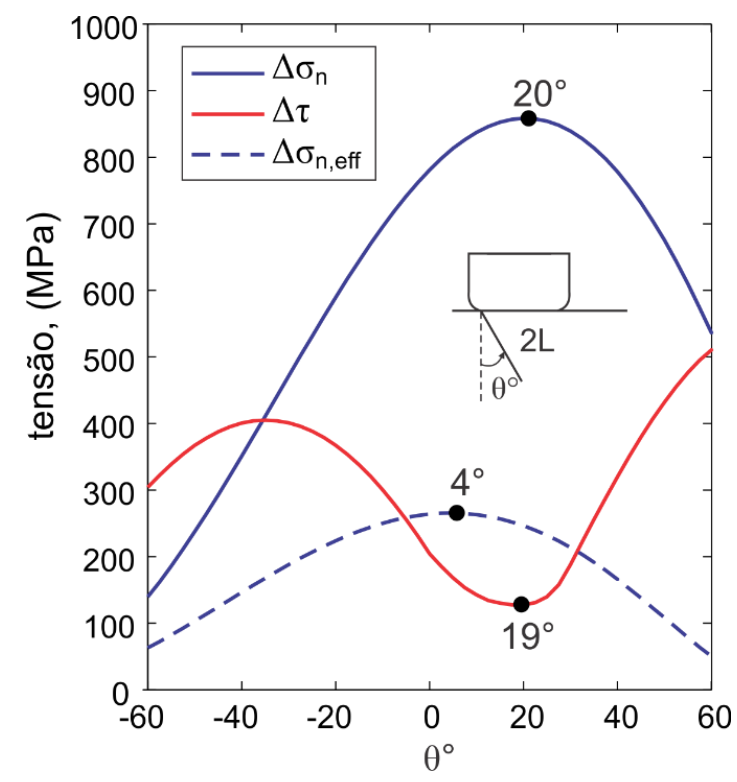

Figura 46- O método da direção crítica aplicada ao aço AISI 1034,

Considerando a complexidade do estado de tensão e da dispersão envolvida no cálculo de parâmetros como L, o método da direção crítica baseado em $\max \left(\Delta \sigma_{n}\right)$ e $\min (\Delta \tau)$ forneceu resultados razoáveis. Entretanto, deve-se notar que o critério baseado em $\Delta \sigma_{n}$ é inconsistente, uma vez que cargas compressivas (cargas persistentes em carregamentos de fretting) não contribuem com a propagação de trincas. 
A Figura 47 ilustra o resultado obtido utilizando o modelo de plano crítico aplicado no centro da zona de processo (L/2) para uma das condições de carregamento do aço AISI 1034 (P=227 N/mm e $\mathrm{Q}_{\max }=169 \mathrm{~N} / \mathrm{mm}$ ). Note que a máxima amplitude de tensão cisalhante é alcançada em dois planos mutualmente ortogonais $\left(-31^{\circ}\right.$ e $\left.59^{\circ}\right)$, mas o plano crítico é o plano a $-31^{\circ}$ uma vez que este experimenta a máxima tensão normal ao longo de um ciclo. Portanto, fica claro que a direção de propagação estimada por esse modelo é oposta a direção de propagação observada em laboratório. Essa discrepância também foi observada por (Susmel e Taylor, 2007) em componentes entalhados submetidos a carregamentos em modo misto.

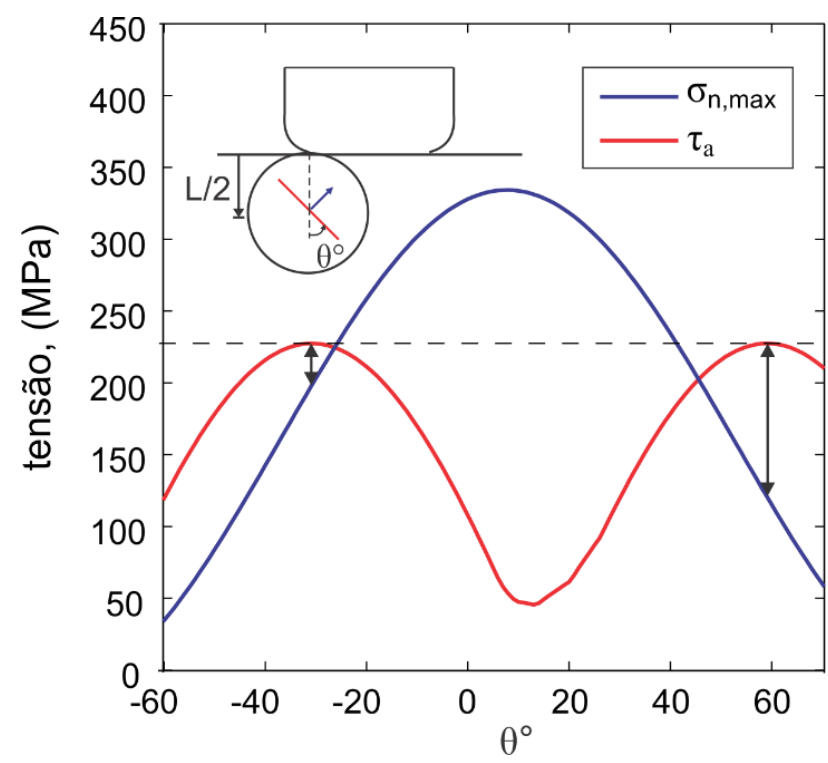

Figura 47- O modelo de plano crítico aplicado no centro da zona de processo para o aço AISI 1034

\subsubsection{AÇO 35NCD16}

Infelizmente, o limiar do fator de intensidade de tensão para trincas longas, $\Delta K_{0}$, não está disponível para o aço 35NCD16, sendo assim, uma estimativa baseada no trabalho de Susmel et al. (2005) foi feita, onde o comprimento característico do material é dador por:

$$
L=\left(\frac{36200}{\sigma_{u t} \Delta \sigma_{-1}}\right)^{1.17}
$$

onde L é dado em mm, $\Delta \sigma_{-1}$ e $\sigma_{u t}$ em MPa. Essa equação empírica possui uma correlação de 0.791, dentro de uma vasta faixa de aços e ferros fundidos. Os resultados para estimativa do ângulo de iniciação de trincas via método da direção crítica e via modelo de plano crítico são mostrados na Fig. 48 e na Tab. 11. Os resultados para o aço AISI 1034 também estão incluídos na Tab. 11 como uma média dos resultados para as várias condições de carregamento testadas com esse material.

Nota-se que a Figura 48 (b) e a Tab. 11 reforçam o resultado anterior que nesse tipo de carregamento o modelo de plano crítico conduz a severos erros na estimativa na direção de iniciação de trincas. 
Considerando $\max \left(\Delta \sigma_{n}\right)$ uma melhor resposta foi obtida novamente, entretanto, como já explicado essa grandeza leva a violação de princípios básicos da mecânica da fratura linear elástica (trincas não devem se propagar enquanto estão fechadas). Portanto, considerando esses aspectos e os resultado obtidos para ambos os materiais, o critério escolhido para prever a direção de iniciação de trincas nesse trabalho de agora em diante será o método da distância crítica associada com a mínima faixa de tensão cisalhante.

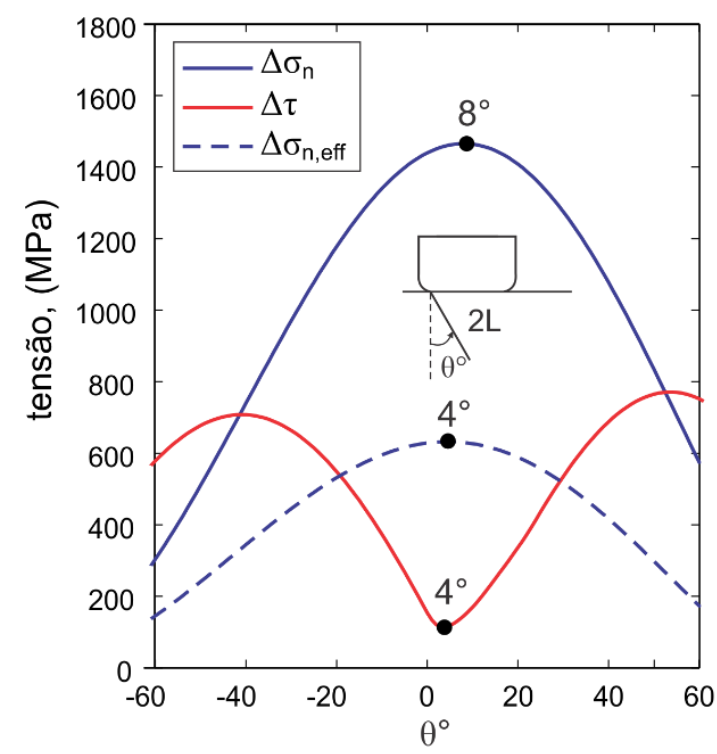

(a)

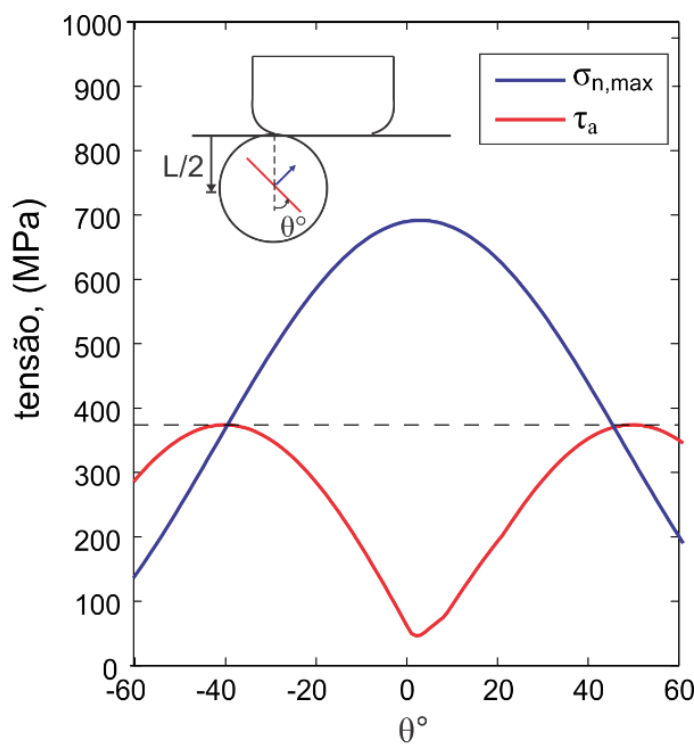

(b)

Figura 48- Resultados para a direção de iniciação de trincas para o aço 35NCD16 (a) método da direção crítica; (b) modelo de plano crítico no centro da zona de processo.

Tabela 11- Resultados para iniciação de trincas.

\begin{tabular}{ccccc}
\hline Material & $\max \left(\Delta \sigma_{n}\right)$ & $\max \left(\Delta \sigma_{n, \text { eff }}\right)$ & $\min (\Delta \tau)$ & Plano crítico \\
\hline AISI 1034 & $20.7^{\circ} \pm 0.5$ & $2.1^{\circ} \pm 1.8$ & $20.7^{\circ} \pm 1.5$ & $-30.0^{\circ} \pm 0.8$ \\
35NCD16 & $8^{\circ}$ & $4^{\circ}$ & $4^{\circ}$ & $-40^{\circ}$ \\
\hline
\end{tabular}

\subsection{CAMINHO DE PROPAGAÇÃO EM CONDIÇOES DE FRETTING}

Duas metodologias distintas apresentadas no capítulo 5 foram utilizadas com o intuito de estimar o caminho de propagação de trincas em condições de fretting $\left(\max \left(\Delta k_{1}\right)\right.$ e $\left.\min (\Delta \tau)\right)$. Os resultados obtidos foram confrontados com os dados experimentais para o aço 35NCD16. No caso do aço AISI 1034 os testes foram conduzidos em regime de trincas curtas, sendo assim, esses dados não serão utilizados para prever o caminho de propagação de trincas. Nessa etapa da análise interações de contato entre as faces da trinca foram consideradas de forma a reproduzir com maior fidelidade o que ocorre no problema real, sendo assim, a análise para estimar cominho e propagação de trincas foi realizada via elementos finitos. 


\subsubsection{MODELAGEM DO PROBLEMA VIA ELEMENTOS FINITOS}

Para a modelagem do problema de fretting em estudo, um modelo 2D em estado plano de deformação foi construído no software comercial Abaqus (ver tutorial no CD-ROM em anexo). O modelo é composto de um cilindro pressionado contra um plano fixo devido à aplicação de um carga normal estática $\mathrm{P}$, seguida da aplicação de uma carga tangencial variável $\mathrm{Q}(\mathrm{t})$ para produzir a condição de escorregamento parcial, Fig. 49 e 50.

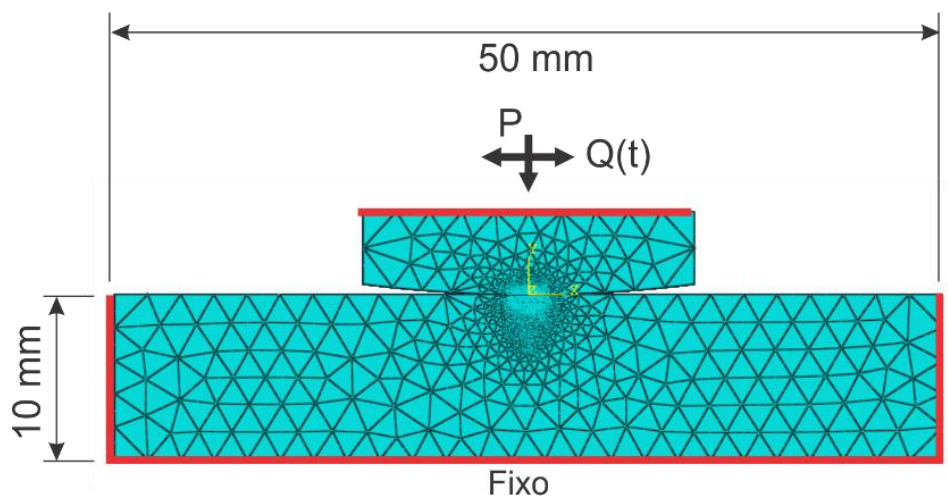

(a)

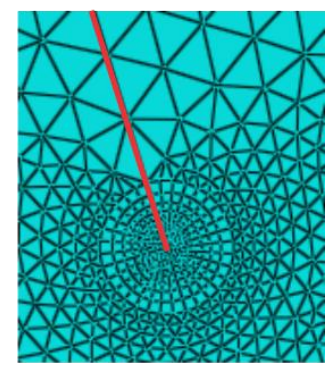

(b)

Figura 49- Modelagem do problema de fretting em um corpo de prova trincado

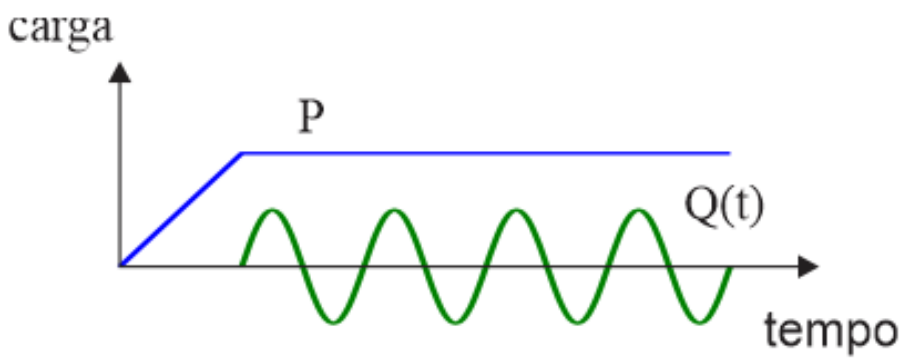

Figura 50- Histórico de carregamento

As interações de contato foram descritas através de multiplicadores de Lagrange com coeficiente de atrito $f$. Devido as características do problema em estudo (escorregamento parcial) a formulação nósegmento (identificação das zonas em contato) foi utilizada na solução do problema de escorregamento fornecendo uma boa relação entre precisão e custo computacional. A malha na região próxima a ponta da trinca foi refinada com elementos quadrilaterais da ordem de $0.5 \mu \mathrm{m}$ em um domínio circular de 5 $\mu m$, Fig. 49 (b). Na zona de contato a malha é composta por elementos triangulares inferiores a $20 \mu \mathrm{m}$ (aproximadamente 100 elementos nessa região). O coeficiente de atrito entre as faces da trinca foi assumido ser o mesmo que ocorre nas zonas de escorregamento para o contato cilindro no plano. $\mathrm{O}$ fator intensidade de tensão foi obtido através de integrais de contorno (rotina Abaqus). O grau de refinamento da malha e o tipo de interação de contato utilizado é proveniente de uma busca por baixo custo computacional e uma boa precisão através de uma análise de convergência.

Na Figura 51, para uma dada condição geométrica e de carregamento, os campos de tensão normal e cisalhante obtidos numericamente são comparados com o campo de tensão superficial analítico do 
problema de fretting. Para a distribuição de pressão normal, o erro obtido na solução numérica para a pressão de pico é de aproximadamente $0.25 \%$ em relação a solução analítica.

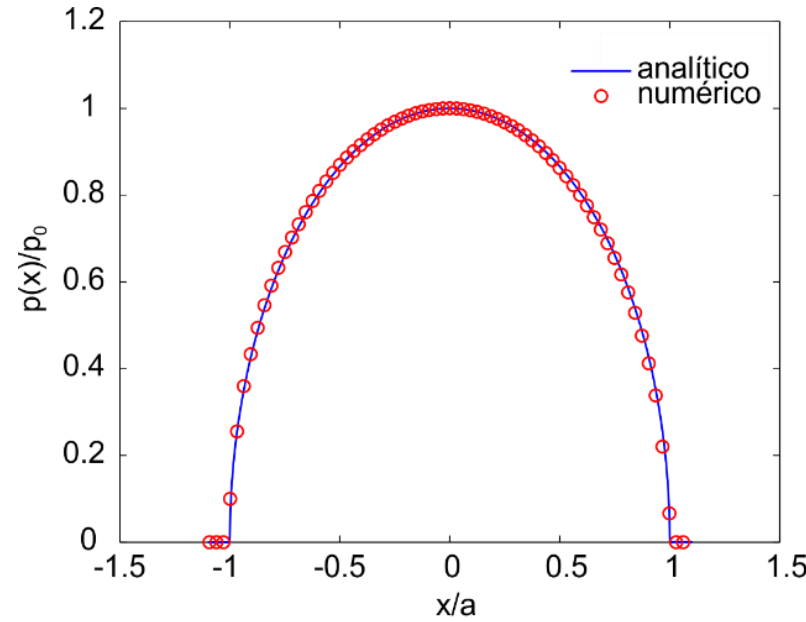

(a)

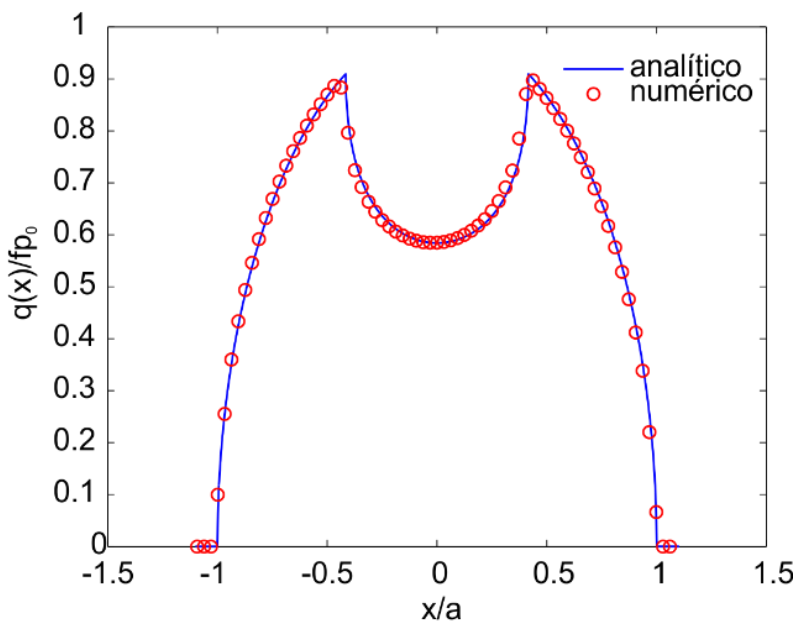

(b)

Figura 51- Distribuição das tensões superficiais em um corpo onde não há presença de trincas (a) pressão normal; (b) tensão cisalhante

Já para verificar a precisão no cálculo do fator de intensidade de tensão via elementos finitos, os fatores de intensidade de tensão modo I para diversos comprimentos de trinca foram comparados com a solução via método da distribuição das discordâncias, Fig. 52.

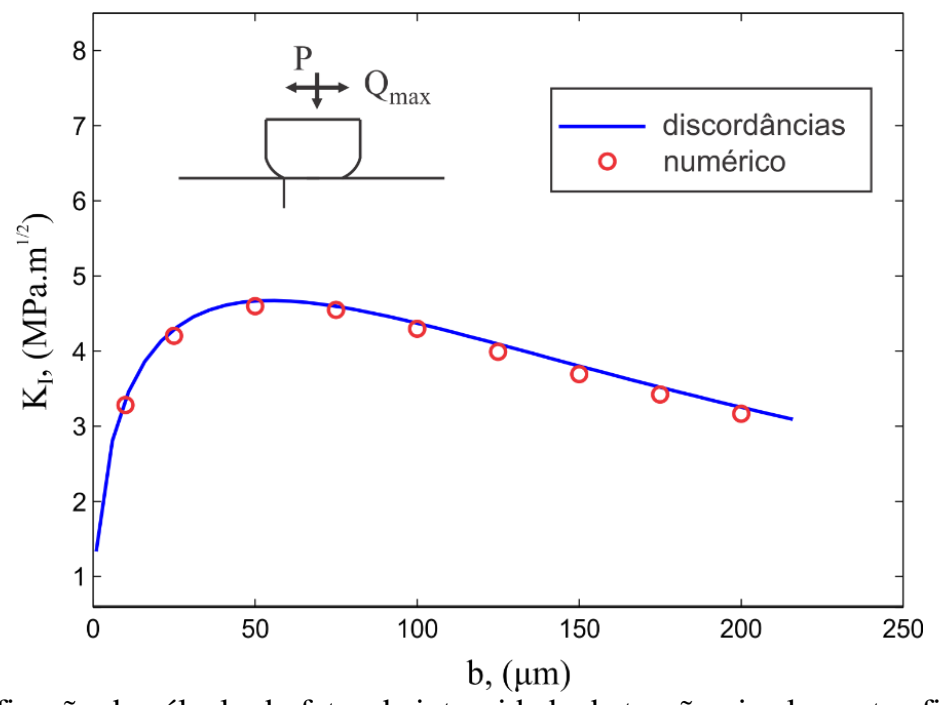

Figura 52- Verificação do cálculo do fator de intensidade de tensão via elementos finitos $Q(t)=Q_{\max }$

\subsubsection{RESULTADOS PARA O CAMINHO DE PROPAGAÇÃO}

Como descrito anteriormente, o caminho de propagação de trincas será avaliado apenas para o aço $35 \mathrm{NCD} 16$ devido ao fato de que apenas nesse caso os dados experimentais serem suficientes. Partindo do ângulo inicial estimado, simulações foram realizadas com incrementos de trinca, $\Delta \mathrm{b}$, onde em cada passo da propagação os fatores de intensidade de tensão modos I e II ao longo de um ciclo de carregamento assim como o campo de tensão nas proximidades da ponta da trinca foram extraídos. 
A direção de propagação da trinca em cada passo foi definida fazendo-se o uso de duas teorias diferentes baseadas no $\max \left(\Delta k_{1}(\theta)\right)$ de uma trinca infinitesimal com origem na trinca já preexistente ou procurando pelo plano material que minimize a faixa de tensão cisalhante, $\min (\Delta \tau)$, nas proximidades da ponta da trinca. O primeiro passo para se aplicar essas metodologias é definir uma trinca inicial (direção e comprimento) no corpo de prova. Nesse caso, foi assumido que a trinca inicial tem um comprimento inicial igual ao incremento $\Delta \mathrm{b}$, nesse caso $70 \mu \mathrm{m}$, e sua direção de propagação é dada pelo método da direção crítica em temos de $\min (\Delta \tau)$, i.e. $4^{\circ}$. A Figura 53 mostra o resultado da simulação considerando ambos os critérios. Como mostrado em Giner et al. (2014) o incremento de trinca não exerce grande influência em aspectos globais, sendo assim, um incremento relativamente grande foi utilizado para simplificar a análise.

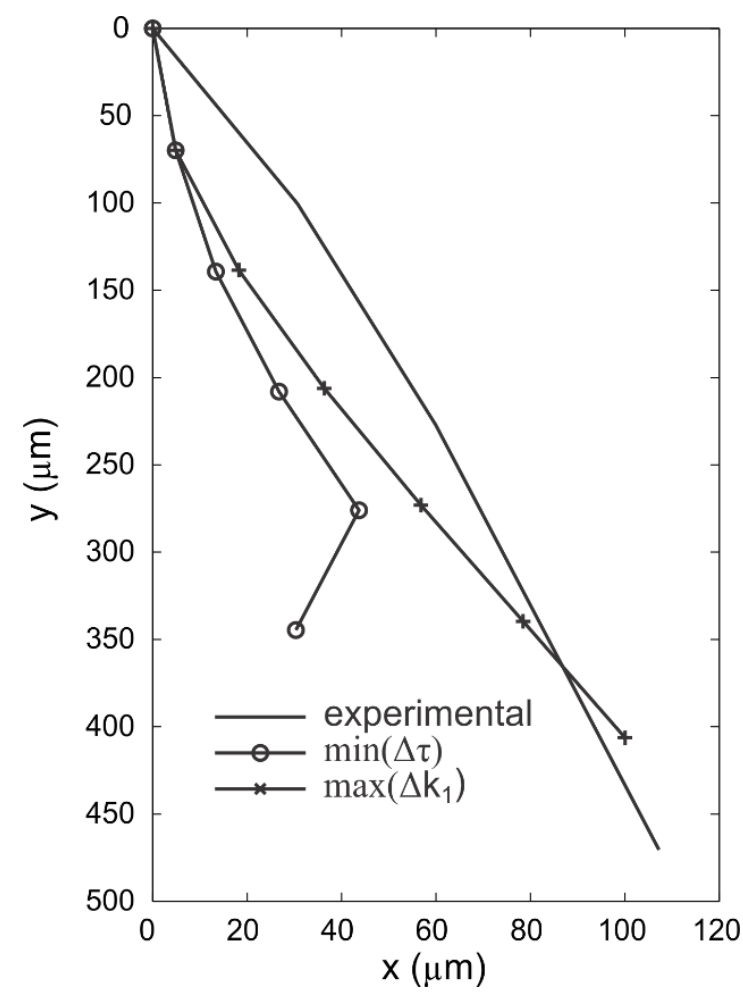

Figura 53- Estimativa do caminho de propagação em trincas em condições de fretting puro

Note que embora o ângulo de propagação inicial estimado tenha sido $4^{\circ}$ enquanto a observação experimental foi de $17^{\circ}$, o caminho de propagação obtido via $\max \left(\Delta k_{1}\right)$ se aproxima do experimental quando a trinca se tonar maior. Já o critério baseado em $\min (\Delta \tau)$ levou a resultados que destoam da observação experimental à medida que a trinca se torna se propaga. 


\section{CONCLUSÃO}

Neste trabalho uma metodologia mais genérica para avaliar o fenômeno de parada de trincas curtas em condições de fretting foi proposta. Para tal fez-se o uso de uma curva mais geral para descrever o limiar de propagação de trincas curtas, curva de Bazant, onde foi possível notar que curvas clássicas como o diagrama de Kitagawa-Takahashi e a curva de El-Haddad funcionam bem dependendo do material em estudo. Para os ensaios de fretting em ligas de aço (AISI 1034) e de alumino (Al4\%Cu) o digrama K-T $(\gamma \rightarrow \infty)$ funcionou melhor na análise de parada de trincas curtas, conseguindo prever com uma boa precisão o comprimento final de trincas curtas que param de crescer e as condições de carregamento que causariam ou não falha nos ensaios analisados, respectivamente. Já para a liga de titânio (Ti-6Al-4V), a curva de El-Haddad $(\gamma=2)$ descreveu melhor a resposta dos ensaios. Vale ressaltar que um valor intermediário de $\gamma$ pode ser mais adequado para outros materiais, o que sugere que para análises mais precisas esse parâmetro deve ser levantado previamente. Verificou-se também que modelar o problema considerando a hipótese de uma trinca propagando-se perpendicularmente à superfície de contato, apenas em modo I, é um boa aproximação. Comparando-se estes resultados com os obtidos pela modelagem de uma trinca inclinada se propagando em modo misto obteve-se resultados ligeiramente mais conservadores para a estimativa do comprimento de trincas não propagantes.

Em uma segunda análise, dois modelos baseados na teoria das distâncias críticas foram utilizados na tentativa de estimar a direção de iniciação de trincas em condições de fretting. O método da direção crítica associada com os planos de menor faixa de tensão cisalhante foi capaz de estimar com uma certa precisão a direção preferencial de iniciação da trincas, enquanto que o modelo baseado em plano crítico levou a resultados totalmente destoantes das observações experimentais tanto para o aço AISI 1034 quanto para o aço 35NCD16. Em uma análise posterior, estimada a direção de iniciação da trinca para uma determinada condição de carregamento e geometria (aço 35NCD16), dois modelos foram aplicados para estimar o caminho de propagação de trincas em condições de fretting, um deles baseado na mínima faixa de tensão cisalhante na ponta da trinca, $\min (\Delta \tau)$, e outro baseado no fator intensidade de tensão modo I de uma trinca infinitesimal emergindo de uma trinca já preexistente, $\max \left(\Delta k_{1}\right)$. Nessa etapa uma modelagem via método dos elementos finitos foi realizada, onde levou-se em consideração as interações de contato entre as faces da trinca. O modelo baseado em $\max \left(\Delta k_{1}\right)$ foi capaz de gerar bons resultados, mesmo partindo de uma estimativa para a direção de iniciação da trinca não muito precisa. Já o modelo baseado na mínima faixa de tensão cisalhante na ponta da trinca, $\min (\Delta \tau)$, levou a erros consideráveis à medida que a trinca se tornou maior.

Um dos maiores desafios neste trabalho, e que merece bastante atenção em trabalhos futuros, é o aprimoramento e a proposição de novas metodologias para estimar a direção de iniciação de trincas. Trabalhos nessa área podem ajudar a compreender melhor as propriedades materiais e as características de carregamento que governam o processo de fadiga por fretting. 


\section{REFERENCIAS BIBLIOGRAFICAS}

Amestoy, M., Bui H-D., Dang Van K., Déviation infinités d'une fissure dans une direction arbitraire. CR Acad Sci Paris 1979:289B:99-102.

Araújo, J.A., Nowell, D., "Analysis of pad size effects in fretting fatigue using a short crack arrest methodology. Int J Fatigue, 1999:21:947-56

Araújo, J. A., "On the initiation and arrest of Fretting Fatigue Cracks". 2000. 231 f. These (D.Phil thesis), Oxford University, Oxford.

Araújo, J.A., Nowell D., Vivacqua, R.C., The use of multiaxial fatigue models to predict fretting life of components subjected to different contact stress fields. Fatigue FRACT Eng Mater Struct 2004;27:96-78.

Atzori, B., Lazzarin, P., Tovo, R., "Evaluation of the fatigue strength of a deep drawing steel". Österreichische Ingenieur-und Architekten-Zeitschrift (ÖIAZ) 137, 11/92, p. 556-561, 1992.

Baietto, M.C., Pierres, E., Gravouil, A., Berthel, B., Fouvry, S., Trolle, B., " Fretting fatigue simulation based on a combined experimental and XFEM strategy", Int J Fatigue, 2013:47:3143.

Basquin, O.H., 1910. "The exponential law of endurance tests. Proc. ASTM 10, 625-630.

Bazant, Z.P., "Scalling of quasibrittle fracture: asymptotic analysis". Int J Fract 1997;83:19-40.

Beard, J. "Palliatives for fretting fatigue. In: Waterhouse RB, Lindley TC, editors. Fretting fatigue, ESIS 18”. 2004. London: M.E.P; p. 419-36.

Bin Li, Santos, J. L. T., Freitas, M., 2000, “A Unified Numerical Approach for Multiaxial Fatigue Limit Evaluation", Mech. Struc. \& Mach., 28 (1), pp. 85-103.

Bramhall, R., "Studies in fretting fatigue". 1973. 241 f. Tese (D. Phil. Thesis), Oxford University, Oxford.

Bueckner, H.F., "The propagation of crack and the energy of elastic deformation. Trans ASME 1958;80:1225-30.

Crossland, B., "Effect of large hydroscopic pressures on the torsional fatigue fatigue strength of an alloy steel”, 1956, In Proc. International Conference on Fatigue of Metals, Proc. Inst. Mech., London, pp. 138-149.

Dang Van, K., Griveau, B., Message, O., 1989, "On a New Fatigue Limit Criterion : Theory and Applications, Biaxial and Multiaxial Fatigue", EGF 3 (Edited by M.W. Brown and K. J. Miller), Mechanical Engineering Publications, London, pp. 479-496

Deperrois, A., 1991, "Sur le calcul de limites d'endurance des aciers", Thèse de Doctorat, Ecole Polytechnique, Paris.

Dini, D., "Studies in fretting fatigue with particular application to almost complete contacts". 2004 (D.Phil thesis), Oxford University.

Dini, D., Nowell, D., Dyson, I.N., "The use of notch and short crack approaches to fretting fatigue threshold prediction: Theory and experimental validation". Tribology 2006; 39:1158-1165.

Dubourg M.C., Lamacq V., "Stage II crack propagation direction determination under fretting fatigue loading: a new approach in accordance with experimental observations". In: Hoeppner DW, et al., editors. Fretting fatigue: current technology and practices, ASTM STP 1367, West Conshohocken; 2000. p. 436-50.

Dundurs, J., Mura, T., Interactions Between an Edge Dislocation and a Circular Inclusion, Jnl. Mech. Phys., 1964, 36;3353-3354.

Dundurs, J., Sendeckyj, G.P., "Behaviour of an edge dislocation near a bimetallic interface, Jnl. Mech. Phys. Solids, 1965, 12:177-189.

Eden, E. M., Rose, W.N., Cunningham, F.L. "The endurance of metals". 1911. ProcI Mech E; 4:139.

El Haddad, M. H., Topper, T. H., \& Smith, K. N., 1979, "Fatigue crack propagation of short cracks", F. Engng Mater. Tech. (ASME Trans.), 101, pp. 42-45.

Erdogan F, Sih GC. "On the crack extension in plates under plane loading transverse shear". J Basic Eng 1963:85:519-27.

Fatemi, A., Socie, D.F., 1988, “Acritical Plane Approach to Multiaxial Fatigue Damage Including Out of Phase Loading”, Fatigue Fracture of Engineering Materials and Structures 11, pp. 149-165. 
Fouvry, S., Nowell, D., Nubiak, K., Hills, D.A., "Prediction of fretting crack propagation based on a short crack methodology". Engineering Fracture Mechanics 75 (2008) pp. 1605-1622.

Gerber, W.Z., 1985, "Bestimmung der zulässigen Spannungen in Eisen-Constructionen", Z Bayer Archit Ing Ver, 6(6):1001-10.

Giannakopoulos, A. E., Lindley, T.C., Suresh, S. "Similarities of stress concentration in contact at round punches and fatigue at notches: implication to fretting fatigue crack initiation". 2000. Fatigue and Fracture of Engineering Materials and Structures, 23/2000, pp 561-571.

Giner, E., Sabsabi, M., Ródeans, J, Fuenmayor, J.F., "Direction of crack propagation in a complete contact fretting-fatigue". Int J Fatigue 2014; 58:172-180.

Goodman, J., 1899, "Mechanics applied in engineering". 1st ed. London: Longmans, Green and Co.

Gough, H.J., Pollard, H.V., 1935, "The strength of metals under combined alternating stresses", Proc. Inst. Mech.

Hertz, H. “Über die Berührung fester elastischer Körper". 1882. Jn1 Reine und angewandte Mathematik, 92, pp. 156-171.

Hills, D. A., Nowell, D., Sackfield, A. 1993, "Mechanics of Elastic Contacts”, Butterworth-Heinemann, Oxford.

Hills, D. A., \& Nowell, D., 1994, "Mechanical of Fretting Fatigue, Solid Mechanics and its aplications", Kluver Academic Publishers.

Kitagawa, H., \& Takahashi, S., 1976, "Applicability of fracture mechanics to very small cracks or the crack in early stages", Proceedings of Second International Conference on Mechanical Behavior of Material, pp. 627-31.

Kitagawa, H., \& Tanaka, T., 1990, "Fatigue 90”, Birmingham: Material and Components Engineering Publications.

Krenk, S., 1975 "On the use of the interpolation polynomial for solution of singular integral equation,. Q. Appl. Maths., 32, 479-484.

Lankford, J., 1982, "The growth of small fatigue cracks in 7075-T6 aluminum", Fatigue Engng Master and Struct, 5, pp. 233-248.

Lankford, J., \& Ritchie, R. O., 1986, "Small fatigue cracks", Warrendale: The Metallurgical Society of the American Institute of Mining, Metallurgical and Petroleum Engng.

Lazzarin, P., Tovo, R., Meneghetti, G. "Fatigue crack initiation and propagation phases near notches in metals with low notch sensitivity". International Journal of Fatigue 19, p. 647-657.

Livieri, P., Tovo, R., "Fatigue limit evaluation of notches, small cracks and defects: an engineering approach. Fatigue Fract Eng Mater Struct 2004;27:1037-49.

Mamiya, E.N., Araújo, J.A., 2009, Castro, E.C., "Prismatic hull: A new measure of shear stress amplitude in multiaxial hight cycle fatigue. Int J Fat. Vol 31 pp. 1144-1153.

Mamiya, E.N., Araújo, J.A., 2002, "Fatigue limit under multiaxial loading: on the definition of the equivalent shear stress", Mechanics Research Communications, 29, pp. 141-151.

Matake, T., "An explanation on fatigue limit under combined stress" Bull., 1977, JSME, 20, pp. 257.

McDiarmid, D. L., 1991, "Mean stress effect in biaxial fatigue where the stresses are out of phase and at different frequencies", In: Fatigue under Biaxial/Multiaxial loading. ESIS 10.

Mcdowell, J. R., 1953, "Fretting Corrosion Tendencies of Several Combinations of Materials", Symposium on Fretting Corrsion, ASTM STP 144, Philadelphia, pp. 24-39.

Miller, R. J., \& De Los Rios, E. R., 1986, "The behavior of short fatigue cracks". Mechanical Engng Publ., London.

Muskhelishvili, N. I., 1953, "Some basic problems of Mathematical theory of elasticity", Noordhoff, Gröningen, 36, pp. 99-107.

Nishihara, T., Kawamoto, M., 1945, "The strength of metals under combined alternating bending and twisting", Memoirs, College of Eng, Kyoto Imperial University, Japan, Vol.10, pp. 177-201

Nishioka, K., Hirakawa, K., 1969a, "Fundamental investigations of fretting fatigue (part.2) - Fretting fatigue test machine and some results", Bull, JSME, Vol. 12, No, 50, pp. 180-187.

Nishioka, K., Hirakawa, K., 1969b, "Fundamental investigations of fretting fatigue (part.3) -Some phenomena and mechanics of surface cracks", Bull, JSME, Vol. 12, No, 51, pp. 397-407.

Nishioka, K., Hirakawa, K., 1969c, "Fundamental investigations of fretting fatigue (part.4) -The effect of mean stress", Bull, JSME, Vol. 12, No, 52, pp. 408-414. 
Nishioka, K., Hirakawa, K., 1969d, "Fundamental investigations of fretting fatigue (part.5) -The effect of relative slip amplitude", Bull, JSME, Vol. 12, No, 52, pp. 692-697.

Nishioka, K., Hirakawa, K., 1972, "Fundamental investigations of fretting fatigue (part.6) ", Bull, JSME, Vol. 15, No, 80, pp. 135-144

Nowell, D., 1988, “An analysis of fretting fatigue", D. Phil. Thesis, Oxford University.

Palaniswamy K, Knauss WG. Propagation of a crack under general, in-plane tension. In J Fract 1972:8(1):114-7.

Paris, P.C., Gomes, M.O., Anderson, W.P., 1961, "A rational analytic theory of fatigue". The trend on engineering, 13, pp. 9-14

Peterson, R.E., 1959, "Notch sensitivy”, Metal Fatigue, McGraw-Hill, New York, pp. 293-306.

Ribeaucourt R, Baietto-Dubourg MC, Gravouil A. "A new fatigue frictional contact crack propagation model with the coupled X-FEM/LATIN method". Comput Methods Appl Mech Eng 2007;196:3230-47.

Rice, J.R., Rosengren, G.F., "Plane Strain Deformation Near a Crat Tip in a Pwer Law Hardening Material", Journal of the Mechanics and Physics, vol. 16, pp. 1-12, 1968.

Shepard, S.D., 1991, "Field effects in fatigue crack initiation: Long life fatigue strength",Trans ASME 1991, 113, pp 188-94.

Sih GC. Strain-energy-density factor applied to mixed mode crack problems. Int J Fract 1972:10(3): $305-21$.

Sines, G., 1955, "Failure of materials under repeated stress with superimposed static stress", NACA tech, Note 3495.

Smith, R. A., Liu, Y., \& Grabowski, L., 1996, "Short fatigue crack growth behavior in Waspaloy at room and elevated temperatures", Engng. Mater. Struct., Vol. 19 No. 12, pp. 1505-1514.

Socie, D., 1987, "Multiaxial Fatigue Damage Models", Journal of Engineering Materials Technology, Vol. 109, pp. 293-298.

Soderberg, C.R., 1939, "Factor of Safety and Working Stress", Trans., American Society of Mechanical Engineers, 52, pp. 13-28.

Susmel, L., Taylor, D., 2002, "A bi parametric Wöhler curve for high cycle multiaxial fatigue assessment". Fatigue Fract. Engng. Mater. Struct. 25, 63-78.

Susmel, L., Taylor, D., "Fatigue design in the presence of stress concentrations". International Journal of Strain Analysis for Engineering Components, (2003), 38(5):443-452

Susmel L, Taylor D., "Can the conventional high-Cycle multiaxial fatigue criteria be re-interpreted in terms of the theory of critical distances": SDHM 2006:2:91-180.

Susmel. L, Taylor. D. Non-propagating cracks and high-cycle fatigue failures in sharply notched specimens under in phase Mode I and II loading. Eng F Analysis 2007:14:861-76.

Susmel, L., 2009 "Multiaxial notch fatigue: From nominal to local stress/strain quantities. Woodhead Publishing Limited, UK.

Susmel, L., Atzori, B., Meneghetti, G., "Material Fatigue properties for assessing mechanical components weakened by notches and defects. Fatigue Fract Engng Mater Struct 2005;28:1-15.

Tanaka, K., Nakai, Y., Yamashita, M., "Fatigue growth threshold of small cracks. Int J Fract, 1981;17:519-33.

Tanaka, K., 1983, "Engineering formulae for fatigue strength reduction due to crack-like notches" International Jouranl of Fatigue 21, p.413-420.

Taylor, D., "The Theory of Critical Distancies, A New Perspective in Fracture Mechanics" Elsevier, First edition 2007.

Taylor, D.,1999, "Geometrical effects in fatigue: a unifying theoretical model". International Journal of Fatigue 21, p. 413-420.

Taylor, D., O’Donnell, M., 1994, "Notch geometry effects in fatigue: a conservative design approach". Engineering Failure Analysis; 1: 275-87

Taylor, D., Wang, G., "The validation of some methods of notch fatigue analysis". Fatigue and Fracture of Enginnering Materials and Structures, 2000, 23;397-394

Thomson, D. The national high cycle fatigue (HFC). 1998. Third Nat. Turbine Engine High Cycle Fatigue conference, Saint Antonio, Texas, CD-ROM proceedings, Streange, W. A. (Ed).

Warlow-Davis, F. J., 1941, "Fretting fatigue", Waterhouse, R. B. Editor, Applied Science Publishers, UK.

Wöhler, A., 1960. Versuche über die festiykeit eisenbahnwagenuchsen. Z. Bauwesen 10. 


\section{A.1 MíNIMO CÍRCULO CICUNSCRITO (DANG VAN)}

Seja $\Delta=\left\{S^{k}, k=1: m\right\} \subset \mathbb{R}^{2}$ um conjunto de $m$ pontos contidos em $\mathbb{R}^{2}$. O problema do menor círculo circunscrito consiste em encontrar o círculo de menor raio que envolva todos os pontos. Matematicamente, o problema do MCC é dado pela solução única do seguinte problema de otimização:

$$
\min _{A \in \mathbb{R}^{2}} \max _{k=1: m}\left\|S^{k}-A\right\|
$$

onde $A$ é o centro da circunferência. Vale lembrar que a equação acima pode ser estendido para problemas $\mathbb{R}^{n}$ (problema da hiperesfera).

Apresenta-se a seguir o procedimento iterativo proposto por Dang Van et al. (1989) para solução do problema da menor circunferência.

(i) Defina parâmetros de convergência: $\chi=0.05$, tol $=10^{-6}$

(ii) Inicialize o centro (centroide do conjunto de pontos) e o raio do círculo (valor muito pequeno):

$$
C=\frac{1}{m} \sum_{k=1}^{m} S^{k}
$$

$R=0.01$

(iii) Dados o centro $C^{k}$ e raio $R^{k}$ na iteração $k$, atualize esses valores segundo as regras a seguir:

$$
D=|| S_{k+1}-C^{k}||
$$

se $D>R^{k}$

$$
\begin{aligned}
& R_{k+1}=R_{k}+\chi\left(D-R_{k}\right) \\
& C^{k+1}=C^{k}+\frac{D-R_{k+1}}{D}\left(S^{k+1}-C^{k}\right)
\end{aligned}
$$

A etapa 3 deve ser repetida até que se alcance a convergência. Um possível critério de parada é dado pela Eq. (A.3):

$$
\left(R_{k}-R_{k-1}\right) / R_{k} \leq \text { tol }
$$

A interpretação geométrica do algoritmo de Dang Van é mostrada na Fig. 54. 


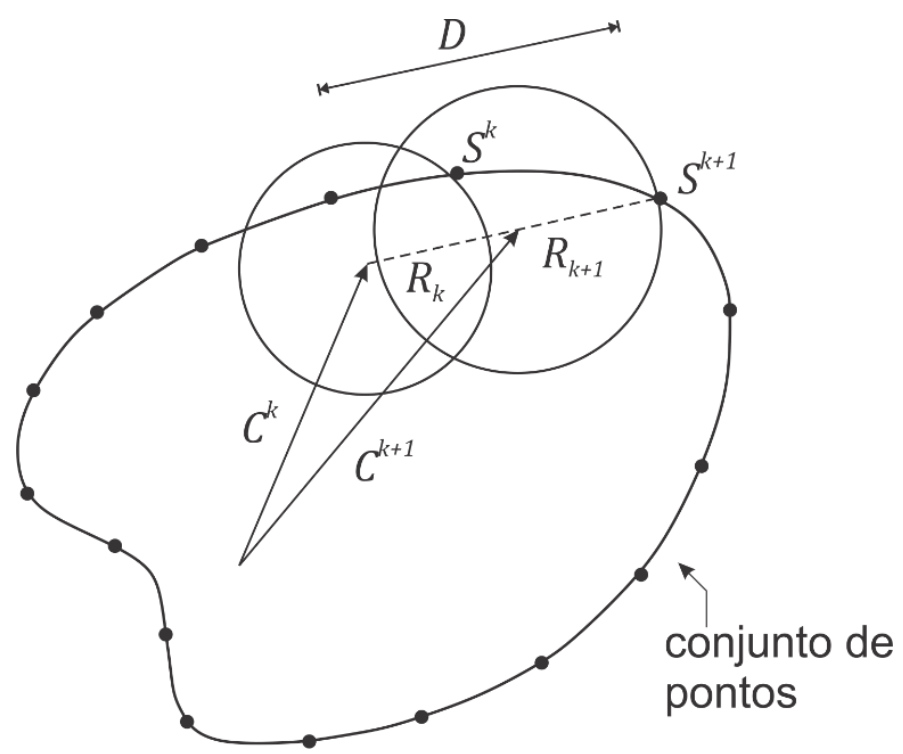

Figura 54- Interpretação geométrica algoritmo de Dang Van

\section{A.2 NÚCLEOS PARA UMA DISCORDÂNCIA EM UM SEMI-PLANO}

Como utilizado na Eq. (5.14):

$$
\begin{aligned}
& G_{x x x}=y\left\{-\frac{2}{r_{1}^{2}}-\frac{4(x-\xi)^{2}}{r_{1}^{4}}+\frac{2}{r_{2}^{2}}+\frac{4(x+\xi)^{2}}{r_{2}^{4}}-\frac{8 \xi(x+\xi)}{r_{2}^{4}}+\frac{32 \xi(x+\xi)^{3}}{r_{2}^{6}}+\frac{8 \xi^{2}}{r_{2}^{4}}-\frac{32 \xi^{2}(x+\xi)^{2}}{r_{2}^{6}}\right\} \\
& G_{x y y}=y\left\{-\frac{2}{r_{1}^{2}}-\frac{4(x-\xi)^{2}}{r_{1}^{4}}+\frac{2}{r_{2}^{2}}-\frac{4(x+\xi)^{2}}{r_{2}^{4}}+\frac{24 \xi(x+\xi)}{r_{2}^{4}}-\frac{32 \xi(x+\xi)^{3}}{r_{2}^{6}}-\frac{8 \xi^{2}}{r_{2}^{4}}\right. \\
& \left.+\frac{32 \xi^{2}(x+\xi)^{2}}{r_{2}^{6}}\right\} \\
& G_{x x y}=\left\{-\frac{2(x-\xi)}{r_{1}^{2}}+\frac{4(x-\xi)^{3}}{r_{1}^{4}}+\frac{2(x+\xi)}{r_{2}^{2}}-\frac{4(x+\xi)^{3}}{r_{2}^{4}}-\frac{4 \xi}{r_{2}^{2}}+\frac{32 \xi(x+\xi)^{2}}{r_{2}^{4}}-\frac{32 \xi(x+\xi)^{4}}{r_{2}^{6}}\right. \\
& \left.-\frac{24 \xi^{2}(x+\xi)}{r_{2}^{4}}+\frac{32 \xi^{2}(x+\xi)^{3}}{r_{2}^{6}}\right\} \\
& G_{y x x}=\left\{-\frac{2(x-\xi)}{r_{1}^{2}}+\frac{4(x-\xi)^{3}}{r_{1}^{4}}+\frac{2(x+\xi)}{r_{2}^{2}}-\frac{4(x+\xi)^{3}}{r_{2}^{4}}-\frac{4 \xi}{r_{2}^{2}}-\frac{16 \xi(x+\xi)^{2}}{r_{2}^{4}}+\frac{32 \xi(x+\xi)^{4}}{r_{2}^{6}}\right. \\
& \left.+\frac{24 \xi^{2}(x+\xi)}{r_{2}^{4}}-\frac{32 \xi^{2}(x+\xi)^{3}}{r_{2}^{6}}\right\} \\
& G_{y y y}=\left\{\frac{6(x-\xi)}{r_{1}^{2}}-\frac{4(x-\xi)^{3}}{r_{1}^{4}}-\frac{6(x-\xi)}{r_{2}^{2}}+\frac{4(x+\xi)^{3}}{r_{2}^{4}}-\frac{4 \xi}{r_{2}^{2}}+\frac{32 \xi(x+\xi)^{2}}{r_{2}^{4}}-\frac{32 \xi(x+\xi)^{4}}{r_{2}^{6}}\right. \\
& \left.-\frac{24 \xi^{2}(x+\xi)}{r_{2}^{4}}+\frac{32 \xi^{2}(x+\xi)^{3}}{r_{2}^{6}}\right\} \\
& G_{y x y}=y\left\{-\frac{2}{r_{1}^{2}}+\frac{4(x-\xi)^{2}}{r_{1}^{4}}+\frac{2}{r_{2}^{2}}-\frac{4(x+\xi)^{2}}{r_{2}^{4}}-\frac{8 \xi(x+\xi)}{r_{2}^{4}}+\frac{32 \xi(x+\xi)^{3}}{r_{2}^{6}}+\frac{8 \xi^{2}}{r_{2}^{4}}-\frac{32 \xi^{2}(x+\xi)^{2}}{r_{2}^{6}}\right\}
\end{aligned}
$$




\section{A.3 FOTORES DE INTENSIDADE DE TENSÃO TRINCA INFINITESIMAL}

Solução para os fatores de intensidade de tensão modos I e II para uma trinca infinitesimal emergindo em um trinca já existente, Fig. 55:

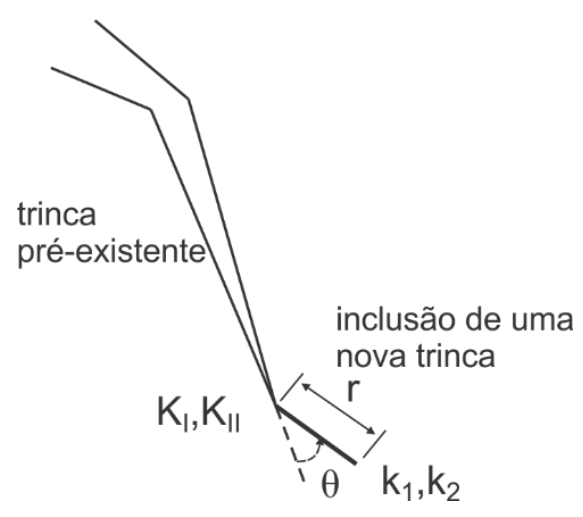

Figura 55- Inclusão de uma trinca infinitesimal emergindo de uma trinca já existente

$$
\left[\begin{array}{l}
K_{1}(r, \theta) \\
K_{2}(r, \theta)
\end{array}\right]=\left[\begin{array}{ll}
K_{11}(\theta) & K_{12}(\theta) \\
K_{21}(\theta) & K_{22}(\theta)
\end{array}\right]\left[\begin{array}{l}
K_{I} \\
K_{I I}
\end{array}\right]+O(\sqrt{r})
$$

onde os coeficiente $K_{i j}$ são definidos pelas seguintes relações:

$$
\begin{aligned}
& K_{11}(\theta)=\left(\frac{1-\eta}{1+\eta}\right)^{\frac{\eta}{2}}\left(\cos (\theta)-\frac{1}{2 \pi} \sin (l \theta)\right) \\
& K_{12}(\theta)=\left(\frac{1-\eta}{1+\eta}\right)^{\frac{\eta}{2}}\left(-\frac{3}{2} \sin (\theta)\right) \\
& K_{21}(\theta)=\left(\frac{1-\eta}{1+\eta}\right)^{\frac{\eta}{2}}\left(\frac{1}{2} \sin (\theta)\right) \\
& K_{22}(\theta)=\left(\frac{1-\eta}{1+\eta}\right)^{\frac{\eta}{2}}\left(\cos (\theta)+\frac{1}{2 \pi} \sin (l \theta)\right)
\end{aligned}
$$

Em que:

$$
l=\ln \left(\frac{1-\eta}{1+\eta}\right)-\frac{2 \eta}{1-\eta^{2}}, \quad \eta=\frac{\theta}{180}
$$

\section{A.4 ROTINAS MATLAB}

CALCULO FATOR DE INTENSIDADE DE TENSÃO (ROTINA PRINCIPAL)

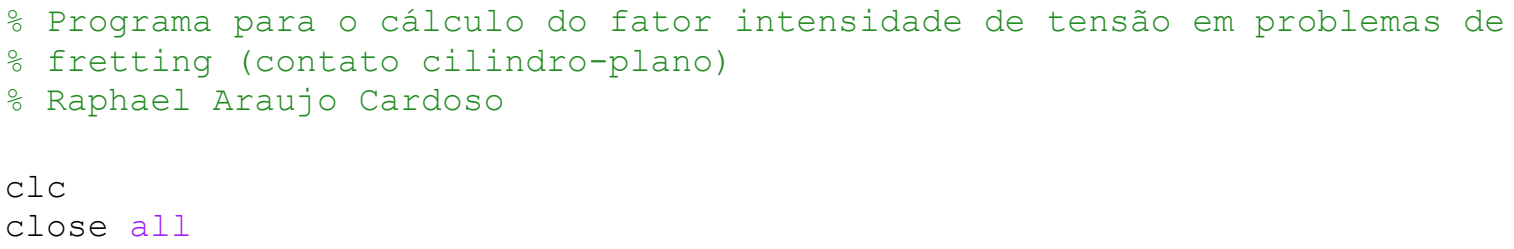


clear all

Condições de carregamento e geométricas

$\begin{array}{lll}\mathrm{P}=227 ; & \circ \text { carga normal por unidade de comprimento } & {[\mathrm{N} / \mathrm{mm}]} \\ \mathrm{Q}=169 ; & \circ \text { carga tangencial por unidade de comprimento } & {[\mathrm{N} / \mathrm{mm}]} \\ \mathrm{SB} A=0 ; & \circ \text { amplitude carga bulk } & {[\mathrm{MPa}]} \\ \mathrm{SB}=0 ; & \div \text { carga bulk média } & {[\mathrm{Mpa}]} \\ \mathrm{R}=40 ; & \div \text { raio sapata } & {[\mathrm{mm}]}\end{array}$

o Propriedades materiais

$\mathrm{V}=0.33 ; \quad \therefore$ coeficiente de poisson

$\mathrm{f}=0.9 ; \quad$ \% coeficiente de atrito zonas de escorregamento

\% Cálculo parâmetros básicos

$\mathrm{v} 1=\mathrm{v} ; \quad \mathrm{v} 2=\mathrm{v}$;

$\mathrm{E} 1=\mathrm{E}(1) ; \mathrm{E} 2=\mathrm{E}(2)$;

$\div \mathrm{MPa}]$

Req $=\mathrm{R}$;

$\mathrm{Eeq}=\left(\left(\left(1-\mathrm{V} 1^{\wedge} 2\right) / \mathrm{E} 1\right)+\left(\left(1-\mathrm{v} 2^{\wedge} 2\right) / \mathrm{E} 2\right)\right)^{\wedge}(-1) ;$

$\mathrm{p} 0=\operatorname{sqrt}\left(\left(\mathrm{P}^{\star} \mathrm{Eeq}\right) /(\mathrm{pi} * \operatorname{Req})\right) ;$

$a=2 *((P *$ Req $) /(p i * E e q)) \wedge(1 / 2)$;

$\mathrm{mi}=\mathrm{E}(2) /(2 *(\mathrm{v}+1))$;

$\mathrm{k}=3-4{ }^{*} \mathrm{v}$;

\% pressão de pico

\% semi largura do contato \% [mm]

\% módulo de rigidez $\quad$ [Mpa]

\% constande de Kolosov

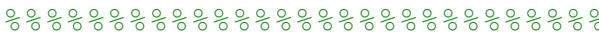

$t=\left[\begin{array}{ll}0.25 & 0.75\end{array}\right]$;

$\mathrm{th}=30 * \mathrm{pi} / 180$;

\% intervalo de tempo (normalizado)

o inclinação da trinca (em relação a vertical)

Processamento

o Cálculo do fator intensidade de tensão (distribuiçãos das discordâncias)

$\mathrm{n}=40$;

$\mathrm{bf}=0.2$;

$\mathrm{b}=10^{\wedge}-4: \mathrm{bf} / 30: \mathrm{bf}$

$\mathrm{Qmax} f \mathrm{P}=\mathrm{Q} /(\mathrm{f} * \mathrm{P})$;

\% Pre alocando algumas variáveis

$\mathrm{nt}=$ length $(\mathrm{t})$;

$\mathrm{nb}=$ length (b) ;

$\mathrm{A}=\operatorname{zeros}\left(2^{\star} \mathrm{n}\right)$;

$\mathrm{sn}=\operatorname{zeros}(\mathrm{n}, 1)$;

$\mathrm{st}=\operatorname{zeros}(\mathrm{n}, 1)$;

$\mathrm{KI}=\operatorname{zeros}(\mathrm{nb}, \mathrm{nt})$;

$\mathrm{KII}=\operatorname{zeros}(\mathrm{nb}, \mathrm{nt})$;

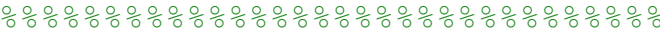

for $1=1: n t$;

for $i i=1$ : length (b)

for $i=1: n$

$\mathrm{s}=\cos (2 * i /(2 * \mathrm{n}+1) * \mathrm{pi})$;

$\mathrm{xp}=(\mathrm{s}+1) * \mathrm{~b}(\mathrm{i} i) / 2$;

for $j=1: n$
\% número de discretização

\% comprimento final da trinca (mm)

\% domínio do cálculo de K 


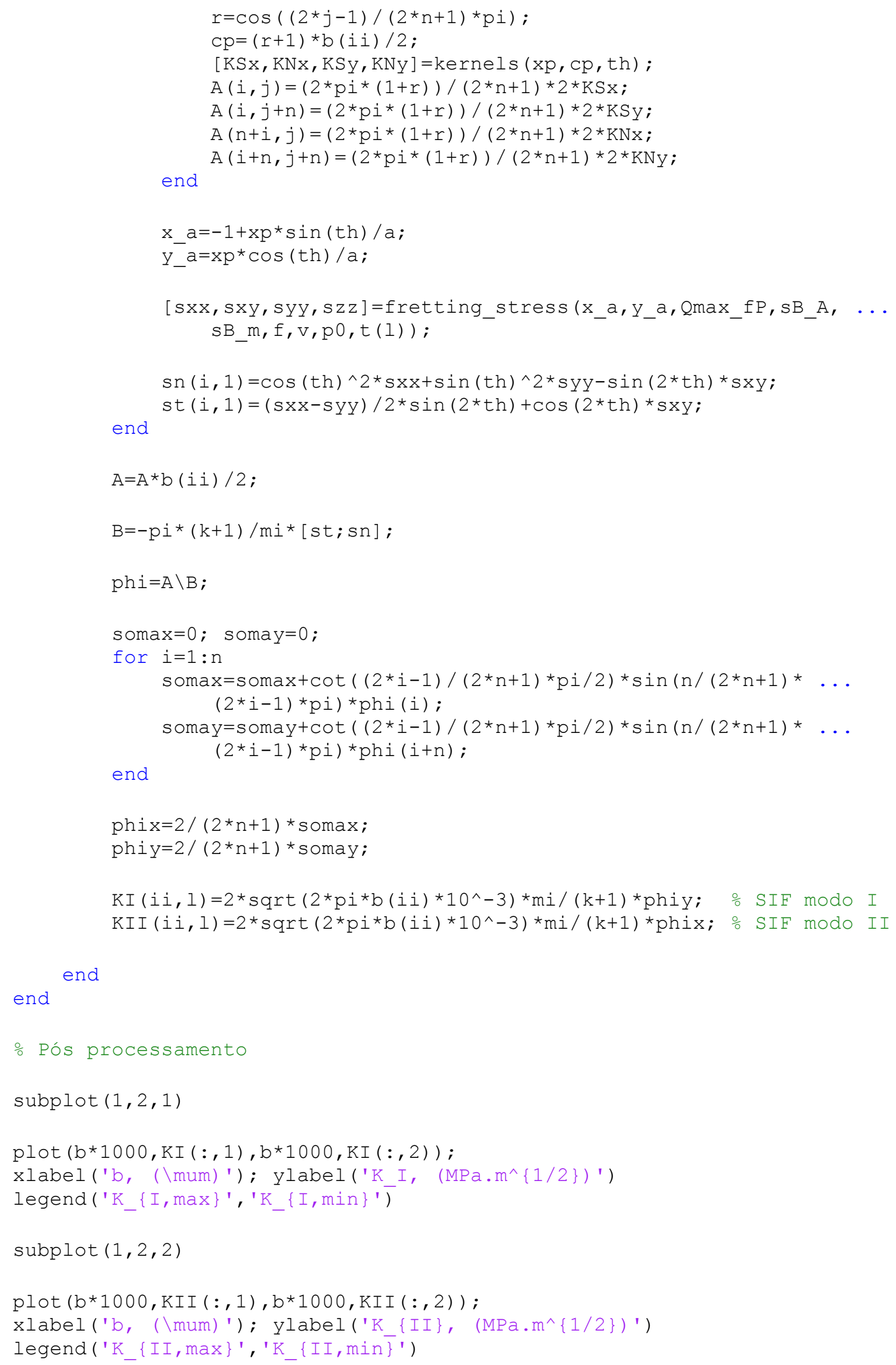

\section{CAMPO DE TENSÃO DE FRETTING (SUB ROTINA)}

Rotina para o cálculo das tensões de fretting $\% \frac{0}{0} \% \circ \% \% \%$ 
end

$z=x \_a+y \_a * 1 i$

$\mathrm{s}=\operatorname{sign}\left(\mathrm{x}_{-} \mathrm{a}\right)$

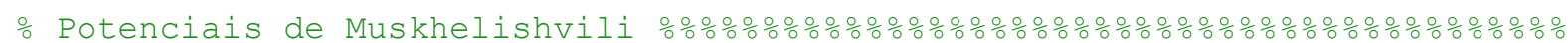

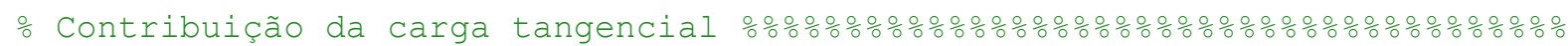

$\mathrm{c} 1=\operatorname{sqrt}\left(\mathrm{z}^{\wedge} 2-1\right) ;$

c2 $=\operatorname{conj}(z)-s^{*} \operatorname{sqrt}\left(\operatorname{conj}(z)^{\wedge} 2-1\right)$;

phi1_q $=-0.5 *(z-s * c 1)$;

phi2 $q=-0.5 *\left(1-s^{*} \mathrm{z} / \mathrm{cl}\right)$;

phi3_q=phi1_q;

phi4_q $=-0.5{ }^{\star} \mathrm{c} 2$;

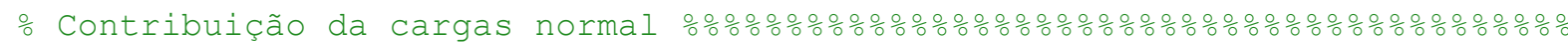
phi1 $\mathrm{p}=-0.5 * 1 i *\left(\mathrm{z}-\mathrm{s}{ }^{*} \mathrm{c} 1\right)$;

phi2_p $=-0.5 * 1 i *(1-s * z / c 1)$;

phi3_p $=-$ phi1_p;

phi4_p $=-0.5 *(-1 i) * c 2$;

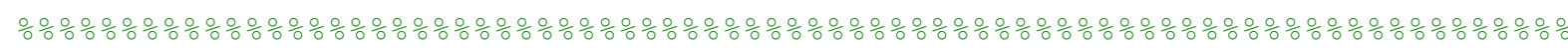

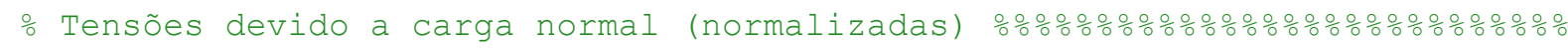

soma1 $=($ phi1_p + phi4_p $)+\left((\operatorname{conj}(z)-z) * p h i 2 \_p-p h i 3 \_p-p h i 1 \_p\right)$;

syyn_p0=real (soma1);

sxyn_p0=imag ( soma1);

sxxn_p $0=2 *($ phi1_p+phi4_p) -syyn_p0;

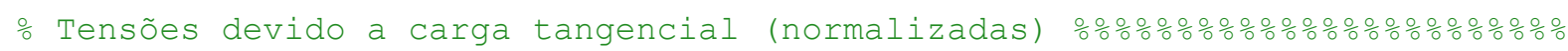

soma2 $=($ phi1_q+phi4_q $)+((\operatorname{conj}(z)-z) *$ phi2_q-phi3_q-phi1_q $)$;

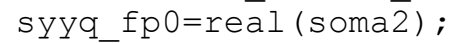

sxyq_fp0=imag (soma2);

sxxq_fp0 $=2 *\left(p h i 1 \_q+p h i 4 \_q\right)-s y y q \_f p 0$;

end

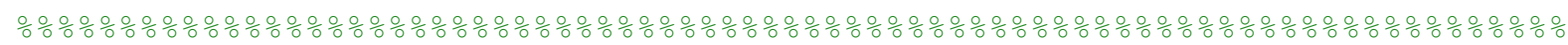

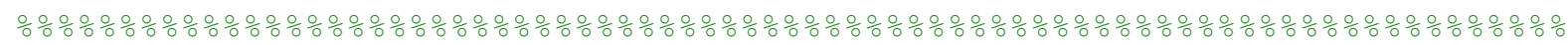

\section{NÚCLEOS DE UMA DESCONTINUIDADE (SUB ROTINA)}

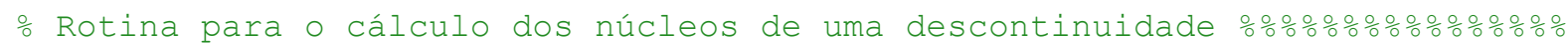

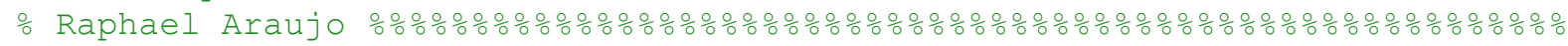

function $[\mathrm{KSx} K N x \mathrm{KSy} K N y]=\operatorname{kernels}(\mathrm{xp}, \mathrm{cp}$, th)

$\mathrm{y}=(\mathrm{xp}-\mathrm{cp}) * \sin (\mathrm{th}) ;$

$\mathrm{x}=\mathrm{xp} * \cos (t h)$;

- Coordenata em y (horizontal)

$\mathrm{c}=\mathrm{Cp}{ }^{*} \cos (\mathrm{th})$;

- Coordenada em x (vertical)

o Ponto de colocação da descontinuidade

$\mathrm{x} 1=\mathrm{x}-\mathrm{C} ;$

$x 2=x+c ;$ 
$r 1=\operatorname{sqrt}\left(\mathrm{x} 1^{\wedge} 2+\mathrm{y}^{\wedge} 2\right)$

$r 2=\operatorname{sqrt}\left(x 2^{\wedge} 2+y^{\wedge} 2\right) ;$

\section{․ Funções Kernels}

$\mathrm{Gxxx}=\mathrm{y}^{\star}\left(-1 / \mathrm{r} 1^{\wedge} 2-2^{\star} \mathrm{x} 1^{\wedge} 2 / \mathrm{r} 1^{\wedge} 4+1 / \mathrm{r} 2^{\wedge} 2+2^{\star} \mathrm{x} 2^{\wedge} 2 / \mathrm{r} 2^{\wedge} 4-4^{\star} \mathrm{C}^{\star} \mathrm{x} 2 / \mathrm{r} 2^{\wedge} 4+\ldots\right.$ $\left.4{ }^{\star} C^{\wedge} 2 / r 2^{\wedge} 4+16^{\star} C^{\star} \times 2^{\wedge} 3 / r 2^{\wedge} 6-16^{\star} C^{\wedge} 2^{\star} \times 2^{\wedge} 2 / r 2^{\wedge} 6\right) ;$

$\mathrm{Gxyy}=\mathrm{y}^{\star}\left(-1 / \mathrm{r} 1^{\wedge} 2+2^{\star} \mathrm{x} 1^{\wedge} 2 / \mathrm{r} 1^{\wedge} 4+1 / \mathrm{r} 2^{\wedge} 2-2{ }^{\star} \mathrm{x} 2^{\wedge} 2 / \mathrm{r} 2^{\wedge} 4+12^{\star} \mathrm{C}^{\star} \mathrm{x} 2 / \mathrm{r} 2^{\wedge} 4-\ldots\right.$ $\left.4{ }^{\star} C^{\wedge} 2 / r 2^{\wedge} 4-16^{\star} C^{\star} \times 2^{\wedge} 3 / r 2^{\wedge} 6+16^{\star} C^{\wedge} 2^{\star} \times 2^{\wedge} 2 / r 2^{\wedge} 6\right) ;$

$\mathrm{Gxxy}=-\mathrm{x} 1 / \mathrm{r} 1^{\wedge} 2+2^{\star} \mathrm{x} 1^{\wedge} 3 / \mathrm{r} 1^{\wedge} 4+\mathrm{x} 2 / \mathrm{r} 2^{\wedge} 2-2^{\star} \mathrm{C} / \mathrm{r} 2^{\wedge} 2-2^{\star} \mathrm{x} 2^{\wedge} 3 / \mathrm{r} 2^{\wedge} 4+\ldots$ $16{ }^{\star} C^{\star} \times 2^{\wedge} 2 / r 2^{\wedge} 4-12^{\star} C^{\wedge} 2^{\star} \times 2 / r 2^{\wedge} 4-16{ }^{\star} C^{\star} \times 2^{\wedge} 4 / r 2^{\wedge} 6+16^{\star} C^{\wedge} 2{ }^{\star} \times 2^{\wedge} 3 / r 2^{\wedge} 6 ;$ $\mathrm{Gyxx}=-\mathrm{x} 1 / \mathrm{r} 1^{\wedge} 2+2^{\star} \mathrm{x} 1^{\wedge} 3 / \mathrm{r} 1^{\wedge} 4+\mathrm{x} 2 / \mathrm{r} 2^{\wedge} 2-2^{\star} \mathrm{C} / \mathrm{r} 2^{\wedge} 2-2^{\star} \mathrm{x} 2^{\wedge} 3 / \mathrm{r} 2^{\wedge} 4-\ldots$

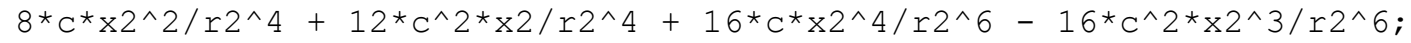
Gyyy $=3^{\star} x 1 / r 1^{\wedge} 2-2{ }^{\star} x 1^{\wedge} 3 / r 1^{\wedge} 4-3^{\star} x 2 / r 2^{\wedge} 2-2{ }^{\star} \mathrm{C} / r 2^{\wedge} 2+2{ }^{\star} x 2^{\wedge} 3 / r 2^{\wedge} 4+\ldots$

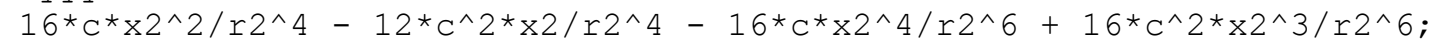
$\mathrm{Gyxy}=\mathrm{y}^{\star}\left(-1 / \mathrm{r} 1^{\wedge} 2+2^{\star} \mathrm{x} 1^{\wedge} 2 / \mathrm{r} 1^{\wedge} 4+1 / r 2^{\wedge} 2-2^{\star} \mathrm{x} 2^{\wedge} 2 / \mathrm{r} 2^{\wedge} 4-4^{\star} \mathrm{C}^{\star} \mathrm{x} 2 / \mathrm{r} 2^{\wedge} 4+\ldots\right.$ $\left.4{ }^{\star} C^{\wedge} 2 / r 2 \wedge 4+16{ }^{\star} C^{\star} \times 2 \wedge 3 / r 2 \wedge 6-16{ }^{\star} C^{\wedge} 2{ }^{\star} \times 2 \wedge 2 / r 2 \wedge 6\right) ;$

o Transformação para o plano inclinado da trinca

$\mathrm{Tx}=[\mathrm{Gxxx} ; \mathrm{Gxyy} ; \mathrm{Gxxy}]{ }^{*} \cos (\mathrm{th})+[\mathrm{Gyxx} ; \mathrm{Gyyy} ; \mathrm{Gyxy}]{ }^{*} \mathrm{sin}($ th) ; $\mathrm{Ty}=[\mathrm{Gxxx} ; \mathrm{Gxyy} ; \mathrm{Gxxy}]$ * (-sin (th) ) +[Gyxx; Gyyy; Gyxy] ${ }^{*} \cos ($ th $)$;

$\mathrm{KSx}=\left[-\sin (t h){ }^{*} \cos (t h) \sin (t h){ }^{*} \cos (t h) \cos (2 * t h)\right] * \operatorname{Tx} ;$ $\mathrm{KNx}=[\sin (\mathrm{th}) \wedge 2 \cos (t h) \wedge 2-\sin (2 * t h)] * \operatorname{Tx} ;$

$\mathrm{KSY}=\left[-\sin (t h){ }^{*} \cos (t h) \sin (t h){ }^{*} \cos (t h) \cos \left(2 \star^{*} h\right)\right]{ }^{*} \mathrm{Ty}$; $\mathrm{KNY}=\left[\sin (t h)^{\wedge} 2 \cos (t h)^{\wedge} 2-\sin (2 * t h)\right] * \mathrm{Ty} ;$

end 